LBNL-53410

\title{
Duct Thermal Performance Models for Large Commercial Buildings
}

\author{
Craig Wray
}

\section{Environmental Energy Technologies Division Indoor Environment Department Lawrence Berkeley National Laboratory Berkeley, CA 94720}

October 2003

This report describes work supported by the California Energy Commission through the Public Interest Energy Research program under contract no. 400-99-012-1, and by the Assistant Secretary for Energy Efficiency and Renewable Energy, Building Technologies Program, of the U.S. Department of Energy under contract no. DE-AC03-76SF00098. 
The Lawrence Berkeley National Laboratory, 1 Cyclotron Road, Berkeley, CA 94720 is a national laboratory of the U.S. Department of Energy managed by the Regents of the University of California for the U.S. Department of Energy under Contract Number DEAC03-76SF00098. This report was prepared as a result of work sponsored by the California Energy Commission (Commission). It does not necessarily represent the views of the Commission, its employees, or the State of California. The Commission, the State of California, its employees, contractors, and subcontractors make no warranty, express or implied, and assume no legal liability for the information in this report, nor does any party represent that the use of this information will not infringe upon privately owned rights. This report has not been approved or disapproved by the Commission nor has the Commission passed upon the accuracy or adequacy of the information in this report.

THE GOVERNMENT AND THE CONTRACTOR MAKE NO EXPRESS OR IMPLIED WARRANTY AS TO THE CONDITIONS OF THE RESEARCH OR ANY INTELLECTUAL PROPERTY, GENERATED INFORMATION, OR PRODUCT MADE OR DEVELOPED UNDER THIS AGREEMENT, OR THE OWNERSHIP, MERCHANTABILITY, OR FITNESS FOR A PARTICULAR PURPOSE OF THE RESEARCH OR RESULTING PRODUCT; THAT THE GOODS, SERVICES, MATERIALS, PRODUCTS, PROCESSES, INFORMATION, OR DATA TO BE FURNISHED HEREUNDER WILL ACCOMPLISH INTENDED RESULTS OR ARE SAFE FOR ANY PURPOSE INCLUDING THE INTENDED PURPOSE; OR THAT ANY OF THE ABOVE WILL NOT INTERFERE WITH PRIVATELY OWNED RIGHTS OF OTHERS. NEITHER THE GOVERNMENT NOR THE CONTRACTOR SHALL BE LIABLE FOR SPECIAL, CONSEQUENTIAL, OR INCIDENTAL DAMAGES ATTRIBUTED TO SUCH RESEARCH OR RESULTING PRODUCT, INTELLECTUAL PROPERTY, GENERATED INFORMATION, OR PRODUCT MADE OR DELIVERED UNDER THIS AGREEMENT. 


\section{ACKNOWLEDGEMENTS}

The largest debt of gratitude goes to former and current Energy Performance of Buildings staff members: Ellen Franconi (Nexant Corporation) for her development of the DOE-2 / TRNSYS modeling approach and for implementing the duct models in a form that could readily be used in this project; to Iain Walker (LBNL) for his assistance in defining the duct surface heat transfer models described in the body of this report; Nance Matson (LBNL) for her review and refinement of the DOE-2 data interchange with TRNSYS; and Brian Smith (LBNL) for computer applications support throughout the project.

LBNL staff members in the Building Technologies Department were also helpful and supportive of this work, particularly regarding the intricacies of DOE-2.1E and EnergyPlus. The author wishes to thank Phil Haves, Fred Winklemann, Fred Buhl, Joe Huang, and Steve Selkowitz.

The duct modeling discussions with Lixing Gu, Jim Cummings, Muthusamy Swami, and Don Shirey of the Florida Solar Energy Center and Pete Jacobs of the Architectural Energy Corporation helped define the approaches that we selected for duct thermal performance modeling in large commercial buildings, and the author is grateful for their input.

Advice from Michaël Kummert of the Solar Energy Laboratory, University of WisconsinMadison regarding TRNSYS compiling issues was greatly appreciated; as was the explanation by Tim McDowell of Thermal Energy System Specialists about the details involved in coupling TRNSYS and EnergyPlus.

This project evolved from the ideas and work of Mark Modera (LBNL), who was the original project lead. Even after he left the project, Mark continued to provide contributions and was a valuable resource for the project team.

Finally, the author would like to acknowledge the support and contributions of the PIER Contract Manager, Martha Brook, and the Buildings Program team under the leadership of Nancy Jenkins. 


\section{TABLE OF CONTENTS}

ACKNOWLEDGEMENTS

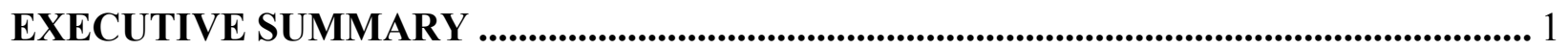

1. INTRODUCTION............................................................................................................................ 3

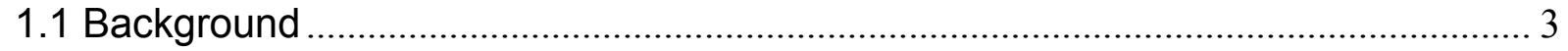

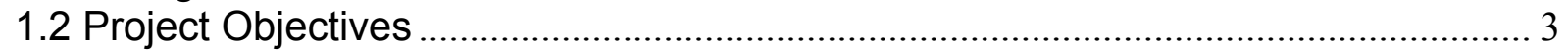

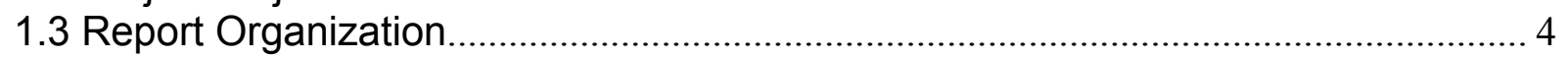

2. MODELING CONTEXT …............................................................................................... 5

2.1 California Title 24 - Compliance Path Overview........................................................... 5

2.2 California Duct Systems ............................................................................................ 6

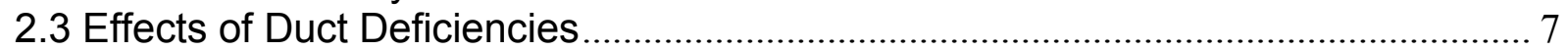

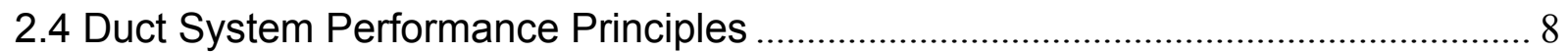

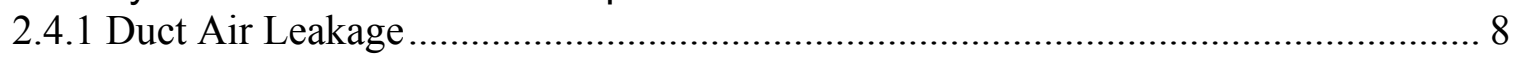

2.4.2 Fan Performance ......................................................................................... 10

2.4.3 Duct Surface Heat Transfer ............................................................................... 11

3. REVIEW OF MODEL IMPLEMENTATIONS.................................................................... 13

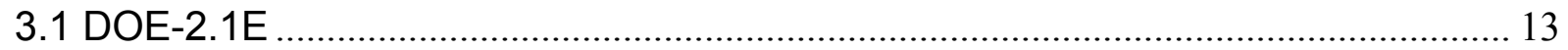

3.2 Other Commercially Available Simulation Programs .............................................. 14

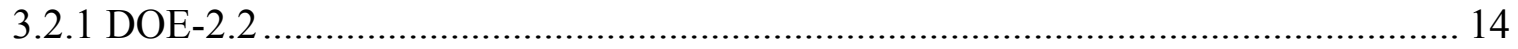

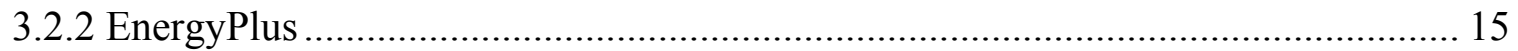

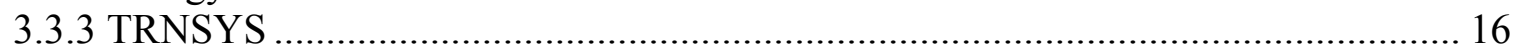

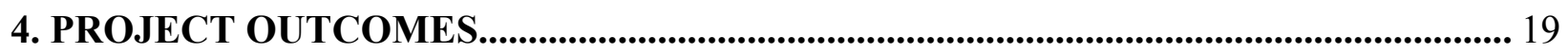

4.1 Recommended Short-Term Modeling Approach ................................................... 19

4.2 Recommended Long-Term Modeling Approach ......................................................... 19

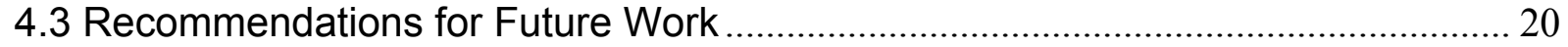

GLOSSARY ......................................................................................................................................... 22

APPENDIX I: BIBLIOGRAPHY _........................................................................................... 23

APPENDIX II: TRNSYS DUCT PERFORMANCE SUBROUTINES ................................... 38

Subroutine TYPE 70: Fan (Supply or Return)...................................................................... 38

Subroutine TYPE 75: Cooling Coil ............................................................................................ 44

Subroutine TYPE 77: Zone Return Air Mixing ......................................................................... 82

Subroutine TYPE 80: Economizer ................................................................................................. 84

Subroutine TYPE 81: Ceiling Return Plenum ................................................................................ 93

Subroutine TYPE 82: Upstream Ducts ................................................................................... 96

Subroutine TYPE 86: VAV Box and Downstream Ducts..................................................... 100 


\section{EXECUTIVE SUMMARY}

Introduction. Despite the potential for significant energy savings by reducing duct leakage or other thermal losses from duct systems in large commercial buildings, California Title 24 has no provisions to credit energy-efficient duct systems in these buildings. A substantial reason is the lack of readily available simulation tools to demonstrate the energy-saving benefits associated with efficient duct systems in large commercial buildings.

Purpose. The overall goal of the Efficient Distribution Systems (EDS) project within the PIER High Performance Commercial Building Systems Program is to bridge the gaps in current duct thermal performance modeling capabilities, and to expand our understanding of duct thermal performance in California large commercial buildings. As steps toward this goal, our strategy in the EDS project involves two parts: 1) developing a whole-building energy simulation approach for analyzing duct thermal performance in large commercial buildings, and 2) using the tool to identify the energy impacts of duct leakage in California large commercial buildings, in support of future recommendations to address duct performance in the Title 24 Energy Efficiency Standards for Nonresidential Buildings.

Project Objectives. The specific technical objectives for the EDS project were to:

1. Identify a near-term whole-building energy simulation approach that can be used in the impacts analysis task of this project (see Objective 3), with little or no modification. A secondary objective is to recommend how to proceed with long-term development of an improved compliance tool for Title 24 that addresses duct thermal performance.

2. Develop an Alternative Calculation Method (ACM) change proposal to include a new metric for thermal distribution system efficiency in the reporting requirements for the 2005 Title 24 Standards. The metric will facilitate future comparisons of different system types using a common "yardstick".

3. Using the selected near-term simulation approach, assess the impacts of duct system improvements in California large commercial buildings, over a range of building vintages and climates. This assessment will provide a solid foundation for future efforts that address the energy efficiency of large commercial duct systems in Title 24.

This report describes our work to address Objective 1, which includes a review of past modeling efforts related to duct thermal performance, and recommends near- and long-term modeling approaches for analyzing duct thermal performance in large commercial buildings. Modera (2002) and Wray and Matson (2003) respectively describe work to address Objectives 2 and 3.

\section{Project Outcomes}

Recommended Short-Term Modeling Approach. Our review of 188 documents related to past modeling efforts, and supplemental discussions with other simulation experts, has helped define a set of modeling principles that can be used to guide duct thermal performance modeling for large commercial buildings. Based on this review, we conclude that the best approach for our impacts analysis task is to build upon past research that used DOE-2 and TRNSYS in a sequential method to evaluate HVAC system performance.

An advantage of this approach is that DOE-2 prototypical models for a large commercial California building are available, as are TRNSYS component models that LBNL developed in the past to model duct leakage effects in VAV systems. Another advantage is that this modeling approach and its results for a California building have already been validated, and no substantial changes are required to the simulation tool to carry out our impacts analysis. No other whole- 
building modeling approach to assess duct system performance for large commercial buildings is currently as advanced as this approach. To assist other modelers, this report presents the source code for the TRNSYS component models, which were never published.

Recommended Long-Term Modeling Approach. Although DOE-2.1E Version 110 is the reference simulation tool for Title 24 compliance evaluations, we have concluded that its duct modeling limitations, convoluted structure, and the lack of government support for future development make it unsuitable as a platform for long-term modeling of duct thermal performance in large commercial buildings. Instead, we have suggested that EnergyPlus, which is based in part on DOE-2, be developed to include component models like the TRNSYS ones that we identified for short-term use in our impacts analysis task. Currently, EnergyPlus has no duct performance models, but we expect that the recommended enhancements could be applied in a relatively straightforward manner. This approach has the advantage that EnergyPlus is better suited than DOE-2.1E for future analyses of innovative low-energy cooling designs.

Our recommendation carries with it a set of challenges that need to be met by the summer of 2005 if EnergyPlus is to be used in support of the 2008 Title 24 Standards: 1) an interface needs to be rapidly developed to facilitate program use in Title 24 compliance analyses, 2) duct performance models need to be integrated with the program, 3) EnergyPlus needs to be validated against measured data and certified as either an alternative or primary compliance analysis tool, and 4) utilities to convert DOE-2 input files for use in EnergyPlus are needed to help current DOE-2.1E users migrate to using EnergyPlus. Further collaborative efforts between DOE and the California Energy Commission would help ensure that these challenges can be met, and would likely lead to substantial energy reduction benefits in California over the long-term.

Recommendations for Further Work. Before duct performance in large commercial buildings can be accounted for in Title 24 nonresidential building energy standards, several issues must be addressed and resolved. These include:

1. Specifying reliable duct air leakage measurement techniques that can be practically applied in the large commercial building sector.

2. Defining the duct leakage condition for the standard building used in Title 24 compliance simulations.

3. Assuring consistency between simulated duct performance impacts and actual impacts.

4. Developing compliance tests for the Alternative Calculation Method (ACM) Approval Manual (CEC 2001b) to evaluate duct performance simulations.

Three additional steps will be required to further develop duct-modeling capabilities that address limitations in existing models and to initiate strong market activity related to duct system improvements. We recommend that these steps include:

1. Implementing duct models in user-friendly commercially-available software for building energy simulation, validating the implementations with case studies and demonstrations, and obtaining certification for software use as a primary or alternative compliance tool in support of the Title 24 Nonresidential Standards.

2. Developing methodologies to deal with airflows entering VAV boxes from ceiling return plenums (e.g., parallel fan-powered VAV boxes), to deal with duct surface heat transfer effects, and to deal with static pressure reset and supply air temperature reset strategies.

3. Transferring information to practitioners through publications, conferences, workshops, and other education programs. 


\section{INTRODUCTION}

\subsection{Background}

Previous research suggests that duct systems in California commercial buildings suffer from a number of problems, such as thermal losses due to duct air leakage. For example, measurements by Diamond et al. (2003) in a large commercial building confirmed predictions by Franconi et al. (1998) that duct leakage can significantly increase HVAC system energy consumption: adding $15 \%$ duct leakage at operating conditions leads to a fan power increase of 25 to $35 \%$. Diamond et al. also estimated that eliminating duct leakage airflows in half of California's existing large commercial buildings has the potential to save about 560 to $1,100 \mathrm{GWh}$ annually $(\$ 60-\$ 110$ million per year or the equivalent consumption of 83,000 to 170,000 typical California houses), and about 100 to $200 \mathrm{MW}$ in peak demand.

California Title 24, Part 6 (CEC 2001a) is one of the most advanced energy codes in the United States. The impacts of duct thermal performance in residences are already addressed by Title 24 compliance procedures; duct-system energy efficiency requirements have recently been added for small commercial buildings with individual packaged equipment serving $5,000 \mathrm{ft}^{2}$ or less where ducts are located in spaces between insulated ceilings and the roof, or outside the building; and new requirements for duct performance in other small commercial buildings are being developed. However, despite the potential for significant energy savings by reducing thermal losses from duct systems in large commercial buildings, Title 24 has no provisions to credit energy-efficient duct systems in these buildings. A substantial reason is the lack of readily available simulation tools to demonstrate the energy-saving benefits associated with efficient duct systems in large commercial buildings.

\subsection{Project Objectives}

The work reported here is part of the Efficient Distribution Systems (EDS) project within the PIER High Performance Commercial Building Systems Program. The EDS project goal is to bridge the gaps in duct system modeling capabilities, and to expand our understanding of duct thermal performance in California's large commercial buildings, by following through on the strategy outlined by Xu et al. (1999a). As steps toward this goal, the project involves three specific technical objectives:

1. Identify a near-term whole-building energy simulation approach that can be used in the impacts analysis task of this project (see Objective 3), with little or no modification. A secondary objective is to recommend how to proceed with long-term development of an improved compliance tool for Title 24 that addresses duct thermal performance.

2. Develop an Alternative Calculation Method (ACM) change proposal to include a new metric for thermal distribution system efficiency in the reporting requirements for the 2005 Title 24 Standards. The metric will facilitate future comparisons of different system types using a common "yardstick".

3. Using the selected near-term simulation approach, assess the impacts of duct system improvements in California large commercial buildings, over a range of building vintages and climates. This assessment will provide a solid foundation for future efforts that address the energy efficiency of large commercial duct systems in Title 24. 
To meet these objectives, we carried out the EDS project in steps. Work to address Objectives 1 and 2 was carried out in parallel, and was followed by work on Objective 3. This report describes our efforts related to Objective 1:

- Carrying out a review of documents related to past HVAC system modeling efforts, supplemented by discussions on these issues with other simulation experts;

- Defining a set of modeling principles and publishing HVAC component models that can be used now to guide duct thermal performance modeling for large commercial buildings; and

- Identifying what aspects can be carried forward for use in Title 24 compliance processes related to large commercial buildings.

The efforts related to Objective 1 are necessary precursors to assessing the impacts of duct system improvements in California large commercial buildings, which is the focus of Objective 3. A follow-on report by Wray and Matson (2003) describes the latter effort in detail ${ }^{1}$.

Regarding Objective 2, the California Energy Commission has accepted the ACM change that Modera (2002) proposed for the 2005 Title 24 Standards to address HVAC distribution system efficiency in large commercial buildings. The metric of interest, HVAC Transport Efficiency, characterizes the overall efficiency of the thermal distribution system as the ratio between the energy expended to transport heating, cooling, and ventilation throughout a building and the total thermal energy delivered to the various conditioned zones in the building. Because the ACM proposal is for a set of reporting changes, implementing the changes in existing Title 24 nonresidential compliance software should not require significant effort from ACM providers.

This project contributes to the PIER program objective of improving the energy cost and value of California's electricity in two ways. One is by developing analytical methods to show that well designed duct systems in large commercial buildings can save much of the energy used to move and condition air. The other is by making progress toward new requirements for commercial duct system efficiency in future revisions of Title 24 . We expect that the new analytical capabilities and performance requirements will ultimately result in smaller capacity, more energy-efficient building systems, which will also reduce peak electrical demand from California's commercial building sector and improve the reliability and quality of California's electricity.

\subsection{Report Organization}

In Section 2, Modeling Context, we discuss issues that delineate modeling needs, and that provide rationale for selecting near- and long- term modeling approaches.

In Section 3, Modeling Reviews, we present the key results from our review.

In Section 4, Conclusions and Recommendations, we present what we learned from the research and what we recommend for future activities.

Following the Glossary, there are two Appendices:

"Appendix I. Bibliography" lists the 188 documents related to HVAC air-handling system performance simulation and assessment that we reviewed in our search for information about duct thermal performance modeling.

\footnotetext{
${ }^{1}$ Wray, C.P. and N.E. Matson. 2003. "Duct Leakage Impacts on VAV System Performance in California Large Commercial Buildings". Lawrence Berkeley National Laboratory Report. LBNL-53605.
} 
Particularly relevant documents are:

- Past efforts that assessed DOE-2 capabilities for modeling ducts in commercial buildings (Modera et al. 1999, Xu et al. 1999a),

- A recent doctoral dissertation that used DOE-2 and TRNSYS to model duct thermal losses in large commercial buildings (Franconi 1999),

- Recent DOE-2.2 modeling efforts that assessed duct system improvements for small commercial buildings (PG\&E 2003a, 2003b), and

- Discussions of residential duct thermal models (Gu et al. 1998a, 1998b), which are the basis for a recent proposal by the Florida Solar Energy Center to integrate duct thermal performance modeling into EnergyPlus for residential and small-commercial buildings.

To supplement these reviews, we also hosted several conference calls and meetings between LBNL and Florida Solar Energy Center staff to map out a long-term strategy for adding ductmodeling capabilities into EnergyPlus for large-commercial buildings.

“Appendix II. TRNSYS Duct Performance Subroutines" lists the FORTRAN source code implementations of the seven models that Franconi (1999) used in a DOE-2 / TRNSYS simulation approach to predict the effects of duct leakage on HVAC system performance.

\section{MODELING CONTEXT}

The background information in this section serves as a basis for evaluating and selecting methods that evaluate duct performance impacts. We first summarize the two different compliance paths in Title 24 to help the reader understand the reasons why one needs simulation tools to evaluate duct performance. Next, we describe duct system types that are common in California's large commercial buildings, present an example to illustrate the effects of duct system deficiencies, and describe the underlying principles that govern duct performance.

\subsection{California Title 24 - Compliance Path Overview}

Two compliance paths are available for non-residential buildings that are subject to California Title 24 requirements:

1. The simplest approach is prescriptive: compliance is achieved by designing and constructing the building to meet specified minimum characteristics for the envelope, space-conditioning system, hot-water heating system, and lighting system.

2. The more complex approach is performance based and is intended to provide flexibility for innovative design and construction by allowing efficiency tradeoffs between various building components. As part of this approach, energy uses of the proposed building and of a standard building in the same climate zone are calculated using a simulation tool. Compliance at the design stage is achieved if the energy use calculated for the proposed building does not exceed the energy use calculated for the standard building. The standard building is physically similar to the proposed building, but is equipped with components that meet the requirements outlined in the prescriptive compliance approach.

Only two software packages are commercially available and certified for performance-based compliance evaluations: Perform95 from the Commission, and EnergyPro from EnergySoft, LLC. Both programs serve as a front-end to DOE-2.1E.

DOE-2.1E is an hour-by-hour energy analysis program that calculates whole-building energy performance and life-cycle economics (Winkelmann et al. 1993). Other simulation programs 
could be used to evaluate compliance, but the Commission must certify each one for such use. To be considered for certification, the alternative tool must meet the analysis specifications outlined in the Alternative Calculation Method (ACM) Approval Manual (CEC 2001b) and must be tested to assess modeling accuracy relative to DOE-2.1E Version 110 predictions. Accuracy is assessed using 76 conformance tests that involve several building prototypes, climate zones, and design/system permutations; each test systematically varies one or more features that impact building energy use. Acceptable accuracy means that the performance differences between the proposed and standard buildings calculated using the alternative tool must be within $15 \%$ of the differences calculated using DOE-2.1E.

\subsection{California Duct Systems}

Using survey data collected from 1988 through 1993 by or for California utilities and for the California Energy Commission, Modera et al. (1999) determined that there are three basic types of duct systems in California commercial buildings:

- Single-duct systems generate either a cool or warm air stream at the air-handler. The supply air is delivered to the conditioned zones through a single duct system connected to the air-handler. Reheat coils at individual terminal units can be used to add heat to the supply air when needed.

- Dual duct systems generate a cool air stream and a warm air stream at the air-handler. Each air stream is supplied to terminal boxes through a separate duct system. The terminal boxes mix the air streams before the supply air enters the zones.

- Multizone duct systems also generate a cool air stream and a warm air stream at the airhandler, but they use dampers at the air-handler instead of at a terminal box to mix the cool and warm air streams for each zone. Each zone's supply air is delivered through a separate duct system (this system is somewhat like several single-duct systems operating in parallel).

All of these duct systems use one of two methods to control the amount of energy supplied to each zone. A constant-air-volume ( $C A V$ ) system delivers a fixed quantity of supply air to the conditioned space and maintains desired conditions by varying the temperature of the supply air. A variable-air-volume $(V A V)$ system maintains space temperature by varying the quantity of supply air, generally at a fixed temperature.

Based on the floor area served by these duct systems (Modera et al. 1999), the most common system across different building types is the single duct CAV system (71\%). The next most common system type is the multizone system (19\%). Single-duct VAV systems (8\%) and dual duct systems $(2 \%)$ serve the remainder of the floor area. Note that the fraction of multizone systems might be overrepresented by these data. Modera et al. indicated that the survey data may include some inappropriate affirmative responses for multizone systems. In some cases, the respondent may have called a system that serves more than one zone a multizone system, even though the system is not really a multizone system as described above. For example, some of the multizone systems might actually be single-duct VAV systems that serve multiple zones.

The fractions of floor areas served by CAV and VAV system types are difficult to determine, because the fractions for multizone and dual-duct systems are unknown. However, based on data from Modera et al. (1999) and EIA (2002), the fraction of VAV systems may be in the range of 8 to $34 \%$. The EIA data indicate that VAV systems serve $34 \%$ of the large commercial building floor area in the U.S. Pacific region, which includes California. 
Although there are substantially fewer VAV systems than CAV systems in California, it is clear that VAV systems are used in a significant fraction of California buildings and need to be addressed when developing duct models for large commercial buildings. A reason to focus on VAV systems is that if one is able to model a VAV system, then a CAV system can also be modeled (it is a simplification of a VAV system). Another reason is that an EPRI study (Pietsch 1991) suggested a significant national trend over the past 30 years towards the use of VAV systems in new construction (e.g., about $75 \%$ of new duct systems in the period 1980 through 1990 were VAV systems).

Of the floor area served by single-duct VAV systems, the data from Modera et al. (1999) indicate that most (98\%) of it is in large office buildings; the remainder $(2 \%)$ is primarily in hotel and retail buildings. For this reason, we focused on large office buildings in our study.

\subsection{Effects of Duct Deficiencies}

In large commercial buildings, duct systems and the effects of deficiencies in these systems are much more complex than in most residential and small-commercial buildings. As an example to illustrate the effects of duct system deficiencies, consider a large commercial building equipped with a single-duct terminal-reheat VAV system that has leaky supply ducts located within a ceiling return air plenum.

When conditioned air leaks from the supply ducts, the heating or cooling energy associated with leakage heats or cools the return air and changes its temperature (and enthalpy). Depending on the temperature difference across each surface that separates the plenum from adjacent conditioned spaces and the outdoors, some of the energy associated with the leakage airflow is transferred from the plenum by conduction across these surfaces. The energy transferred by conduction between the plenum and adjacent zones may be beneficial or detrimental to zone loads. For example, when there is simultaneous heating of perimeter zones and cooling of the core zone, the heating energy associated with leakage from ducts that serve the perimeter zones will tend to increase plenum temperatures; the cooling energy associated with leakage from ducts that serve the core zone will tend to decrease plenum temperatures. A net increase in plenum temperatures will increase the core-zone cooling load and decrease the perimeter-zone heating loads. Conversely, a net decrease in plenum temperatures will decrease the core-zone cooling load and increase the perimeter-zone heating loads.

If the VAV boxes deliberately induce airflows from the ceiling plenum (driven by induction effects or by VAV box fans), the change in return air enthalpy affects the mixed supply air enthalpy within and downstream of the VAV box. This in turn affects the energy that is transferred to the conditioned spaces by these airflows. It can also affect VAV box reheat coil loads (e.g., reduced return air enthalpy due to cool supply air leakage upstream of the VAV box or from other ducts reduces the VAV box mixed air enthalpy and increases reheat coil loads).

A change in return air temperature due to duct leakage will also change cooling coil loads when the economizer is not operating. For example, consider an air-handler with an economizer that is controlled based on dry-bulb temperatures (rather than on enthalpies). When the outdoor air temperature is above the return air temperature high-limit set point, the amount of outdoor air entering the air-handler is the minimum required for ventilation. The remainder of the mixed airflow entering the air-handler (same flow rate as the supply airflow) is return air. Mechanical cooling is used to maintain the desired supply air temperature. In this case, the change in return air enthalpy due to duct leakage will affect the mixed air enthalpy entering the air-handler coils, and therefore will affect the cooling coil loads (e.g., reduced return air enthalpy due to cool supply air leakage reduces mixed air enthalpy and therefore reduces cooling coil loads). To 
maintain the desired air pressure differentials across the building envelope, some return air is discharged outdoors. This arrangement means that some of the heating or cooling energy associated with leakage is discharged to outdoors and is not recaptured at the air-handler.

When the outdoor air temperature is between the desired supply air temperature and return air temperature high-limit set point, the economizer operates with $100 \%$ outdoor air and no return air enters the air-handler (all of the return air is discharged outdoors). In this case, even though mechanical cooling is used as a supplement to maintain the desired supply air temperature, the change in return air enthalpy due to duct leakage does not affect mixed air enthalpy or cooling coil loads. When the outdoor air temperature is below the desired supply air temperature, there is no mechanical cooling and duct leakage again has no impact on air-handler coil loads. However, to maintain the desired supply air temperature in this case, a change in return air temperature (e.g., due to duct leakage) will cause the economizer to alter the amounts of return air and outdoor air that enter the air-handler.

In the case of a VAV box with leaky downstream ducts, the duct leakage means that insufficient heating or cooling energy is delivered to the conditioned spaces. As a result, the thermostat call for heating or cooling is not satisfied and the thermostat calls for more air to be supplied through the VAV box. To deliver more supply air, the VAV box primary air damper opens further, which in turn reduces the resistance to airflow in the duct system. Consequently, to maintain the main duct static pressure at its set point, the supply fan airflow must increase to compensate for the downstream leakage airflows. Upstream leakage has a similar effect on supply fan airflow, but no effect on VAV box flows (unless the supply fan is too small to maintain duct static pressure in the leaky duct system).

Because the relationship between fan power and airflow is somewhere between a quadratic and cubic function (as described later in Section 2.4.2), the increase in supply airflow to compensate for duct leakage means that supply fan power consumption increases significantly, with a large fraction of this fan power used just to move the leaking air. Increasing the fan power also increases cooling coil loads when mechanical cooling is being used to maintain the desired supply air temperature (when the economizer is operating at $100 \%$ or minimum outdoor air). Specifically, the coil load increase occurs because the heat created by the increased fan power tends to increase the supply air temperature downstream of the fan. In response, the cooling coil water valve open furthers to provide more cooling to maintain the desired supply air temperature.

\subsection{Duct System Performance Principles}

A brief overview of duct air leakage, fan performance, and duct surface heat transfer principles is presented here, with a focus on supply ducts; Parker et al. (1993), Bourdouxhe et al. (1998), and ASHRAE (2001a; 2001b) provide more detailed descriptions. Return ducts are governed by similar principles.

\subsubsection{Duct Air Leakage}

A power law can be used to describe the relationship between the flow through the leaks in ducts and the static pressure in the duct relative to surrounding space:

$$
Q_{\text {leak }}=C_{1} \cdot \Delta p_{(\text {duct-space })}^{n}
$$

Equation 1 indicates that higher system static pressures lead to higher duct air leakage rates for a fixed "hole size" (characterized by the coefficient $C_{1}$ and the exponent $n$ ). For leaks that look like orifices (e.g., large holes), $n$ is 0.5 ; for leaks with some length (e.g., lap joints between duct sections), $n$ is larger (on the order of 0.6 or more). 
When testing a duct section for leakage by fan pressurization, a measured pressure differential is applied to the test section through a fan that blows air from the surrounding space into the duct. The supplied flow that maintains this pressure differential is determined using a flow meter. By using several data points for $Q$ and $\Delta p$, one can solve for $C_{1}$ and $n$ using a least squares fit. The effective "hole size" characteristics determined by this pressurization test represent an aggregate of all the leaks in the test section. A common method of reporting the duct leakage uses the leakage class (CL) metric, which expresses the leakage flow in $\mathrm{cfm}$ at a reference pressure (1 in. of water, $250 \mathrm{~Pa}$ ), normalized per $100 \mathrm{ft}^{2}$ of duct surface area.

Duct Leakage in CAV Systems. In CAV systems, the static pressure in the duct is typically not actively controlled: the static pressure at the fan exit is dependent on system flow resistance and fan performance characteristics.

The static pressures across duct leaks $\Delta p_{\text {(duct-space) }}$ can be related to the static pressure drop through the downstream section of the duct after the fan $\Delta p_{\text {duct }}$. Assuming a linear pressure drop through the duct, and that the zone supply air exits the diffuser and enters the space at ambient static pressure, the average static pressure in the duct equals about half the static pressure drop through the duct. If turbulent flow is assumed, the airflow rate through the duct $Q_{\text {duct }}$ is related to the duct pressure drop according to the square law. This pressure-flow relationship can be expressed as:

$$
\Delta p_{(\text {duct-space })}=\frac{\Delta p_{\text {duct }}}{2}=C_{2} \cdot\left(\frac{Q_{\text {duct }}^{2}}{2}\right)
$$

If large holes are assumed in the ducts, then $n=0.5$ in Equation 1. Assuming that the average duct static pressure corresponds with the average leakage rate, Equation 2 can be substituted into Equation 1 to solve for the average leakage rate as follows:

$$
Q_{\text {leak }}=C_{1} \cdot \Delta p_{(\text {duct-space })}^{0.5}=C_{3} \cdot Q_{\text {duct }}
$$

where

$$
C_{3}=C_{1} \cdot\left(\frac{C_{2}}{2}\right)^{0.5}
$$

In this rough simplification, the fractional leakage ratio $C_{3}$ remains fixed regardless of system flow rate and fan pressure. This result assumes that:

- Duct airflow is turbulent,

- Duct pressure varies linearly along the length of the duct,

- Average duct static pressure indicates average leakage rate, and

- Duct leaks are large and have a pressure exponent of 0.5 .

While these assumptions are plausible for CAV systems, they are not consistent with the conditions produced in some parts of a VAV system.

Duct Leakage in VAV Systems. In contrast to CAV systems, VAV systems maintain a constant static pressure at some point in the duct system upstream of the VAV boxes (except when static pressure reset control strategies are implemented). Consequently, duct air leakage occurring upstream of VAV boxes will have essentially the same flow rate at part-load fan operation as at 
design conditions. This means that the leakage fraction in the upstream duct sections is not constant; instead, it varies as the supply flow varies.

The duct static pressure downstream of a VAV box is influenced by the position of the VAV box dampers, as the damper modulates in response to the differential between the room temperature and the thermostat set point. Thus, the duct section downstream of a VAV box behaves much like a CAV system and downstream duct leakage occurs at a fixed fraction of the supply air entering that section.

\subsubsection{Fan Performance}

Fan electric power is dependent on the fan air power (product of the flow through the fan, and the total pressure rise across the fan), the blade efficiency, and the motor and drive efficiencies. The pressure rise across the fan must be sufficient to overcome the pressure drop in the system. This system pressure drop depends on the pressure drops across duct and duct-like elements (e.g., dampers, fittings), coils, and filters, as well as the static-pressure set point.

Duct and duct-like pressure drops increase as a function of the square of the flow through them. If ducts were the only component in the system, the fan air power would be a cubic function of the flow through the system. However, filters and coils usually follow a power-law functional relationship between pressure drop and flow. For these elements, the pressure drop is proportional to the flow raised to $1 / n$ :

$$
\Delta P_{\text {element }}=\frac{Q_{\text {element }}^{1 / n}}{C_{\text {element }}}
$$

The value of $n$ for the elements varies from 0.5 to 1 . If one of these elements were the only one in the system, the fan power would be a function of the fan flow raised to the power $(1+1 / n)$. This bounds the fan air power as somewhere between a square and a cubic function of fan flow.

Knowing the design flows and pressure drops (along with the appropriate $n$ 's), it is possible to plot the system pressure drops over a range of flows. If the system resistance varies due to changes in VAV box damper positions, the plot would consist of a family of system curves. Each system curve presents the pressure-drop/flow relationship for a fixed system resistance. When the system performance curves are plotted along with fan performance curves on flow versus pressure plots, the system-fan curve intersections define a locus of unique system operating points.

In many hourly simulation programs, including DOE-2, the fan performance subroutines are based on a third-order polynomial relating fractional fan shaft power to fan flow part load ratio (Brandemuehl et al. 1993). The form of the equation is:

$$
F P R=c_{0}+c_{1} \cdot P L R+c_{2} \cdot P L R^{2}+c_{3} \cdot P L R^{3}
$$

where

FPR: $\quad$ Fan power ratio, which is the dimensionless ratio of the fan shaft power at a particular time to the fan shaft power under design conditions;

PLR: $\quad$ Part load ratio, which is the dimensionless ratio of the fan flow at the same time to the fan flow under design conditions; and

$c_{0} \ldots c_{3}:$ Constant coefficients for the curve fit. The specific coefficients depend on the pressure drop, pressure control, and flow characteristics of the system. 


\subsubsection{Duct Surface Heat Transfer}

Heat transfer across the duct surface is another mechanism for energy transfer to or from the air inside a duct. It involves conduction through the duct wall and insulation, convection at the inner and outer surfaces, and radiation between the duct and its surroundings. For simplicity, the following discussion excludes the radiation component, which involves complex calculations to evaluate view factors between the ducts and surrounding surfaces. The discussion also assumes that startup transients can be ignored, because HVAC systems in large commercial buildings usually do not cycle on and off during their daily operating periods.

The steady-state heat transfer rate across the duct wall can be determined using heat exchanger effectiveness methods (Stoecker 1980, Gu et al. 1998b):

$$
q=\varepsilon \cdot C_{\min } \cdot\left(T_{\text {exterior }}-T_{\text {interior }}\right)
$$

where

$\varepsilon: \quad$ Heat exchanger effectiveness, which is the dimensionless ratio of the actual heat transfer rate to the maximum possible heat transfer rate;

$C_{\text {min }}$ : $\quad$ Heat capacity rate, which is the product of the air mass flow rate inside the duct and the air's specific heat $\left(c_{p, a i r}\right), \mathrm{W} /{ }^{\circ} \mathrm{C}$;

$T_{\text {exterior: }} \quad$ Temperature of air surrounding duct exterior, ${ }^{\circ} \mathrm{C}$; and

$T_{\text {interior: }} \quad$ Temperature of air entering duct, ${ }^{\circ} \mathrm{C}$.

Assuming that the heat capacity rate of the air surrounding the duct exterior is infinite (i.e., the temperature of the air surrounding the duct remains approximately constant along the length of the duct), the heat exchanger effectiveness is an exponential relation that depends only on the overall heat transfer coefficient and $C_{\min }$ :

$$
\varepsilon=1-e^{\left(-U A / C_{\min }\right)}
$$

The overall duct heat transfer coefficient (neglecting radiation) in Equation 8 can be determined from the sum of the reciprocals of the resistances associated with the conduction and the convection layers:

$$
U A_{\text {duct }}=\frac{1}{R_{\text {conv, interior }}}+\frac{1}{R_{\text {cond }}}+\frac{1}{R_{\text {conv,exterior }}}
$$

Assuming that turbulent forced convection occurs inside the duct, the convection resistance of the internal flow $R_{\text {conv interior }}$ in Equation 9 can be calculated as:

$$
R_{\text {conv,interior }}=\frac{1}{h_{\text {conv,interior }} \cdot A_{\text {duct }}}
$$

$R_{\text {conv exterior }}$ in Equation 9 can be calculated in a similar manner.

An empirical expression for the convection coefficient in Equation 10 is (ASHRAE 2001a):

$$
h_{\text {conv,interior }}=0.023 \cdot \frac{k_{\text {air }}}{D_{h}} \cdot \operatorname{Re}^{0.8} \cdot \operatorname{Pr}^{0.4}
$$


where

$$
\begin{array}{ll}
A_{\text {duct }}: & \text { Duct surface area, } \mathrm{m}^{2} ; \\
k_{\text {air }}: & \text { Thermal conductivity of air, } \mathrm{W} /\left(\mathrm{m} \cdot{ }^{\circ} \mathrm{C}\right) ; \\
D_{h}: & \text { Duct hydraulic diameter, } \mathrm{m} ; \\
\text { Re: } & \text { Reynolds number }\left(\mathrm{Re}=\rho_{\text {air }} \cdot V_{\text {duct }} \cdot D_{h} / \mu_{\text {air }}\right), \text { dimensionless; } \\
\text { Pr: } & \text { Prandtl number }\left(\mathrm{Pr}=\mu_{\text {air }} \cdot c_{p, \text { air }} / k_{\text {air }}\right), \text { dimensionless; } \\
\rho_{\text {air }}: & \text { Air density inside duct, } \mathrm{kg} / \mathrm{m}^{3} ; \\
V_{\text {duct }}: & \text { Bulk air velocity through duct, } \mathrm{m} / \mathrm{s} ; \text { and } \\
\mu_{\text {air }}: & \text { Air viscosity in duct, } \mathrm{N} \cdot \mathrm{s} / \mathrm{m}^{2} .
\end{array}
$$

The conduction resistance of the duct wall $R_{\text {cond }}$ is dependent on the duct construction material and thickness, and the insulation R-value, and is calculated as the sum of the duct wall resistance and the insulation resistance.

Outside the duct, combined natural and forced convection can occur. Determining a generally applicable combined convection coefficient is difficult because of the wide variation in duct characteristics and environmental conditions that can be found in the large commercial building stock. Based on conditions in residential attics, which are somewhat like ceiling return air plenums, Walker (1993) has suggested that the coefficient can be determined by the following correlation, which makes the larger of the two coefficients most dominant and maintains a smooth transition from one to the other:

$$
h_{\text {conv, exterior }}=\left(h_{\text {natural,exterior }}^{3}+h_{\text {forced, exterior }}^{3}\right)^{1 / 3}
$$

The forced convection coefficient in Equation 12 can be expressed by the following empirical correlation that has been linearized over the range of temperatures expected in residential attics:

$$
h_{\text {forced,exterior }}=\left[18.192-0.0378 \cdot\left(\frac{T_{\text {duct, surface }}+T_{\text {exterior }}}{2}\right)\right] \cdot V_{\text {exterior }}^{0.8}
$$

and the natural convection coefficient can be expressed by another empirical correlation, which uses the same length scale as the forced convection coefficient:

$$
h_{\text {natural }, \text { exterior }}=3.2 \cdot\left|T_{\text {duct, surface }}-T_{\text {exterior }}\right|^{1 / 3}
$$

where

$T_{\text {duct,surface: }}$ Average temperature of duct exterior surface, ${ }^{\circ} \mathrm{C}$; and

$V_{\text {exterior: }} \quad$ Bulk air velocity across duct exterior, $\mathrm{m} / \mathrm{s}$.

By definition, the average temperature of the duct exterior surface can be determined as:

$$
T_{\text {duct,surface }}=T_{\text {exterior }}-\left(\frac{q}{h_{\text {conv, exterior }} \cdot A_{\text {duct }}}\right)
$$

In calculating the duct surface heat transfer, an iterative solution is needed to account for the interdependencies between $T_{\text {duct,surface }}, q$, and $U A_{\text {duct }}$. 


\section{REVIEW OF MODEL IMPLEMENTATIONS}

\subsection{DOE-2.1E}

Given that the current Title 24 compliance procedures are based upon DOE-2.1E (Version 110), it useful to describe the duct thermal performance modeling capabilities and limitations of DOE2.1E. Xu et al. (1999a) have reviewed these capabilities in detail; the following summarizes and expands upon their findings.

The DOE-2 computer simulation program has five major subprograms that are executed in sequence to simulate mass and energy flows in a building:

1. The BDL Processor subprogram translates user input for use in the other four subprograms.

2. The LOADS subprogram calculates the sensible and latent components of the hourly heating or cooling load for each user-designated space in the building.

3. Using the zone loads calculated by the LOADS subprogram, the SYSTEMS subprogram calculates airflow rates, fan power, and coil loads for airside equipment (fans, coils, and ducts).

4. Using the coil loads calculated by the SYSTEMS subprogram, the PLANT section calculates the energy used by primary equipment, such as boilers, chillers, cooling towers, and storage tanks.

5. Based on the energy use calculated in the SYSTEMS and LOADS subprograms, the ECON subprogram calculates the cost of energy.

At a deeper level within the program structure, there are hundreds of FORTRAN subroutines intertwined together like "spaghetti" (Crawley et al. 1998). This non-modular structure has resulted from various program development efforts by many different people over the past three decades. As a result, making even minor changes or improvements to the program is difficult and expensive. This is a significant problem, given that the capabilities of DOE-2.1E to account for duct leakage and surface heat transfer effects are extremely limited.

In DOE-2.1E, up to and including the last official, federal government-sanctioned version of the program (Version 117), the DUCT-AIR-LOSS program keyword is used to account for air leaking out of supply ducts. With this keyword, the user specifies the constant fraction of the system supply airflow that is lost from the ducts, thereby reducing the amount of supply air that reaches the conditioned zones. Surface heat transfer effects for supply ducts are accounted for by the DUCT-DELTA-T keyword, which simply specifies a constant temperature decrease for hot ducts and a constant temperature increase for cold ducts. Energy associated with supply air duct leakage and supply air temperature changes is not included in the building energy balance; instead, it is assumed that energy is transferred directly between the supply ducts and outdoors, regardless of where the ducts are actually located (Buhl et al. 1981). Effectively, there is no duct model within the reference version of DOE-2.1E; the user must use an external model or engineering judgment to determine values for these keywords.

According to Xu et al. (1999a), later proprietary versions of DOE-2.1E were improved so that the user could specify a supply duct heat loss coefficient instead of simply a supply duct temperature change. The building space that "receives" the supply duct leakage air and that is linked to the surface heat transfer effects could also be specified using a new keyword: PIPE\&DUCT-ZONE. Typically, this is a ceiling return plenum (specified by the keyword ZONE-TYPE $=$ PLENUM), but could be an unconditioned space. If the plenum or 
unconditioned space is adjacent to conditioned zones, the zone loads must be determined by specifying SIZING-OPTION = ADJUST-LOADS for the conditioned spaces under the ZONE command. In doing so, the adjacent zones will have their load calculations adjusted for changes in the plenum or unconditioned space temperature.

With the newer versions of DOE-2.1E, if the supply and return flows are both ducted, a different modeling strategy is required than the one outlined above. In this case, the space surrounding the ducts should not be modeled as a ZONE-TYPE = PLENUM, but should be modeled as a ZONETYPE $=$ UNCONDITIONED instead. This allows the user to specify the RETURN-AIR-PATH keyword to be DUCT without its value being overwritten (which occurs when ZONE-TYPE = PLENUM).

In spite of the improvements made recently, significant limitations for modeling duct thermal performance in large commercial buildings remain in DOE-2.1E:

- The supply duct air leakage rate is modeled as a fixed fraction for all system flow rates and types. While this assumption is plausible for some CAV systems, it is not consistent with the conditions that occur in duct sections upstream of terminal boxes in a VAV system. Furthermore, leakage cannot currently be divided into upstream and downstream components relative to the location of terminal boxes, which means the effects of these different types of leakage on terminal box reheat loads and fan power cannot be properly modeled.

- The supply duct heat loss coefficient is constant and does not include radiation effects, or the dependence of convection on airflows and duct interior-exterior air temperature differences. The impact of these assumptions for ducts in large commercial buildings is not clear. However, for ductwork located in an unconditioned rooftop ceiling space, the effect of radiation might be significant (Hirsch 1996). Also, in the duct heat transfer calculation, heat exchanger analysis methods are not used to account for the variation in air temperature along the length of duct (which occurs in real systems); instead, the heat transfer rate is simply based on the average supply-air temperature.

- Duct leakage and surface heat transfer effects are not modeled for return ducts.

\subsection{Other Commercially Available Simulation Programs}

The U.S. Department of Energy (DOE 2003a) lists 256 software tools for energy-related analyses of buildings. Only a small number of these programs can simulate the whole-building energy use of HVAC systems in large commercial buildings, on an hourly or sub-hourly time scale; even fewer have open source code that is publicly available for review and modification. Other than the two DOE-2.1E Version 110 based programs (EnergyPro and Perform95) identified earlier in this report, none are certified for use in Title 24 compliance analyses.

The following describes three notable programs that can be used now for energy analyses of large commercial buildings, and that have duct thermal performance models beyond the capabilities of DOE-2.1E or that might be adapted to include such models because of their expanded features and other modeling capabilities.

\subsubsection{DOE-2.2}

In 1993, the Simulation Research Group of Lawrence Berkeley National Laboratory (LBNL) and James J. Hirsch \& Associates (JJH) started developing a new version of the DOE-2 building energy simulation program. This new version, to be called DOE-2.2, was intended to replace the current version, DOE-2.1E. Funding the development efforts were the U.S. Department of 
Energy (DOE), the Electric Power Research Institute, and others. For various reasons, DOE and LBNL are no longer involved in developing DOE-2.2; however, JJH has continued to develop the program and a proprietary beta version is now available for testing.

Two significant improvements to the duct leakage and surface heat transfer algorithms in the latest versions of DOE-2.1E have been made in DOE-2.2. These include:

- Air leakage from return ducts is now modeled, although surface heat transfer for return ducts is still not modeled.

- The supply duct surface heat transfer algorithm is now based on a heat exchanger model.

Even with these improvements, most of the significant limitations for modeling duct thermal performance in large commercial buildings that were identified in DOE-2.1E remain in DOE 2.2.

\subsubsection{EnergyPlus}

Since 1996, DOE has been funding LBNL, the University of Illinois, the U.S. Army Construction Engineering Research Laboratory, and others to develop EnergyPlus. This new program is intended to replace both DOE-2 and BLAST (a whole-building energy analysis program sponsored by the Department of Defense). It builds on the strengths of DOE-2 and BLAST by combining the best attributes of both hour-by-hour energy analysis programs into a modular program that can be more easily maintained and upgraded. EnergyPlus includes a number of innovative simulation features (DOE 2003b, 2003c), such as variable time steps (as small as 1 minute) and modular system and plant models that are solved simultaneously with a heat balance-based loads simulation. Within the PIER High Performance Commercial Building Systems program, UC San Diego is completing work on a two-node-zone displacement ventilation model for EnergyPlus to deal with the effects of room air mixing, jets, and buoyancy on space temperature distribution and thermal comfort. All of these features make EnergyPlus attractive for evaluating innovative low-energy cooling building designs.

EnergyPlus has no duct thermal performance models to account for duct leakage or surface heat transfer effects. However, the modular nature of EnergyPlus and a planned link with the SPARK equation-based component simulation tool (Crawley et al. 2001, LBNL 2002) should make model integration relatively straightforward once the models have been defined. The DOE "Guide for Module Developers: Everything You Need to Know about EnergyPlus Calculational Development" (DOE 2003e) provides explicit instructions on how to proceed with module development and integration. The Florida Solar Energy Center is currently integrating a residential duct thermal performance model (Gu et al. 1998b) into EnergyPlus, but it is unlikely that this model will be able to deal with the complex duct systems and operation strategies in large commercial buildings without further development.

A link with COMIS (a multizone airflow network simulation program) is included in EnergyPlus to determine time-varying envelope and interzonal flows. However, at this time, duct flows are either user-specified or are determined solely based on thermal requirements, rather than being determined using COMIS flow and pressure correlations. COMIS (like other similar programs) cannot accurately model duct components involving multi-port flow junctions, because it assumes that duct flows depend on zonal pressure differences, but not directly on flows in other branches (Lorenzetti 2001). In real systems, duct flows (and pressure loss coefficients) in adjacent duct branches can be interdependent.

Assuming that a reliable airflow network solution could be developed to model duct flows in EnergyPlus, there is still the question of appropriate inputs and who would use such models. The location and size distribution of leaks in a duct system are practically unknowable, which means 
there may be little point to conducting detailed duct airflow-pressure simulations in other than research investigations. Even if detailed leakage data could be gathered in a real building (likely at great expense), these data would be so voluminous that the burden of entering them might dissuade users from using the model. For compliance evaluations involving hypothetical buildings, large amounts of input data are undesirable for the same reason. Simplifying assumptions could be made about leak location and size distribution (e.g., fixed leakage flows, or fixed fractional leakage flows, as appropriate to various duct sections). Bayesian data analysis methods could also be used to identify key input data (and to develop measurement and performance verification protocols); however, these techniques are only now being developed for use in whole-building airflow simulations (Sohn et al. 2000), and the size and distribution of duct leaks in the large commercial building stock is not yet well defined.

\subsubsection{TRNSYS}

The TRNSYS simulation program is a transient simulation program that has been in use since 1975, primarily to model building thermal energy systems in research applications (Klein et al. 1996). Because of its modular nature, it allows substantial flexibility for a user to specify a building and its HVAC system component by component. User-specified parameters describe the characteristics of each component, and user-specified interconnections between inputs and outputs link the components. Simulations involve the simultaneous solution of large systems of equations contained in the FORTRAN subroutines that describe the specified component models. Each subroutine defines a component model; user inputs describe to TRNSYS which subroutines should be linked and executed to define the thermal system of interest. This simulation strategy is distinctly different from the sequential solution, predefined system schematic strategy used in programs such as DOE-2.

Many component models are already available in TRNSYS for simulating HVAC system performance in large commercial buildings, and are well documented using the same source code style that is used in the ASHRAE HVAC Secondary Toolkit (Brandemuehl et al. 1993). Franconi (1999) used TRNSYS to model the effects of duct leakage on VAV system performance for a 10 -story office building. Problem specific equipment and control models were developed using FORTRAN subroutines from the ASHRAE Toolkit (e.g., a VAV fan, an air-side economizer). New models were also created to represent duct air leakage, VAV boxes with reheat coils, and ceiling return plenums.

The Franconi simulation approach involved a quasi-steady-state strategy with a one-hour time step, and can be described by three sequential steps:

1. Hourly zone loads (heat extraction and addition rates) and zone air temperatures are calculated using DOE-2, for a constant air volume (CAV) system that has no duct leakage. These results are then output to a data file, which is read as input by TRNSYS. The data file also includes the corresponding hourly weather conditions, latent heat gains in conditioned spaces, and heat input to the ceiling plenum from lights.

2. TRNSYS generates hourly HVAC system fan and coil energy consumption data using interconnected detailed component models for the heating and cooling coils, fans, ducts, terminal boxes, economizer, and return plenum. The solution for each hour involves numerous iterations that terminate when convergence is achieved; convergence occurs when the error tolerances associated with component input and output variables are satisfied. Various duct leakage configurations are modeled at this stage. The TRNSYS analysis considers only hours when the HVAC system is operating. 
3. Regression analyses based on correlations between DOE-2 system and plant energy use are used to translate the TRNSYS system level coil load data to plant level energy use; energy costs are subsequently calculated based on this energy use.

In this approach, the distribution system simulation is uncoupled from the loads and plant simulations of DOE-2, in the same manner that DOE-2 itself uses. The difference is that the TRNSYS system simulation expands beyond DOE-2 modeling capabilities to offer more flexibility in modeling duct thermal performance issues. A more rigorous approach would involve a coupled simultaneous solution of the loads, system, and plant performance, which could be done now using EnergyPlus if the TRNSYS models were integrated with that program.

Appendix II contains the FORTRAN source code implementations of the seven models that Franconi used in TRNSYS (TYPES: 70, Fan (supply and return); 75, Cooling Coil; 77, Zone Return Air Mixing; 80, Economizer; 81, Ceiling Return Plenum; 82, Upstream Ducts; and 86, VAV Box and Downstream Ducts). For each model, a subroutine and function call mapping is provided to help the reader follow the program logic. Then, the source code begins by defining the purpose of the model, the input and output variables, and the parameters used to characterize component performance. Finally, the source code that follows defines component performance and is essentially self-documenting.

For the most part, the seven models that Franconi used reflect the modeling principles discussed earlier in this report. The exception is that duct surface heat transfer effects are not fully or properly addressed; preliminary efforts to model these effects were included in the subroutine for ducts upstream of VAV boxes (TYPE82), but were never tested or used. Also, it appears that some of the assumptions and duct surface heat transfer equations defined in that subroutine are incorrect (particularly when ducts are insulated) and require further development. Furthermore, the ceiling return plenum model (TYPE81) does not include a storage term to account for the thermal mass of the concrete ceiling of the plenum. Excluding the storage term means that the amplitude of return air temperature variations in the plenum might be larger than actually occurs, especially when the air-handling system is off, and may also be improperly phased as well. The impacts of this omission on duct surface heat transfer rates during system operation are not clear and require further investigation. However, it likely has no significant impact on the most important parameter affected by supply duct air leakage: fan power consumption.

Figure 1 shows a sample of the performance parameters calculated by TRNSYS using the seven models for one hour of VAV system operation during the cooling season, for a case with $10 \%$ duct leakage upstream and 10\% duct leakage downstream of the VAV boxes (leakage paths shown by dashed lines leading to ceiling plenum). This graphic representation of the TRNSYS output is based on a spreadsheet recently developed by the author as an aid to understand and test the model, and is not generated by TRNSYS itself. 


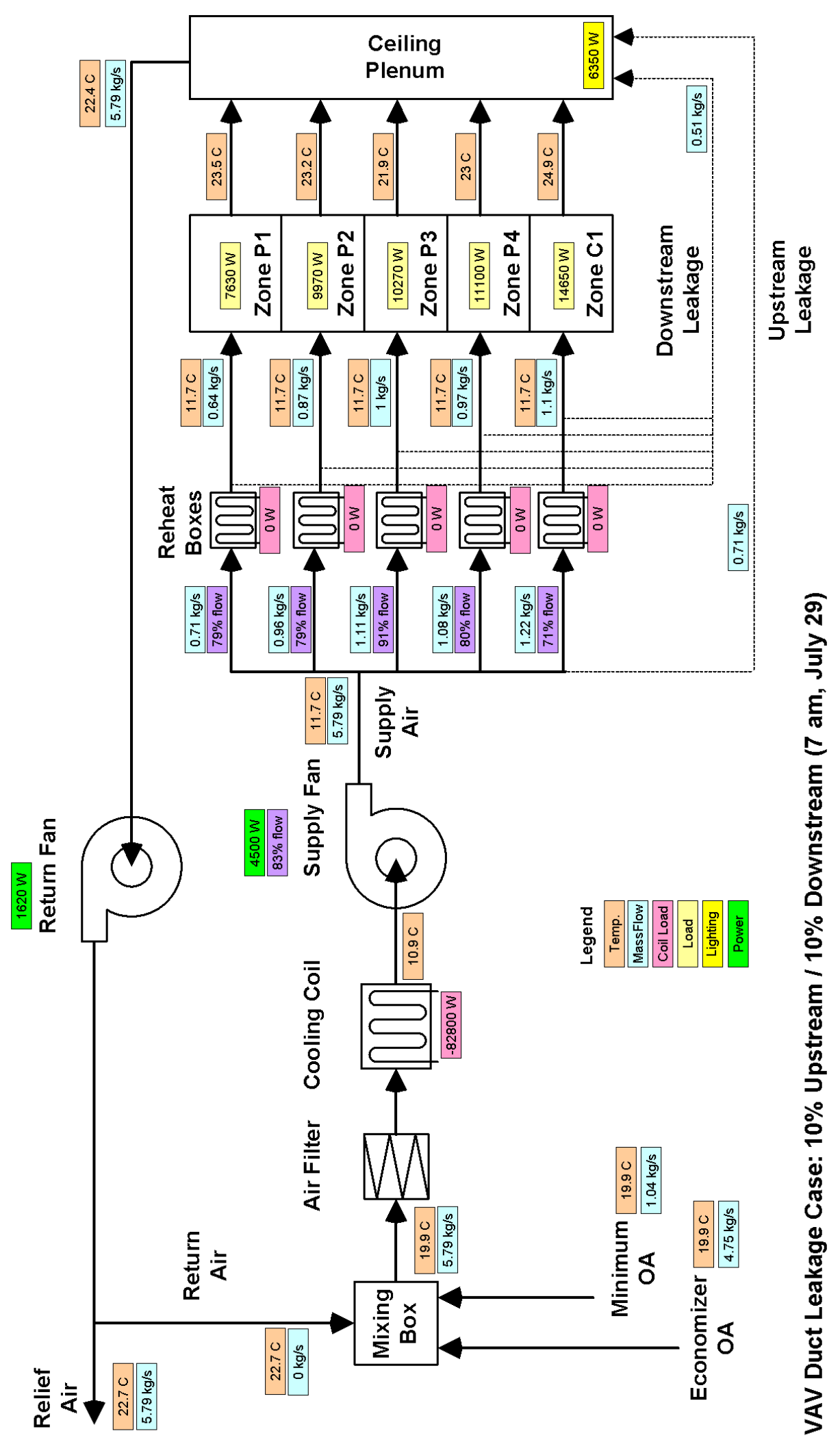

Figure 1. Sample TRNSYS Output 


\section{PROJECT OUTCOMES}

Our duct modeling review involved a literature review of 188 documents related to past HVAC system modeling efforts. We supplemented the review through discussions with building simulation experts to assess new, unpublished, relevant work. Based on this review, we have the following two recommendations for duct modeling approaches: one is for a short-term approach that can be used in the impacts analysis task of this project; the other is for the long-term development of an improved compliance tool for Title 24.

\subsection{Recommended Short-Term Modeling Approach}

We conclude that the best approach for our impacts analysis task in this project is to build upon the Franconi (1999) research that used DOE-2 and TRNSYS to evaluate HVAC system performance. An advantage of using the DOE-2/TRNSYS approach in this project is that DOE-2 prototypical models for a large commercial California building are already available, as are the custom TRNSYS component models. Another advantage is that the duct leakage modeling approach and its results for a California building have already been validated, and no substantial changes to the simulation tool are required to carry out our analyses. No other whole-building modeling approach to assess duct system performance for large commercial buildings is currently as advanced as this approach.

\subsection{Recommended Long-Term Modeling Approach}

The choices for incorporating the impacts of duct performance in large commercial buildings into the Title-24, Non-Residential Building Energy Standards include:

1. Using the current DOE-2.1E program,

2. Using an add-on calculation routine along with DOE-2, or

3. Using an alternative calculation method or simulation program.

Initially, it would seem that using the first path might be the most appropriate. The DOE-2.1E program is well entrenched into the Title- 24 compliance path, and most importantly, it is used to benchmark alternative compliance models, which means that unless the DOE-2.1E program gets the correct answer, alternative programs that do get the right answer will not be certified.

However, as described in this report, there are a number of modeling problems in DOE-2.1E that need to be addressed. Because DOE no longer supports the development of DOE-2, it is likely that modifications would need to be made in the private sector, which could result in proprietary source code that might not be available for public inspection. Furthermore, the convoluted structure of DOE-2 will make modifications difficult and expensive, which is one of the reasons DOE decided to pursue the development of EnergyPlus.

The second path provides a possible alternative. However, the sequential DOE-2 / TRNSYS modeling approach could best be described as "user hostile". Even though an Excel spreadsheet "interface" has been recently developed to help organize and visualize the input and output of TRNSYS, this simulation approach remains inappropriate outside a research environment. It is unlikely this approach would be practical on a day-to-day basis for compliance analyses.

Assuming that EnergyPlus could be certified as a compliance tool for use in support of the 2008 revisions to Title 24, we suggest that the long-term strategy should involve integrating duct thermal performance models with EnergyPlus. This long-term approach focuses on EnergyPlus rather than on the current compliance version of DOE-2, because we expect that the 
recommended enhancements could be more easily applied and used in EnergyPlus for future analyses of innovative low-energy cooling designs. In particular, although EnergyPlus at this time has no capabilities to model duct system thermal losses, we expect that the TRNSYS HVAC system models or ones like them could be incorporated into EnergyPlus directly or through a planned SPARK link to provide a more practical integrated tool for designers.

During the development of EnergyPlus, a link to TRNSYS was planned; such a link would make it easier to add the current TRNSYS models to EnergyPlus. However, it is unlikely that this link will be established, because TRNSYS and EnergyPlus each have separate means to determine simulation time steps, and a way to link these time steps in an external-coupling run-time mode has not been resolved. Essentially, one of the two programs needs to be the "brain" running the simulation and TRNSYS is not setup to give control to EnergyPlus for this functionality. As a result, simply linking the TRNSYS duct thermal performance models to EnergyPlus is not a practical option at this time.

Apart from needing to be certified as an alternative calculation method, a key issue related to using EnergyPlus as a compliance tool is whether users could easily operate the program. At this time, a rudimentary user-interface has been developed for EnergyPlus, but is not yet publicly available. If EnergyPlus is to be used in support of the 2008 Standards, then the development of this interface needs to be accelerated. A related issue is that there is already a well-established user base that knows how to operate DOE-2.1E for compliance analyses. To make it easy for current DOE-2 (and BLAST) users to move to EnergyPlus, utilities are already being developed to convert BLAST and DOE-2 input files for use in EnergyPlus.

\subsection{Recommendations for Future Work}

Incorporating duct-modeling capabilities into compliance tools is only one aspect of the changes that need to be made to the non-residential standards. Before duct performance in large commercial buildings can be accounted for in Title 24 nonresidential building energy standards, there are several other issues that must be addressed and resolved. These include:

1. Specifying reliable duct air leakage measurement techniques that can be practically applied in the large commercial building sector.

2. Defining the duct leakage condition for the standard building used in Title 24 compliance simulations.

3. Assuring consistency between simulated duct performance impacts and actual impacts.

4. Developing compliance tests for the Alternative Calculation Method (ACM) Approval Manual (CEC 2001b) to evaluate duct performance simulations.

Regarding Issues 1 and 2, new duct air leakage measurement techniques for large commercial buildings are already under development at LBNL. These efforts are focused on developing a rapid technique that measures leakage flows rather than leakage area, and we expect that it could be used to populate a database of duct leakage conditions in the existing building stock.

After the "typical" duct leakage for the building stock is defined, then a decision can be made about what duct leakage level to assign to the standard building. If the standard building description includes a typical duct air leakage rate, then proposed buildings will be rewarded for sealing ducts. If instead the standard building has a reduced leakage level, proposed buildings that are not sealed will be penalized. The decision about what leakage level to assume for the standard building description will depend upon the preparedness of the market to handle required duct efficiency improvements, as opposed to optional improvements. 
In terms of prescriptive compliance options, if the standard-building duct performance parameters are established to correspond to typical duct air leakage, determining compliance using the prescriptive approach is straightforward. If the proposed building has a typical duct air leakage level and has ducts insulated to Title 24 requirements, the building complies with respect to ducts. In other words with nothing done to improve duct performance in the building, it would meet the minimal duct performance level in this case. On the other hand, if the standard building has tighter-than-typical duct air leakage specifications, then compliance would require either performance measurements (i.e., duct air leakage measurements), or increased energy efficiency of other building components.

With the standard building defined as having leaky ducts, improving the duct performance in the proposed building affects compliance only if the performance budget approach is used. If leaks are sealed as a compliance conservation measure, standardized testing methods must be adopted to verify reduced leakage rates. Leakage rates determined from the tests would be part of the duct performance input data in the performance compliance analysis for the proposed building.

For Issue 3, one study has already shown through detailed minute-by-minute field measurements in a large commercial building that duct leakage has a significant impact on HVAC system performance (Diamond et al. 2003). The extensive set of HVAC system performance data collected by Diamond et al. could be used to validate simulation tools that are used to predict the duct performance impacts.

Regarding Issue 4, several tests must be performed already on alternative calculation methods before they are approved. Although a test does not yet exist, the proper modeling of duct performance in these alternative methods should be evaluated as part of these capability tests. Given that the current two certified nonresidential compliance tools depend upon DOE-2.1E as the reference evaluation program, and that DOE-2.1E cannot properly account for duct thermal performance, it is expected that results obtained using an alternative calculation method that properly accounts for duct thermal performance might differ substantially from the reference program results. Thus, we recommend that a new reference program be identified for use at least in this test (e.g., EnergyPlus). A prerequisite in this case is that the reference method be appropriately validated against field measurements.

When this project is complete, we expect that it will successfully demonstrate to the building industry that duct leakage in commercial buildings is an important performance issue, and that there is value in reducing thermal losses associated with this leakage. It will also provide the basis for the development of standards that address thermal deficiencies in large commercial duct systems. Three additional steps will be required to further develop duct-modeling capabilities that address limitations in existing models and to initiate strong market activity related to duct system improvements. We recommend that these steps include:

1. Implementing duct models in user-friendly commercially-available software for building energy simulation, validating the implementations with case studies and demonstrations, and obtaining certification for software use as a primary or alternative compliance tool in support of the Title 24 Nonresidential Standards.

2. Developing methodologies to deal with airflows entering VAV boxes from ceiling return plenums (e.g., to model parallel fan-powered VAV boxes), to deal with duct surface heat transfer effects, and to deal with static pressure reset and supply air temperature reset strategies.

3. Transferring information to practitioners through publications, conferences, workshops, and other education programs. 


$\begin{array}{ll}\text { GLOSSARY } & \\ \text { ACM } & \text { Alternative Calculation Method } \\ \text { ASHRAE } & \text { American Society of Heating, Refrigerating, and Air-Conditioning Engineers } \\ \text { CAV } & \text { Constant Air Volume } \\ \text { CEC } & \text { California Energy Commission } \\ \text { DOE } & \text { U.S. Department of Energy } \\ \text { EIA } & \text { Energy Information Administration } \\ \text { GWh } & \text { Giga Watt hours, } 10^{9} \text { Wh, } 10^{6} \text { kWh } \\ \text { HVAC } & \text { Heating, Ventilating, and Air Conditioning } \\ \text { JJH } & \text { James J. Hirsch \& Associates } \\ \text { LBNL } & \text { Lawrence Berkeley National Laboratory } \\ \text { MW } & \text { Mega Watt, } 10^{6} \text { W } \\ \text { PIER } & \text { Public Interest Energy Research } \\ \text { UC } & \text { University of California } \\ \text { VAV } & \text { Variable Air Volume }\end{array}$




\section{APPENDIX I: BIBLIOGRAPHY}

1. Akbari, H., J. Eto, S. Konopacki, and A. Afzal. 1993. "Integrated Estimation of Commercial Sector End-Use Load Shapes and Energy Use Intensities in PG\&E Service Area". Second Interim Report, Lawrence Berkeley National Laboratory, June 12.

2. ASHRAE. 2001a. "Handbook of Fundamentals: Chapter 3, Heat Transfer". Atlanta: American Society of Heating, Refrigeration, and Air-Conditioning Engineers, Inc.

3. ASHRAE. 2001b. "Handbook of Fundamentals: Chapter 32, Duct Design." Atlanta: American Society of Heating, Refrigeration, and Air-Conditioning Engineers, Inc.

4. Atkinson, G.V. 1986. "VAV System Volume Control using Electronic Strategies". ASHRAE Transactions, V. 92, Pt. 2B. American Society of Heating, Refrigerating and Air-Conditioning Engineers, Inc.

5. Beausoleil-Morrison, I., R. Calla, M. Mottillo, J. Purdy, P. Wyndham-Wheeler, P. Lopez, F. Dubrous, and M. Lubun. 2001. "Using Building Simulation to Support an EnergyEfficient Incentive Program (CBIP)". Proceedings of Building Simulation '01, International Building Performance Simulation Association; Rio de Janeiro; August 13-15.

6. Blair, N.J., J.W. Mitchell, and W.A. Beckman. 1995. "Demonstration of TRNSYS Use in Building Simulations". Proceedings of Building Simulation '95, International Building Performance Simulation Association; Madison, Wisconsin, August 14-16.

7. Blair, N.J., W.A. Beckman, S.A. Klein, and J.W. Mitchell. 1996. "TRNSYS for Windows Packages". Proceedings of Solar '96, The 1996 American Solar Energy Society Annual Conference; Asheville, North Carolina, April 13-18.

8. Bourdouxhe, J.-P., M. Grodent, and J. Lebrun. 1998. "Reference Guide for Dynamic Models of HVAC Equipment". American Society of Heating, Refrigerating and AirConditioning Engineers, Inc.

9. Brandemuehl, M.J., S. Gabel, and I. Andresen. 1993. "HVAC 2 Toolkit: Algorithms and Subroutines for Secondary HVAC System Energy Calculations". American Society of Heating, Refrigerating and Air-Conditioning Engineers, Inc.

10. Brothers, P.W. and M.L. Warren. 1986. "Fan Energy Use in Variable Air Volume Systems". ASHRAE Transactions, V. 92, Pt. 2B. American Society of Heating, Refrigerating and Air-Conditioning Engineers, Inc.

11. Brown, R.E. and J.G. Koomey. 2002. "Electricity Use in California: Past Trends and Present Usage Patterns". Lawrence Berkeley National Laboratory Report, LBNL-47992. May.

12. BSO. 1992. "BLAST: The Building Loads Analysis and System Thermodynamics Program - Volume 2 - Technical Reference Manual". BLAST Support Office, Department of Mechanical and Industrial Engineering, University of Illinois at Urbana-Champaign.

13. Buhl, W.F., B. Birdsall, A.E. Erdem, R. Curtis, K. Olson, K.L. Ellington, F.C. Winkelmann, and Group Q-11, Los Alamos National Laboratory. 1981. "DOE-2 Reference Manual, Version 2.1A, Rev. 2" Lawrence Berkeley National Laboratory, May. LBL-8706. 
14. Buhl, W.F., A.E. Erdem, F.C. Winkelmann, and E.F. Sowell. 1993. "Recent Improvements in SPARK: Strong Component Decomposition, Multivalued Objects, and Graphical Interface". Proceedings of Building Simulation '93, International Building Performance Simulation Association; Adelaide, Australia; August 16-18.

15. Busch, J. and W. Tschudi. 1999. "Design Survey and Assessment Of Cleanroom Energy Analysis Tools". Lawrence Berkeley National Laboratory Draft Report, October.

16. Cappellin, T.E. 1997. "VAV Systems - What Makes Them Succeed? What Makes Them Fail?". ASHRAE Transactions, V. 103, Pt. 2. American Society of Heating, Refrigerating and Air-Conditioning Engineers, Inc.

17. Carrié, F.R., J. Andersson, and P. Wouters. 1999. "Improving Ductwork: A Time for Tighter Air Distribution Systems - A Status Report on Ductwork Airtightness in Various Countries with Recommendations for Future Designs and Regulations". Air Infiltration and Ventilation Centre, Coventry, UK.

18. CEC. 2001a. "Nonresidential Manual for Compliance with the 2001 Energy Efficiency Standards (for Nonresidential Buildings, High-Rise Residential Buildings, and Hotels/Motels)". California Energy Commission, P400-01-023, August.

19. CEC. 2001b. "Alternative Calculation Method (ACM) Approval Manual for the 2001 Energy Efficiency Standards for Nonresidential Buildings". California Energy Commission, P400-01-011, April.

20. CEC. 2003. "List of Approved Computer Programs for the 2001 Energy Efficiency Standards". California Energy Commission. March 3.

21. Chen, S. and S. Demster. 1996. "Variable Air Volume Systems for Environmental Quality". New York: McGraw-Hill.

22. Chen, X., Y. Zhu, and M. Nakahara. 2000. "Improvement of the Fluid Network's Module Construction for HVACSIM+". Proceedings of 6th International Conference on Healthy Buildings, International Society of Indoor Air Quality and Climate; Espoo, Finland, August 6-10.

23. Chimack, M.J., C.E. Walker, and E. Franconi. 2001. "Determining Baseline Energy Consumption and Peak Cooling Loads of a 107-Year-Old Science Museum using DOE 2.1E'. Proceedings of Building Simulation '01, International Building Performance Simulation Association; Rio de Janeiro; August 13-15.

24. Crawley, D.B., L.K. Lawrie, F.C. Winkelmann, C.O. Pedersen, R.J. Liesen, and D.E. Fisher. 1996. "Workshops on Next-Generation Building Energy Simulation Tools". IbspaNews, Volume 8, Number 1, International Building Performance Simulation Association. July.

25. Crawley, D.B., L.K. Lawrie, F.C. Winkelmann, W.F. Buhl, A.E. Erdem, C.O. Pedersen, R.J. Liesen, and D.E. Fisher. 1997. "What Next For Building Energy Simulation - A Glimpse Of The Future”. Proceedings of Building Simulation '97, International Building Performance Simulation Association; Prague, Czech Republic; September 8-10. 
26. Crawley, D., Lawrie, L., Pedersen, C., Liesen, R., Fisher, D., Strand, R., Taylor, R., Winkelmann, F., Buhl, F., Huang, J., and Erdem, E. 1998. "Beyond BLAST and DOE-2:

EnergyPlus, A New-Generation Energy Simulation Program". Proceedings of the ACEEE 1998 Summer Study on Energy Efficiency in Buildings, Efficiency and Sustainability, Asilomar Conference Center, Pacific Grove, CA, August.

27. Crawley, D.B., L.K. Lawrie, C.O. Pedersen, R.J. Liesen, D.E. Fisher, R.K. Strand, R.D. Taylor, F.C. Winkelmann, W.F. Buhl, Y.J. Huang, and A.E. Erdem. 1999. "EnergyPlus, A New-Generation Building Energy Simulation Program”. Proceedings of the Renewable and Advanced Energy Systems for the 21st Century, American Society of Mechanical Engineers; Lahaina, Maui, Hawaii, April 11-15. RAES99-7601.

28. Crawley, D.B., L.K. Lawrie, C.O. Pedersen, and F.C. Winkelmann. 2000. "EnergyPlus: Energy Simulation Program”. ASHRAE Journal, Vol. 42, April. LBNL-46002.

29. Crawley, D., L.K. Lawrie, F.C. Winkelmann, W.F. Buhl, Y.J. Huang, C.O. Pedersen, R.K. Strand, R.J. Liesen, D.E. Fisher, M.J. Witte, and J. Glazer. 2001a. "EnergyPlus: Creating a New-Generation Building Energy Simulation Program". Energy and Buildings, Volume 33, Issue 4, April.

30. Crawley, D.B., L.K. Lawrie, F.C. Winkelmann, and C.O. Pedersen. 2001b. "EnergyPlus: New Capabilities in a Whole-Building Energy Simulation Program". Proceedings of Building Simulation '01, International Building Performance Simulation Association; Rio de Janeiro; August 13-15.

31. Crawley, D.B., L.K. Lawrie, C.O. Pedersen, F.C. Winkelmann, M.J. Witte, R.K. Strand, R.J. Liesen, W.F. Buhl, Y.J. Huang, R.H. Henninger, J. Glazer, D.E. Fisher, and D. Shirey. 2002. "EnergyPlus: New, Capable and Linked". Green Building International Conference and Expo, U.S. Green Building Council; Austin, Texas, November 13-15.

32. deWit, S. and G. Augenbroe. 2001. "Uncertainty Analysis of Building Design Evaluations". Proceedings of Building Simulation '01, International Building Performance Simulation Association; Rio de Janeiro; August 13-15.

33. Diamond, R., C. Wray, D. Dickerhoff, N. Matson, and D. Wang. 2003. "Thermal Distribution Systems in Commercial Buildings". Lawrence Berkeley National Laboratory Report, LBNL-51860.

34. DOE. 2003a. "Building Energy Software Tools Directory”. U.S. Department of Energy, Office of Building Technology, State and Community Programs. http://www.eere.energy.gov/buildings/tools_directory/.

35. DOE. 2003b. "EnergyPlus Engineering Document: The Reference to EnergyPlus Calculations". Board of Trustees of the University of Illinois and Regents of the University of California through the Ernest Orlando Lawrence Berkeley National Laboratory, U.S. Department of Energy. April 7.

36. DOE. 2003c. "Input Output Reference: The Encyclopedic Reference to EnergyPlus Input and Output". Board of Trustees of the University of Illinois and Regents of the University of California through the Ernest Orlando Lawrence Berkeley National Laboratory, U.S. Department of Energy. April 14. 
37. DOE. 2003d. "Guide for Interface Developers: Everything You Need to Know about EnergyPlus Input and Output". Board of Trustees of the University of Illinois and Regents of the University of California through the Ernest Orlando Lawrence Berkeley National Laboratory, U.S. Department of Energy. April 13.

38. DOE. 2003e. "Guide for Module Developers: Everything You Need to Know about EnergyPlus Calculational Development". Board of Trustees of the University of Illinois and Regents of the University of California through the Ernest Orlando Lawrence Berkeley National Laboratory, U.S. Department of Energy. April 13.

39. DOE. 2003f. "Output Details and Examples: An In-Depth Guide to EnergyPlus Outputs, Example Inputs and Data Set Files". Board of Trustees of the University of Illinois and Regents of the University of California through the Ernest Orlando Lawrence Berkeley National Laboratory, U.S. Department of Energy. April 13.

40. Donn, M., J. Lee, N. Isaacs, and P. Bannister. 1995. “Decision Support Tools for Building Code Energy Efficiency Compliance". Proceedings of Building Simulation '95, International Building Performance Simulation Association; Madison, Wisconsin, August 14-16.

41. Dorer, V., A. Haas, W. Keilholz, R. Pelletret, and A. Weber. 2001. "COMIS V3.1 Simulation Environment for Multizone Air Flow and Pollutant Transport Modelling". Proceedings of Building Simulation '01, International Building Performance Simulation Association; Rio de Janeiro; August 13-15.

42. EIA. 2002. "1999 Commercial Buildings Energy Consumption Survey - Detailed Tables". Energy Information Administration, U.S. Department of Energy. August. http://www.eia.doe.gov/emeu/cbecs/pdf/alltables.pdf

43. Eilert, P. 2000. "Air Distribution Systems: Codes and Standards Enhancement (CASE) Study". Pacific Gas and Electric Company Report, November 28.

44. Eley, C. 2001. "Measure Identification and Analysis Plan - 2005 California Building Energy Efficiency Standards - Envelope: T-Bar Ceilings". Draft Report of Eley Associates to the California Energy Commission, Contract Number 400-00-061. November 8.

45. Eriksson, J.B. 1999. "A Method For Analysis of Controllability of Duct Systems Designed For Variable Ventilation Flow Rates". Proceedings of Building Simulation '99, International Building Performance Simulation Association; Kyoto, Japan, September 1315.Emmerich, S.J., A.K. Persily, and D.A. VanBronkhorst. 1995. "A Workplan to Analyze the Energy Impacts of Envelope Airtightness in Office Buildings". Report of Building and Fire Research Laboratory, National Institute of Standards and Technology, NISTIR 5758. December.Englander, S.L. and L.K. Norford. 1992. "Saving Fan Energy in VAV Systems Part 1: Analysis of a Variable-Speed-Drive Retrofit". ASHRAE Transactions, V. 98, Pt. 1. American Society of Heating, Refrigerating and Air-Conditioning Engineers, Inc.

48. Englander, S.L. and L.K. Norford. 1992. "Saving Fan Energy in VAV Systems - Part 2: Supply Fan Control for Static Pressure Minimization using DDC Feedback". ASHRAE Transactions, V. 98, Pt. 1. American Society of Heating, Refrigerating and AirConditioning Engineers, Inc.

49. Eriksson, J.B. 1999. “A Method to Study Air Distribution Control”. Master's Thesis, Royal Institute of Technology, Stockholm, Sweden. Swedish Council for Building Research, Bulletin no. 49. ISRN KTH/IT/M-49-SE. August. 
50. Fisher, D.E., R.D. Taylor, F. Buhl, R.J. Leisen, and R.K. Strand. 1999. "A Modular, LoopBased Approach To HVAC Energy Simulation And Its Implementation In EnergyPlus". Proceedings of Building Simulation '99, International Building Performance Simulation Association; Kyoto, Japan, September 13-15.

51. Fisher, D.E. and C.O. Pedersen. 1998. "Convective Heat Transfer in Building Energy and Thermal Load Calculations". Report of BLAST Support Office, University of Illinois at Urbana-Champaign.

52. Fisk, W.J., W. Delp, R. Diamond, D. Dickerhoff, R. Levinson, M. Modera, M. Nematollahi, and D. Wang. 2000. "Duct Systems in Large Commercial Buildings: Physical Characterization, Air Leakage, and Heat Conduction Gains". Energy and Buildings, Vol. 32, No. 1. LBNL-42339.

53. Franconi, E. and Y.J. Huang. 1996. "Shell, System, and Plant Contributions to the Space Conditioning Energy Use of Commercial Buildings". Proceedings of the ACEEE 1996 Summer Study on Energy Efficiency in Buildings, Efficiency and Sustainability, Asilomar Conference Center, Pacific Grove, CA, August 25-31.

54. Franconi, E. 1998. "Measuring Advances in HVAC Distribution System Design". Proceedings of the ACEEE 1998 Summer Study on Energy Efficiency in Buildings, Efficiency and Sustainability, Asilomar Conference Center, Pacific Grove, CA, August 2328. LBNL-43188.

55. Franconi, E., W. Delp, and M. Modera. 1998. "Impact of Duct Air-Leakage on VAV System Energy Use”. Lawrence Berkeley National Laboratory Draft Report. LBNL-42417.

56. Franconi, E.M. 1999. “Thermodynamic Analysis for Improved HVAC Distribution System Performance". Ph.D. Dissertation, Department of Civil, Environmental, and Architectural Engineering, University of Colorado, Boulder.

57. Gu, L., J.E. Cummings, M.V. Swami, and P.W. Fairey. 1998a. "Comparison of Duct Computer Models that Could Provide Input to the Proposed Thermal Distribution Standard Method of Test"'. ASHRAE Transactions, V. 104, Pt. 1. American Society of Heating, Refrigerating and Air-Conditioning Engineers, Inc.

58. Gu, L., M.V. Swami, J.E. Cummings, P.W. Fairey, T.W. Petrie, and J.E. Christian. 1998 b. "Comparison of a Duct System Computer Model with Measured Data in a Residential Attic with a Duct System". ASHRAE Transactions, V. 104, Pt. 2. American Society of Heating, Refrigerating and Air-Conditioning Engineers, Inc.

59. Hackner, R.J., J.W. Mitchell, and W.A. Beckman. 1984. "HVAC System Dynamics and Energy Use in Existing Buildings - Part I". ASHRAE Transactions, V. 90, Pt. 2B. American Society of Heating, Refrigerating and Air-Conditioning Engineers, Inc.

60. Haltrecht, D., R. Zmeureanu, and I. Beausoleil-Morrison. 1999. "Defining The Methodology For The Next - Generation HOT2000"TM Simulator". Proceedings of Building Simulation '99, International Building Performance Simulation Association; Kyoto, Japan, September 13-15.

61. Hand, J. and L. McElroy. 2002. "Simulation, No Problem, Of Course We Offer This Service! (Observations on Firms Who Have Worked to Make This True)". Proceedings of eSim 2002, International Building Performance Simulation Association -Canada; Montréal, Québec, Canada, September 11-13. 
62. Haves, P. 1995. "Detailed Modelling And Simulation Of A VAV Air-Conditioning System". Proceedings of Building Simulation '95, International Building Performance Simulation Association; Madison, Wisconsin, August 14-16.

63. Haves, P. 1997. "Fault Modelling in Component-Based HVAC Simulation". Proceedings of Building Simulation '97, International Building Performance Simulation Association; Prague, Czech Republic; September 8-10.

64. Haves, P., L.K. Norford, and M. DeSimone. 1998. "A Standard Simulation Test Bed for the Evaluation of Control Algorithms and Strategies". ASHRAE Transactions, V. 104, Pt. 1. American Society of Heating, Refrigerating and Air-Conditioning Engineers, Inc.

65. Haves, P. and S.K. Khalsa. 2000. "Model-Based Performance Monitoring: Review of Diagnostic Methods and Chiller Case Study". Proceedings of the ACEEE 2000 Summer Study on Energy Efficiency in Buildings, Efficiency and Sustainability, Asilomar Conference Center, Pacific Grove, CA, August 20-25. LBNL-45949.

66. Haves, P., T. Salsbury, D. Claridge, and M. Liu. 2001. "Use of Whole-Building Simulation in On-Line Performance Assessment: Modeling and Implementation Issues". Proceedings of Building Simulation '01, International Building Performance Simulation Association; Rio de Janeiro; August 13-15.

67. Hedrick, R. 2001. "Integrated Energy Systems Productivity and Building Science Program: Literature Search on Enclosing Ducts in Conditioned Space, Task 6.3.1a". GARD Analytics Report to New Buildings Institute, Inc. August 10.

68. Hedrick, R. 2001. "Integrated Energy Systems Productivity \& Building Science Program: Element 6 - Integrated Design of Residential Ducting \& Air Flow Systems". GARD Analytics and New Buildings Institute, Inc. Annual Report, Volume 6 of 7. August 16.

69. Henninger, R.H. and M.J. Witte. 2002. "EnergyPlus Testing with ANSI/ASHRAE Standard 140-2001 (BESTEST), EnergyPlus Version 1.0.3.019”. Report of GARD Analytics, Park Ridge, Illinois, December.

70. Henninger, R.H. and M.J. Witte. 2002. "EnergyPlus Testing with HVAC BESTEST, Part 1 - Tests E100 to E200, EnergyPlus Version 1.0.3.019”. Report of GARD Analytics, Park Ridge, Illinois, December.

71. Hensen, J. 1995. “On System Simulation For Building Performance Evaluation”. Proceedings of Building Simulation '95, International Building Performance Simulation Association; Madison, Wisconsin, August 14-16.

72. Hensen, J. and A. Yahiaoui. 2002. "Towards Run-Time Coupling of Building Performance Simulation Programs". Center for Building \& Systems TNO-TU/e, Technische Universiteit Eindhoven, Netherlands. October.

73. Hiller, M., S. Holst, A. Knirsch, and M. Schuler. 2001. "TRNSYS 15 - A Simulation Tool for Innovative Concepts". Proceedings of Building Simulation '01, International Building Performance Simulation Association; Rio de Janeiro; August 13-15.

74. Hirsch, J. 1996. "DOE-2.1E-110 Enhancements". Application notes for the DOE 2.1E program version 110 , September. 
75. Hirsch, J.J., S.D. Gates, S.A. Criswell, M.S. Addison, F.C. Winkelmann, W.F. Buhl, and K.L. Ellington. 1998. "DOE-2.2 and PowerDOE: The New Generation in DOE-2 Building Energy Analysis". James. J. Hirsch and Associates and Lawrence Berkeley National Laboratory.

76. Huang, Y.J., J.W. Hanford, and M. Piraino. 1993. "The Impact of Variations in Building Parameters and Operating Conditions on Commercial Building Energy Use and Load Shapes". Proceedings of Building Simulation '93, International Building Performance Simulation Association; Adelaide, Australia; August 16-18.

77. Huang, J. and E. Franconi. 1999. "Commercial Heating and Cooling Loads Component Analysis". Lawrence Berkeley National Laboratory Report, LBL-37208.

78. Huang, J., F. Winkelmann, F. Buhl, C. Pedersen, D. Fisher, R. Liesen, R. Taylor, R. Strand, D. Crawley, and L. Lawrie. 1999. "Linking The COMIS Multi-Zone Airflow Model With The EnergyPlus Building Energy Simulation Program”. Proceedings of Building Simulation '99, International Building Performance Simulation Association; Kyoto, Japan, September 13-15.

79. Huang, Y.J. and J. Brodrick. 2000. “A Bottom-Up Engineering Estimate of the Aggregate Heating and Cooling Loads of the Entire US Building Stock". Proceedings of the ACEEE 2000 Summer Study on Energy Efficiency in Buildings, Efficiency and Sustainability, Asilomar Conference Center, Pacific Grove, CA, August 20-25. LBNL-46303.

80. Hunn, B.D. (Editor). 1996. "Fundamentals of Building Energy Dynamics". Cambridge, Massachusetts: The MIT Press.

81. IEA. 1999. "Models for Building Indoor Climate and Energy Simulation: A Report of Task 22, Building Energy Analysis Tools". International Energy Agency, Solar Heating and Cooling Programme. December.

82. IEA. 2001. "Empirical Validation of Iowa Energy Resource Station Building Energy Analysis Simulation Models: A Report of Task 22, Subtask A Building Energy Analysis Tools, Project A.1 Empirical Validation". International Energy Agency, Solar Heating and Cooling Programme. Edited by: J. Travesi, CIEMAT; G. Maxwell, Iowa State University; C. Klaassen, Iowa Energy Resource Station, and M. Holtz, Architectural Energy Corporation. June.

83. Jacobs P., T. Conlon, H. Henderson, M. Brandemuehl, and K. Rice. 2001. "State-of-the-Art Review of Building Simulation and Design Tools, Part 1: Whole-Building and Building Envelope Simulation Design Tools; Part 2: HVAC Component and System Simulation and Design Tools". TC 4.7 Seminar: A Review of State-of-the-Art in Building Simulation, ASHRAE Annual Meeting, Cincinnati, Ohio, June.

84. Jacobs, P. 2001. “Integrated Energy Systems Productivity \& Building Science Program: Element 4 - Integrated Design of Small Commercial HVAC Systems". Architectural Energy Corp. and New Buildings Institute, Inc. Annual Report, Volume 4 of 7 . August 15.

85. Jacobs, P. 2001. “Integrated Energy Systems Productivity and Building Science Program: Background Research Summary, Task 4.3.1". Architectural Energy Corporation Draft Report to New Buildings Institute, Inc. August 15.

86. Jacobs, P. 2001. "Integrated Energy Systems Productivity and Building Science Program: System Integration Research Issues, Task 4.3.2”. Architectural Energy Corporation Report to New Buildings Institute, Inc. December 7. 
87. Jansky, R. and M. Modera. 1995. "Sensitivity Analysis of Residential Duct System Efficiency in California". Lawrence Berkeley National Laboratory Draft Report, LBL34674. May 12.

88. Johnson, G.A. 1985. "From Constant Air to Variable: Alternative Airflow Control Techniques and Variable Speed Drive Help Convert Single-Zone Constant Volume to Single-Zone Variable Air Volume System”. ASHRAE Journal, Vol. 27. American Society of Heating, Refrigerating and Air-Conditioning Engineers, Inc. January.

89. Kim, T., J.D. Spitler, and R.D. Delahousssaye. 2002. "Optimum Duct Design for Variable Air Volume Systems, Part 1: Problem Domain Analysis of VAV Duct Systems". ASHRAE Transactions, V. 108, Pt. 1. American Society of Heating, Refrigerating and AirConditioning Engineers, Inc.

90. Kim, T., J.D. Spitler, and R.D. Delahousssaye. 2002. "Optimum Duct Design for Variable Air Volume Systems, Part 2: Optimization of VAV Duct Systems". ASHRAE Transactions, V. 108, Pt. 1. American Society of Heating, Refrigerating and Air-Conditioning Engineers, Inc.

91. Klein, S.A., W.A. Beckman, J.W. Mitchell, J.A. Duffie, N.A. Duffie, T.L. Freman, J.C. Mitchell, J.E. Braun, B.L. Evans, J.P. Kummer, R.E. Urban, A. Fiskel, and J.W. Thornton. 1996. “TRNSYS: A Transient System Simulation Program”. Solar Energy Laboratory, University of Wisconsin-Madison. Version 14.2.

92. Knebel, D.E. 1983. "Simplified Energy Analysis using the Modified Bin Method". American Society of Heating, Refrigerating and Air-Conditioning Engineers, Inc.

93. Kolderup, E. 2001. “Integrated Energy Systems Productivity and Building Science Program: Onsite Inspection Summary Report, Task 3.2.4". Eley \& Associates Report to New Buildings Institute, Inc. August 10.

94. Kolderup, E. 2001. "Integrated Energy Systems Productivity \& Building Science Program: Element 3 - Integrated Design of Large Commercial HVAC Systems". Eley Associates, Inc. and New Buildings Institute, Inc. Annual Report, Volume 3 of 7. August 16.

95. Kreider, J.F. and A. Rabl. 1994. "Heating and Cooling of Buildings: Design for Efficiency". New York: McGraw-Hill.

96. Kukla, M.D. 1997. "Situations to Consider When Variable Air Volume Is an Option". ASHRAE Transactions, V. 103, Pt. 2. American Society of Heating, Refrigerating and AirConditioning Engineers, Inc.

97. Kusuda, T. 1981. "A Comparison of Energy Calculation Procedures". ASHRAE Journal, Vol. 23. American Society of Heating, Refrigerating and Air-Conditioning Engineers, Inc. August.

98. Kusuda, T. 1999. "Early History and Future Prospects of Building System Simulation”. Proceedings of Building Simulation '99, International Building Performance Simulation Association; Kyoto, Japan, September 13-15.

99. LBNL. 1998. “Overview of DOE-2.2”. Simulation Research Group, Lawrence Berkeley National Laboratory, University of California, and James J. Hirsch and Associates. June.

100. LBNL. 2002. "SPARK 1.0.2 Reference Manual: Simulation Problem Analysis and Research Kernel". Lawrence Berkeley National Laboratory and Ayres Sowell Associates, Inc. 
101. Liesen, R.J. and C.O. Pedersen. 1997. "An Evaluation of Inside Surface Heat Balance Models for Cooling Load Calculations". ASHRAE Transactions, V. 103, Pt. 2. American Society of Heating, Refrigerating and Air-Conditioning Engineers, Inc.

102. Liesen, R.J. 1997. “Atmospheric Pollution Prediction in a Building Energy Simulation Program". Report of BLAST Support Office, University of Illinois at Urbana-Champaign.

103. Liesen, R.J. and C.O. Pedersen. 1999. "Modeling the Energy Effects of Combined Heat and Mass Transfer in Building Elements; Part 1 - Theory". ASHRAE Transactions, V. 105, Pt. 2. American Society of Heating, Refrigerating and Air-Conditioning Engineers, Inc.

104. Liesen, R.J. and C.O. Pedersen. 1999. "Modeling the Energy Effects of Combined Heat and Mass Transfer in Building Elements; Part 2 - Application to a Building Energy Analysis Program and Examples". ASHRAE Transactions, V. 105, Pt. 2. American Society of Heating, Refrigerating and Air-Conditioning Engineers, Inc.

105. Liesen, R.J., R.K. Strand, and C.O. Pedersen. 1998. "The Effect of Varying the Radiative/Convective Split for Internal Loads on Cooling Load Calculations: A Case Study for the Pentagon". Report of BLAST Support Office, University of Illinois at UrbanaChampaign.

106. Linder, R. and C.B. Dorgan. 1997. "VAV Systems Work Despite Some Design and Application Problems". ASHRAE Transactions, V. 103, Pt. 2. American Society of Heating, Refrigerating and Air-Conditioning Engineers, Inc.

107. Lorenzetti, D.M. and L.K. Norford. 1992. "Measured Energy Consumption of VariableAir-Volume Fans Under Inlet Vane and Variable-Speed-Drive Control”. ASHRAE Transactions, V. 98, Pt. 2. American Society of Heating, Refrigerating and AirConditioning Engineers, Inc.

108. Lorenzetti, D.M. 2001. “Assessing Multizone Airflow Software”. Lawrence Berkeley National Laboratory Report, LBNL-47653. December.

109. Lorsch, H.G. 1993. "Air-Conditioning Systems Design Manual”. American Society of Heating, Refrigerating and Air-Conditioning Engineers, Inc.

110. Lunneberg, T.A. 1999. "Improving Simulation Accuracy Through The Use Of Short-Term Electrical End-Use Monitoring". Proceedings of Building Simulation '99, International Building Performance Simulation Association; Kyoto, Japan, September 13-15.

111. MacDonald, A.I., J.A. Clarke, and P.A. Strachan. 1999. “Assessing Uncertainty In Building Simulation". Proceedings of Building Simulation '99, International Building Performance Simulation Association; Kyoto, Japan, September 13-15.

112. Mahone, D. 2001. "Duct Tightening - California Building Energy Efficiency Standards, Revisions for July 2003 Adoption”. Report of Pacific Gas \& Electric Co and Heschong Mahone Group to the California Energy Commission. November 5.

113. Maki, K.S., G.A. Chamberlin, Z. Li, and L.L. Christianson. 1997. "VAV System Performance - Field Characterization of Airflow, System Diagnosis Tools, and Operational Design Implications". ASHRAE Transactions, V. 103, Pt. 2. American Society of Heating, Refrigerating and Air-Conditioning Engineers, Inc. 
114. Maloney, D. 1985. "A Verification of the Use of Heat Conduction Transfer Functions as Used in the Program BLAST'. Student Project Report, BLAST Support Office, University of Illinois at Urbana-Champaign.

115. McClellan, T.M. and C.O. Pedersen. 1997. "Investigation of Outside Heat Balance Models for Use in a Heat Balance Cooling Load Calculation Procedure". ASHRAE Transactions, V. 103, Pt. 2. American Society of Heating, Refrigerating and Air-Conditioning Engineers, Inc.

116. McConahey, E., P. Haves, and T. Christ. 2002. "The Integration of Engineering and Architecture: A Perspective on Natural Ventilation for the New San Francisco Federal Building”. Proceedings of the ACEEE 2002 Summer Study on Energy Efficiency in Buildings, Efficiency and Sustainability, Asilomar Conference Center, Pacific Grove, CA, August 18-23. LBNL-51134.

117. McQuiston, F.C. and J.D. Parker. 1982. "Heating, Ventilating, and Air Conditioning: Analysis and Design". New York: John Wiley and Sons. $2^{\text {nd }}$ Edition.

118. Metcalf, R. R., R. D. Taylor, C. O. Pedersen, R. J. Liesen, and D. E. Fisher. 1995. "Incorporating A Modular System Simulation Program Into A Large Energy Analysis Program: The Linking Of IBLAST And HVACSIM+". Proceedings of Building Simulation '95, International Building Performance Simulation Association; Madison, Wisconsin, August 14-16.

119. Metcalf, R.R. 1994. "Development of a Generalized Fan System Simulation for the Building Loads Analysis and System Thermodynamics Program (BLAST)". Master's Thesis, University of Illinois at Urbana-Champaign.

120. Modera, M.P. and R. Jansky. 1992. "Residential Air-Distribution Systems: Interactions with the Building Envelope". ASHRAE-DOE-BTEC Conference: Thermal Performance of the Exterior Envelopes of Buildings V; Clearwater, FL, December 7-10. LBL-31311.

121. Modera, M.P. and B. Treidler. 1995. "Improved Modelling of HVAC System/Envelope Interactions in Residential Buildings". Proceedings of the ASME International Solar Energy Conference; Maui, Hawaii. March 19-24. LBL-36048.

122. Modera, M. T. Xu, H. Feustel, N. Matson, C. Huizenga, F. Bauman, E. Arens, and T. Borgers. 1999. "Efficient Thermal Energy Distribution in Commercial Buildings". Lawrence Berkeley National Laboratory Report to California Institute for Energy Efficiency, LBNL-41365. August.

123. Modera, M.P. 2002. "Proposed Revisions to 2005 Title 24 Energy Efficiency Standards: Addition of HVAC Transport Efficiency Concept". Memorandum to the California Energy Commission. October 31.

124. Mombourquette, S. 2002. "Building Simulation Software: Improving Development Procedures". Proceedings of eSim 2002, International Building Performance Simulation Association -Canada; Montréal, Québec, Canada, September 11-13.

125. Mutammara, A.W. and D.C. Hittle. 1990. "Energy Effects of Various Control Strategies for Variable-Air-Volume Systems". ASHRAE Transactions, V. 96, Pt. 1. American Society of Heating, Refrigerating and Air-Conditioning Engineers, Inc. 
126. Neymark, J., R. Judkoff, G. Knabe, H. T. Le, M. Durig, A. Glass, and G. Zweifel. 2001. "HVAC BESTEST: A Procedure for Testing the Ability of Whole-Building Energy Simulation Programs to Model Space Conditioning Equipment". Proceedings of Building Simulation '01, International Building Performance Simulation Association; Rio de Janeiro; August 13-15.

127. Neymark, J. and R. Judkoff. 2002. “International Energy Agency Building Energy Simulation Test and Diagnostic Method for Heating, Ventilating, and Air-Conditioning Equipment Models (HVAC BESTEST), Volume 1: Cases E100-E200”. National Renewable Energy Laboratory Report, NREL/TP-550-30152. January.

128. Nishi, Y., X. Chen, and N. Nakahara. 1999. "Development of a Visual Tool for Dynamic Simulation Program HVACSIM+". Proceedings of Building Simulation '99, International Building Performance Simulation Association; Kyoto, Japan, September 13-15.

129. Nishitani, Y., M. Zheng, H. Niwa, and N. Nakahara. 1999. "A Comparative Study of HVAC Dynamic Behavior Between Actual Measurements and Simulated Results by HVACSIM+ $(J)$ '. Proceedings of Building Simulation '99, International Building Performance Simulation Association; Kyoto, Japan, September 13-15.

130. Norford, L.K., A. Rabl, and R.H. Socolow. 1986. "Control of Supply Air Temperature and Outdoor Airflow and Its Effect on Energy Use in a Variable Air Volume System". ASHRAE Transactions, V. 92, Pt. 2B. American Society of Heating, Refrigerating and Air-Conditioning Engineers, Inc.

131. NRCan. 1997. "Defining the Methodology for the Next-Generation HOT2000 Simulator: Loads Workshop Summary”. Natural Resources Canada, Ottawa. July 18.

132. NRCan. 1997. "Defining the Methodology for the Next-Generation HOT2000 Simulator: HVAC Workshop Summary”. Natural Resources Canada, Ottawa. December 11.

133. NTIS. 2001. “DOE-2.1E Basics Manual”. National Technical Information Service, Springfield, VA. NTIS Order Number DE-940-13165. August.

134. Parker, D., P. Fairey, and L. Gu. 1993, "Simulation of the Effects of Duct Leakage and Heat Transfer on Residential Space-Cooling Energy Use". Energy and Buildings, Vol. 20.

135. Parker, D.S., P.A. Broman, J.B. Grant, L. Gu, M.T. Anello, R.K. Vieira, and H.I. Henderson. 1999. "ENERGYGAUGE USA: A Residential Building Energy Simulation Design Tool'. Proceedings of Building Simulation '99, International Building Performance Simulation Association; Kyoto, Japan, September 13-15.

136. Pedersen, C.O., D.E. Fisher, and R.J. Liesen. 1997. "Development of a Heat Balance Procedure for Calculating Cooling Loads". ASHRAE Transactions, V. 103, Pt. 2. American Society of Heating, Refrigerating and Air-Conditioning Engineers, Inc.

137. Pedersen, C. O., D. E. Fisher, R. J. Liesen, R. K. Strand, and R. D. Taylor. 1997. "Energybase: The Merger Of Blast And Doe-2". Proceedings of Building Simulation '97, International Building Performance Simulation Association; Prague, Czech Republic; September 8-10.

138. Pedersen, C.O., D.E. Fisher, J.D. Spitler, and R.J. Liesen. 1998. "Cooling and Heating Load Calculation Principles". American Society of Heating, Refrigerating and AirConditioning Engineers, Inc. 
139. Pelletret, R.Y. and W.P. Keilholz. 1997. "COMIS 3.0 A New Simulation Environment For Multizone Air Flow and Pollutant Transport Modelling”. Proceedings of Building Simulation '97, International Building Performance Simulation Association; Prague, Czech Republic; September 8-10.

140. PG\&E. 2002. "Code Change Proposal: Time Dependent Valuation (TDV) - Economics Methodology". Pacific Gas and Electric Company Report to the California Energy Commission, 2005 Title 24 Building Energy Efficiency Standards Update. March 14.

141. PG\&E. 2003a. "Duct Sealing Requirements upon HVAC or Duct-System Replacement: Light Commercial Buildings". Pacific Gas and Electric Company Draft Report to the California Energy Commission, Codes and Standards Enhancement Initiative, 2005 Title 24 Building Energy Efficiency Standards Update. January 21.

142. PG\&E. 2003b. “Code Change Proposal for Nonresidential Duct Sealing and Insulation, Revised Report". Pacific Gas and Electric Company Report to the California Energy Commission, Codes and Standards Enhancement Initiative, 2005 Title 24 Building Energy Efficiency Standards Update. January 23.

143. Pietsch, J. 1991. “Water- Loop Heat Pump Systems: Assessment Study Update”. Electric Power Research Institute, EPRI- CU- 7535, Project 2480- 2, Final Report.

144. Rabehl, R.J., W.A. Beckman, and J.W. Mitchell. 1997. "Parameter Estimation and The Use of Catalog Data With TRNSYS'. Proceedings of Building Simulation '97, International Building Performance Simulation Association; Prague, Czech Republic; September 8-10.

145. Rock, B.A. and D.J. Wolfe. 1997. “A Sensitivity Study of Floor and Ceiling Plenum Energy Model Parameters". ASHRAE Transactions, V. 103, Pt. 1. American Society of Heating, Refrigerating and Air-Conditioning Engineers, Inc.

146. Salsbury, T. and R. Diamond. 1998. "Performance Validation and Energy Analysis of HVAC Systems using Simulation". Lawrence Berkeley National Laboratory Report, LBNL43638.

147. Sathyanarayanan, R., D. Derome, and H. Rivard. 2002. "The Need for an Integrated Computer-Based Tool to Support Building Envelope Design”. Proceedings of eSim 2002, International Building Performance Simulation Association -Canada; Montréal, Québec, Canada, September 11-13.

148. Schmidt, D. 2002. "Modelling of Hybrid Building Components with R-C Networks in Macro Elements". Proceedings of eSim 2002, International Building Performance Simulation Association -Canada; Montréal, Québec, Canada, September 11-13.

149. Sezgen, O., E.M. Franconi, J.G. Koomey, S.E. Greenberg, A. Afzal, and L. Shown. 1995. "Technology Data Characterizing Space Conditioning in Commercial Buildings: Application to End-Use Forecasting with COMMEND 4.0". Lawrence Berkeley National Laboratory Report, LBL- 37065. December.

150. Siegel, J.A. 1999. "The REGCAP Simulation: Predicting Performance in New California Homes". Master's Thesis, Department of Mechanical Engineering, University of California, Berkeley. May 19.

151. Sohn, M.D., P. Reynolds, N. Singh, and A.J. Gadgil, Ashok. 2000. "Rapidly Locating and Characterizing Pollutant Releases in Buildings: An Application of Bayesian Data Analysis". Journal of the Air and Waste Management Association, March. LBNL-47588. 
152. Sowell, E. F. and M. A. Moshier. 1995. "HVAC Component Model Libraries For Equation-Based Solvers". Proceedings of Building Simulation '95, International Building Performance Simulation Association; Madison, Wisconsin, August 14-16.

153. Sowell, E.F., and P. Haves. 1999. "Numerical Performance Of The Spark Graph Theoretic Simulation Program". Proceedings of Building Simulation '99, International Building Performance Simulation Association; Kyoto, Japan, September 13-15.

154. Sowell, E.F. and P. Haves. 2000. "Efficient Solution Strategies for Building Energy Simulation". Lawrence Berkeley National Laboratory Report. LBNL-45936. March.

155. Spitler, J.D., C.O. Pedersen, D.C. Hittle, and D.L. Johnson. 1986. "Fan Electricity Consumption for Variable Air Volume". ASHRAE Transactions, V. 92, Pt. 2B. American Society of Heating, Refrigerating and Air-Conditioning Engineers, Inc.

156. Spitler, J.D., D.E. Fisher, and C.O. Pedersen. 1997. "The Radiant Time Series Cooling Load Calculation Procedure". ASHRAE Transactions, V. 103, Pt. 2. American Society of Heating, Refrigerating and Air-Conditioning Engineers, Inc.

157. Spitler, J.D., D.E. Fisher, and D.C. Zietlow. 1997. "A Primer on the Use of Influence Coefficients in Building Simulation". Report of BLAST Support Office, University of Illinois at Urbana-Champaign.

158. Stoecker, W.F. 1980. "Design of Thermal Systems". New York: McGraw-Hill. $2^{\text {nd }}$ Edition.

159. Strand, R.K. 1995. "Heat Source Transfer Functions and Their Application to Low Temperature Radiant Heating Systems". Ph.D. Dissertation, University of Illinois at Urbana-Champaign.

160. Strand, R.K. and C.O. Pedersen. 1997. "Analytical Verification of Heat Source Transfer Functions". Report of BLAST Support Office, University of Illinois at UrbanaChampaign.

161. Strand, R., C. Pedersen, D. Fisher, R. Liesen, R. Taylor, J. Huang, F. Winkelmann, F. Buhl, S. Crawley, and L. Lawrie. 1999. "Enhancing And Extending The Capabilities Of The Building Heat Balance Simulation Techniques For Use In EnergyPlus". Proceedings of Building Simulation '99, International Building Performance Simulation Association; Kyoto, Japan, September 13-15.

162. Strand, R.K., C.O. Pedersen, and D.B. Crawley. 2001. "Modularization and Simulation Techniques for Heat Balance Based Energy and Load Calculation Programs: The Experience of the ASHRAE Loads Toolkit and EnergyPlus". Proceedings of Building Simulation '01, International Building Performance Simulation Association; Rio de Janeiro; August 13-15.

163. Strand, R.K., D.E. Fisher, R.J. Liesen, and C.O. Pedersen. 2002. "Modular HVAC Simulation and the Future Integration of Alternative Cooling Systems in a New Building Energy Simulation Program". ASHRAE Transactions, V. 108, Pt. 2. American Society of Heating, Refrigerating and Air-Conditioning Engineers, Inc.

164. Strand, R.K., W.F. Buhl, and L.K. Lawrie. 2003. "EnergyPlus Programming Standard". Board of Trustees of the University of Illinois and Regents of the University of California through the Ernest Orlando Lawrence Berkeley National Laboratory, U.S. Department of Energy. April 13. 
165. Swim, W.B. and E.I. Griggs. 1995. "Duct Leakage Measurement and Analysis". ASHRAE Transactions, V. 101, Pt. 1. American Society of Heating, Refrigerating and AirConditioning Engineers, Inc.

166. Taylor, R.D., C.O. Pedersen, and L. Lawrie. 1997. "Simultaneous Simulation of Buildings and Mechanical Systems in Heat Balance Based Energy Analysis Programs". Report of BLAST Support Office, University of Illinois at Urbana-Champaign.

167. Taylor, R.D., C.O. Pedersen, D.E. Fisher, R.J. Liesen, and L. Lawrie. 1997. “Impact of Simultaneous Simulation of Buildings and Mechanical Systems in Heat Balance Based Energy Analysis Programs on System Response and Control'. Report of BLAST Support Office, University of Illinois at Urbana-Champaign.

168. Treidler, E.B. and M.P. Modera. 1995. "Thermal Performance of Residential Duct Systems in Basements”. Lawrence Berkeley National Laboratory Report, LBL-33962. October.

169. Treidler, B., M.P. Modera, R.G. Lucas, and J.D. Miller. 1995. "Impacts of Residential Duct Insulation on HVAC Energy Use and Life-Cycle Costs to Consumers". Lawrence Berkeley National Laboratory Draft Report, LBL-37441. October 23.

170. Tsal, R.J., H.F. Behls, and L.P. Varvak. 1998. "T-Method Duct Design: Part IV - Duct Leakage Theory". ASHRAE Transactions, V. 104, Pt. 2. American Society of Heating, Refrigerating and Air-Conditioning Engineers, Inc.

171. Tsal, R.J., H.F. Behls, and L.P. Varvak. 1998. "T-Method Duct Design: Part V: Duct Leakage Calculation Technique and Economics". ASHRAE Transactions, V. 104, Pt. 2. American Society of Heating, Refrigerating and Air-Conditioning Engineers, Inc.

172. Tsal, R.J. 1998. “Numerical Modeling of Multi-Fan Air Distribution Systems for Research Laboratories". Draft Report of NETSAL \& Associates, Fountain Valley, CA. September 25.

173. Tsal, R.J. 1999. "Modeling of Laboratory Air Distribution Systems". Report of NETSAL \& Associates, Fountain Valley, CA. September 4.

174. Walker, I.S. 1993. "Prediction of Ventilation, Heat Transfer and Moisture Transport in Attics". Ph.D. Dissertation, Department of Mechanical Engineering, University of Alberta.

175. Walker, I.S., J. Siegel, K. Brown, and M. Sherman. 1999. "Saving Tons at the Register". Lawrence Berkeley National Laboratory Report, LBNL-41957.

176. Walker, I., J. Siegel, and G. Degenetais. 2001. "Simulation of Residential HVAC System Performance”. Lawrence Berkeley National Laboratory Report, LBNL-47622. May.

177. Walker, I., G. Degenetais, and J. Siegel. 2002. "Simulations of Sizing and Comfort Improvements for Residential Forced-Air Heating and Cooling Systems". Lawrence Berkeley National Laboratory Report, LBNL 47309. May.

178. Wetter, M. 2001. “GenOpt® -- A Generic Optimization Program”. Proceedings of Building Simulation '01, International Building Performance Simulation Association; Rio de Janeiro; August 13-15. LBNL-48371.

179. Westphalen, D. and S. Koszalinski. 1999. "Energy Consumption Characteristics of Commercial Building HVAC Systems - Volume II: Thermal Distribution, Auxiliary Equipment, and Ventilation". Arthur D. Little, Inc. Report to U.S. Department of Energy, No. 33745-00. October. 
180. Winkelmann, F., B. Birdsall, F. Buhl, K. Ellington, E. Erdem, J. Hirsch, and S. Gates. 1993. “DOE-2 Supplement, Version 2.IE”. Lawrence Berkeley National Laboratory, LBL34947, November. Also Springfield, Virginia: National Technical Information Service.

181. Witte, M.J., R.H. Henninger, J. Glazer, and D.B. Crawley. 2001. "Testing and Validation of a New Building Energy Simulation Program". Proceedings of Building Simulation '01, International Building Performance Simulation Association; Rio de Janeiro; August 13-15.

182. Wray, C.P. and Yuill, G.K. 1990. "An Annotated Guide to Models and Algorithms for Energy Calculations Relating to HVAC Equipment". American Society of Heating, Refrigerating and Air-Conditioning Engineers, Inc.

183. Xu, T., O. Bechu, R. Carrié, D. Dickerhoff, W. Fisk, E. Franconi, Ø. Kristiansen, R. Levinson, J. McWilliams, D. Wang, M. Modera, T. Webster, E. Ring, Q. Zhang, C. Huizenga, F. Bauman, and E. Arens. 1999a. "Commercial Thermal Distribution Systems". Lawrence Berkeley National Laboratory Report to the California Institute for Energy Efficiency and the California Energy Commission. LBNL-44320. December.

184. Xu, T., R.F. Carrie, D.J. Dickerhoff, W.J. Fisk, J. McWilliams, D. Wang, and M.P. Modera. 1999b. "Performance of Thermal Distribution Systems in Large Commercial Buildings". Lawrence Berkeley National Laboratory, LBNL-44331.

185. Yao, R., N. Baker, and M. McEvoy. 2002. "A Simplified Thermal Resistance Network Model for Building Thermal Simulation”. Proceedings of eSim 2002, International Building Performance Simulation Association -Canada; Montréal, Québec, Canada, September 11-13.

186. Yoon, J.-H., E.-J. Lee. 1999. “Calibration Procedure Of Energy Performance Simulation Model For A Commercial Building". Proceedings of Building Simulation '99, International Building Performance Simulation Association; Kyoto, Japan, September 13-15.

187. Zheng, M., Y. Nishitani, S. Hayashi, and N. Nakahara. 1999. "Comparison of Reproducibility of a Real CAV System By Dynamic Simulation HVACSIM+ and TRNSYS". Proceedings of Building Simulation '99, International Building Performance Simulation Association; Kyoto, Japan, September 13-15.

188. Zmeureanu, R. 1997. "Defining the Methodology for the Next-Generation HOT2000 Simulator: Task 1 - Literature Review". Concordia University Centre for Building Studies Report to Natural Resources Canada. July 21.

189. Zmeureanu, R. 1998. "Defining the Methodology for the Next-Generation HOT2000 Simulator: Task 3 - Starting Points". Concordia University Centre for Building Studies Report to Natural Resources Canada. February 15. 


\title{
APPENDIX II: TRNSYS DUCT PERFORMANCE SUBROUTINES
}

\author{
Subroutine TYPE 70: Fan (Supply or Return) \\ SUBROUTINE AND FUNCTION CALL MAPPING \\ Calculate the fan power and leaving air temperature and humidity for fan using simple \\ part load characteristics. \\ SUBROUTINE TYPE70 (TIME, XIN, OUT, T, DTDT, PAR, INFO, ICNTRL, *) \\ CALL TYPECK -- subroutine in TRNWIN \Kernal \typeck.for \\ CALL RCHECK -- subroutine in TRNWIN\Kernal\rcheck.for \\ hEnt = ENTHALPY5 (CPAIR, HFG, CPVAP, TEnt, WEnt) -- F2 in type 70 \\ rho = RHODRY (PATM, RAIR, TABSADD, TEnt, WEnt) -- F3 in type 70 \\ TLvg = DRYBULB5 (CPAIR, CPVAP, HFG, hLvg,WLVg) -- F1 in type 70 \\ F1 REAL FUNCTION DRYBULB5 (CPAIR, CPVAP, HFG, H, W) \\ Calculate the dry bulb temperature of moist air from enthalpy \\ and humidity. \\ F2 REAL FUNCTION ENTHALPY5 (CPAIR, HFG, CPVAP, TDB, W) \\ Calculate the enthalpy of moist air. \\ F3 REAL FUNCTION RHODRY (PATM, RAIR, TABSADD, TDB, W) \\ Calculate dry air density.
}

$\begin{array}{llr}\text { PATM } & = & 101325.0 \\ \text { CPAIR } & = & 1006.0 \\ \text { CPVAP } & = & 1805.0 \\ \text { HFG } & = & 2501000.0 \\ \text { RAIR } & = & 287.055 \\ \text { TABSADD } & = & 273.15\end{array}$

Atmospheric pressure ( $\mathrm{Pa})$

Specific heat of dry air (J/kg C)

Specific heat of saturated water vapor (J/kg C)

Latent heat of vaporization of water ( $/ \mathrm{kg})$

Gas constant for air ( J/kg C)

Additive factor to convert user $\mathrm{P}$ to Kelvin:

tKel $=\operatorname{Prop}($ TKelMult $) * T+\operatorname{Prop}($ TKelAdd $)$

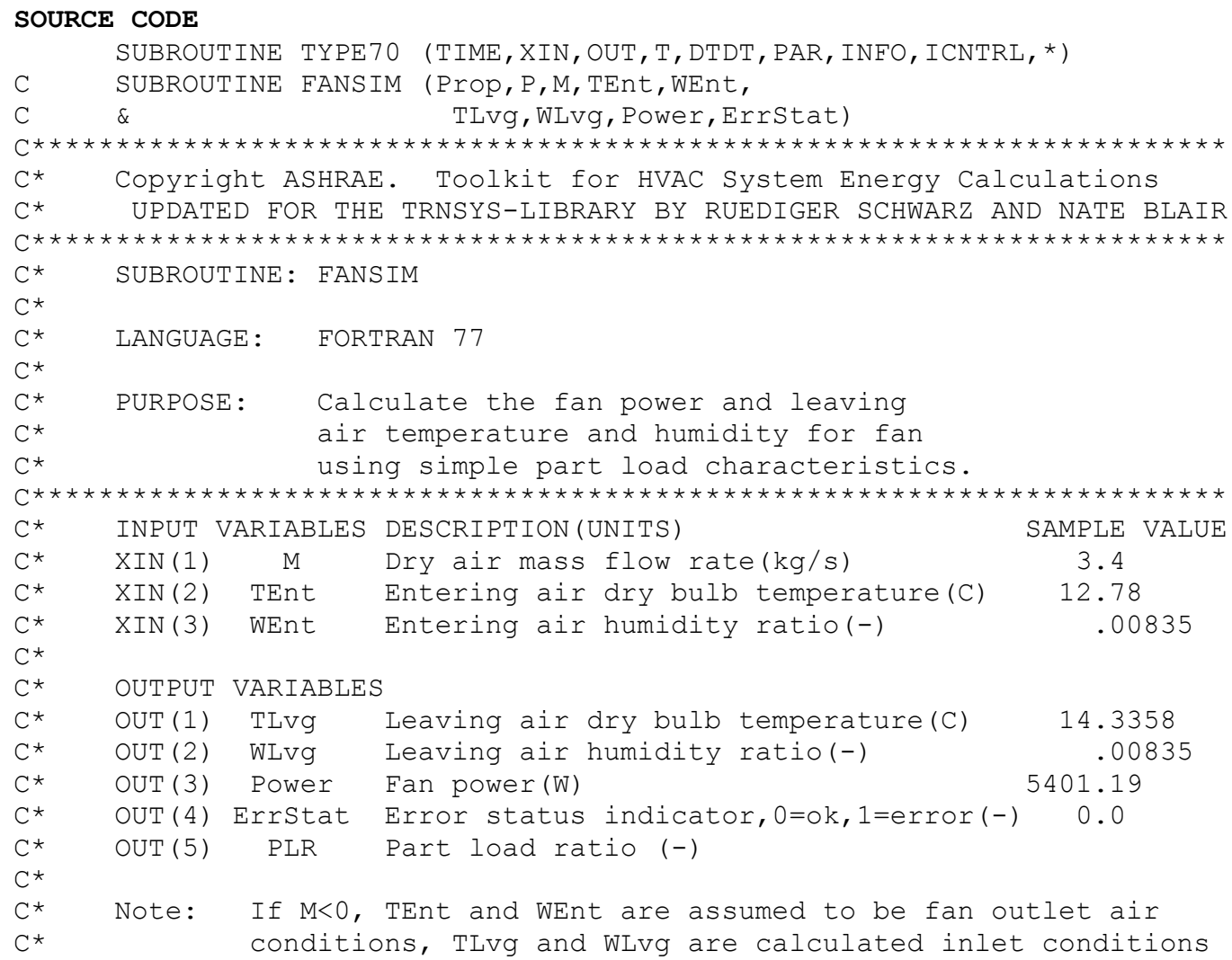




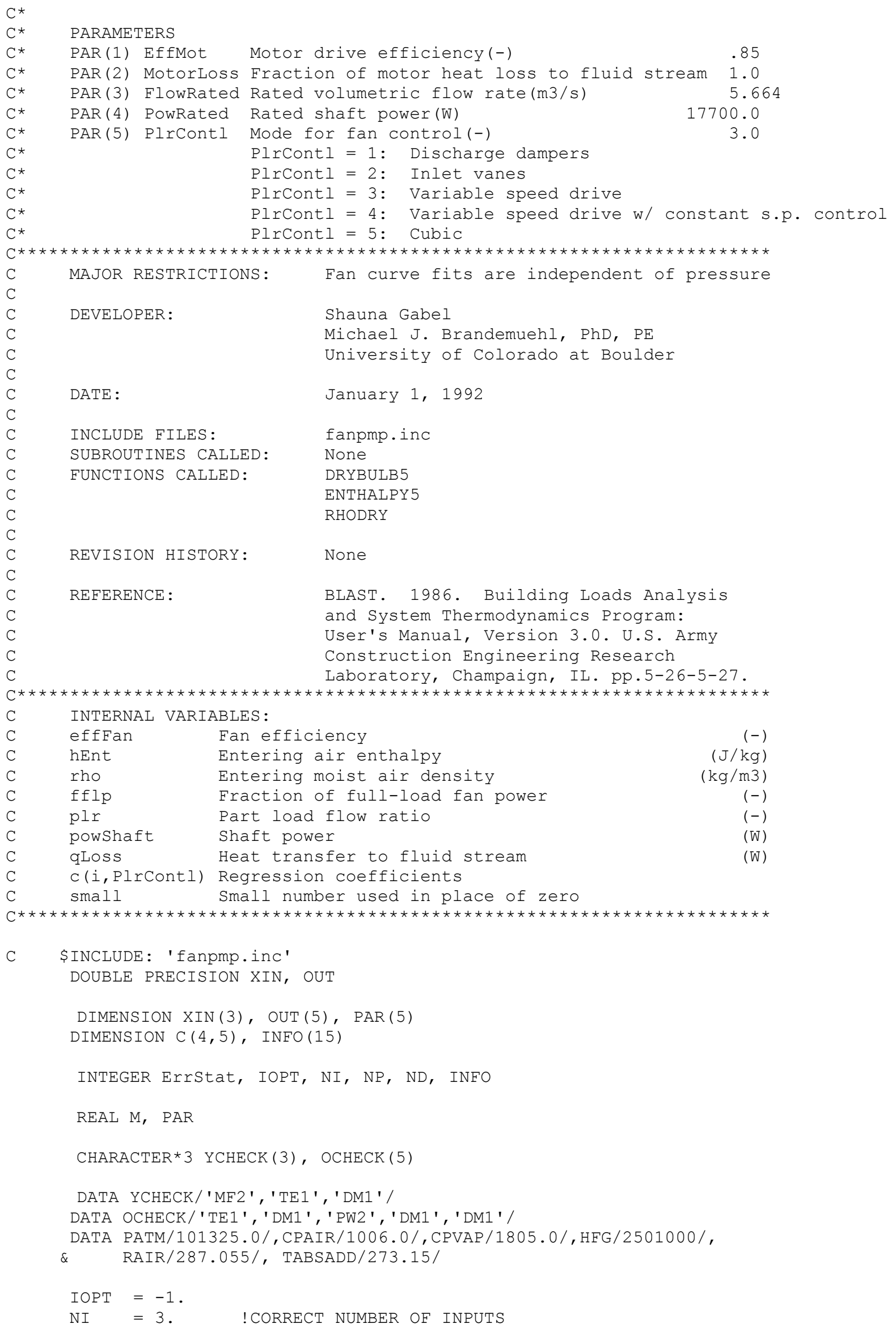




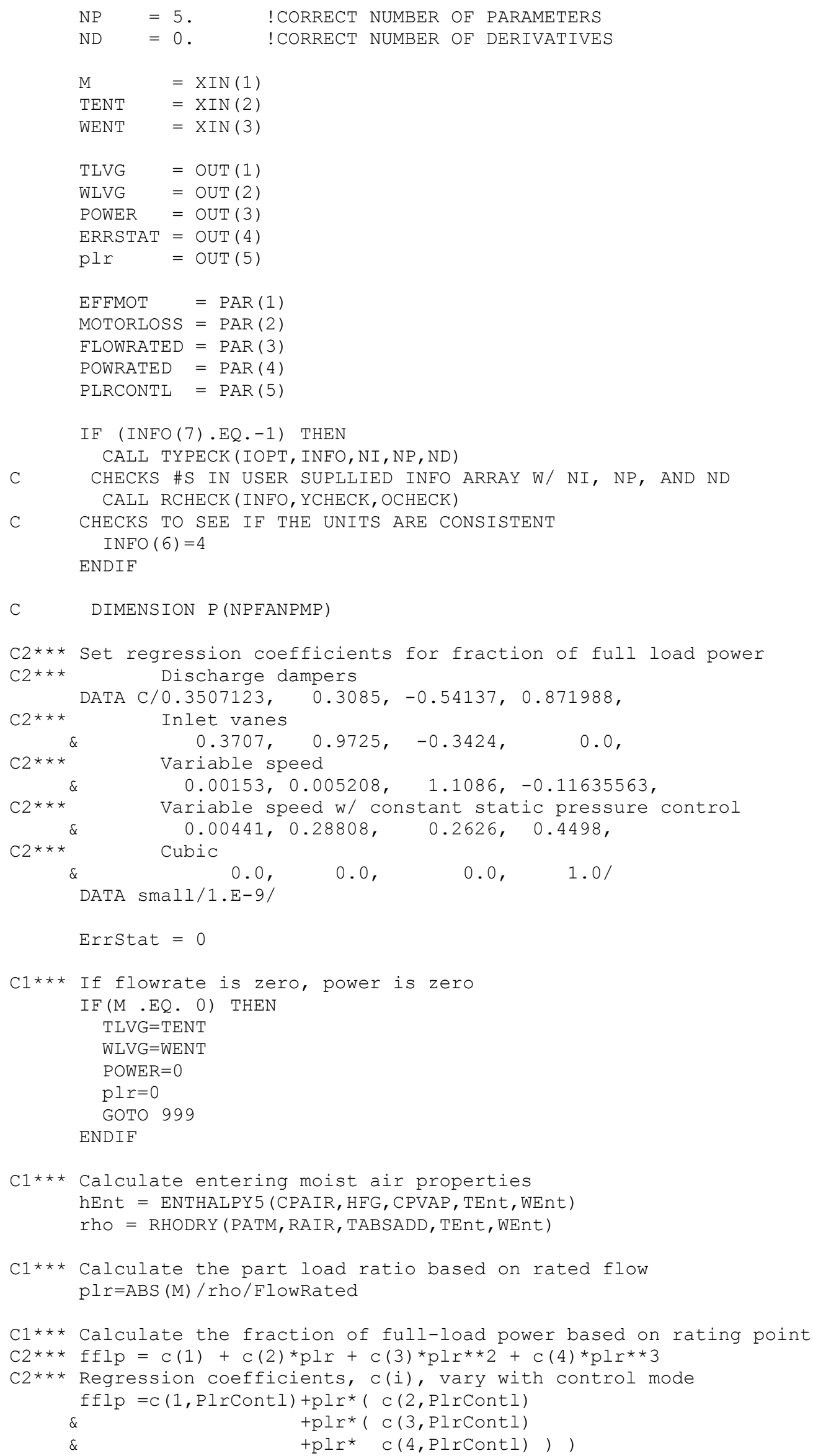




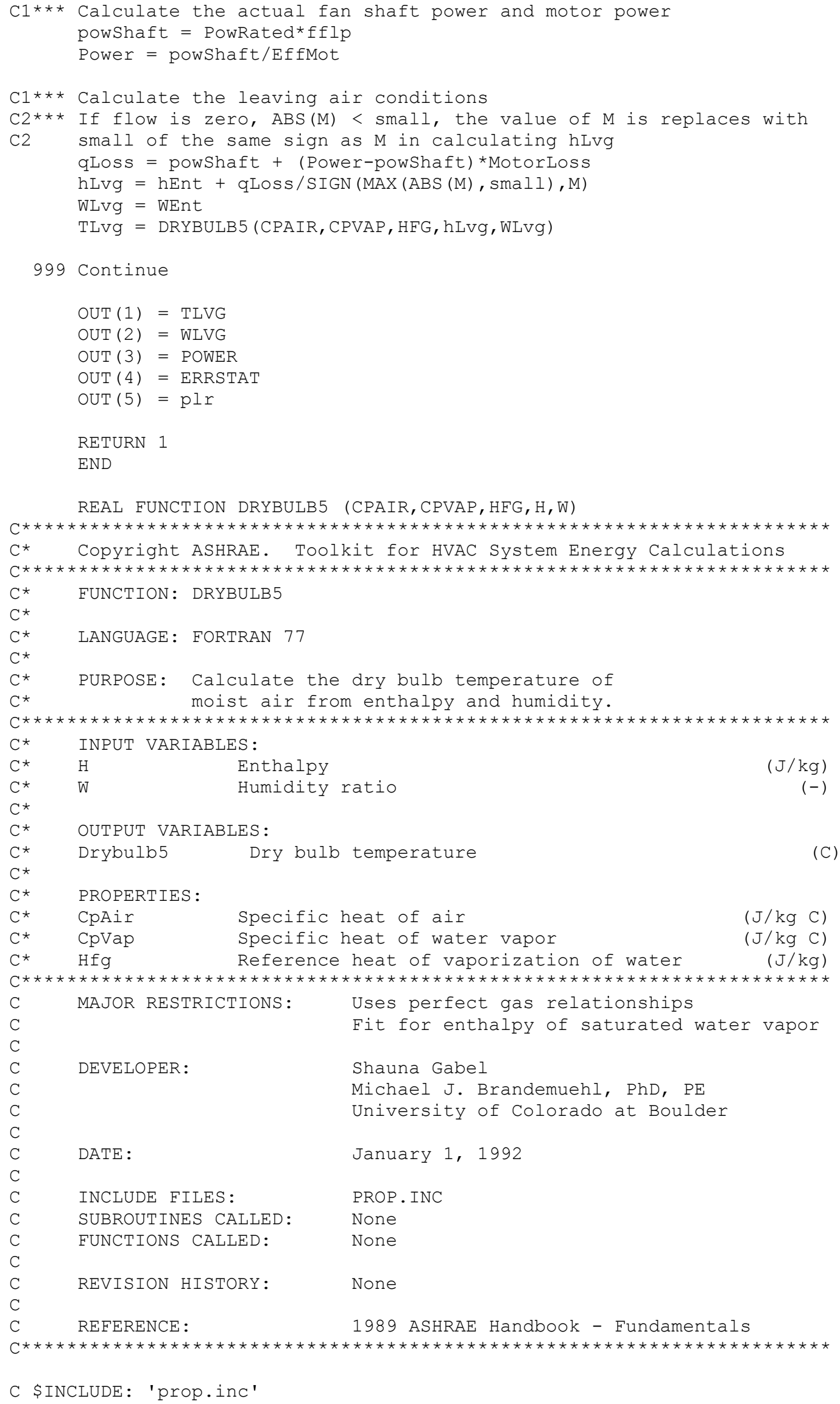




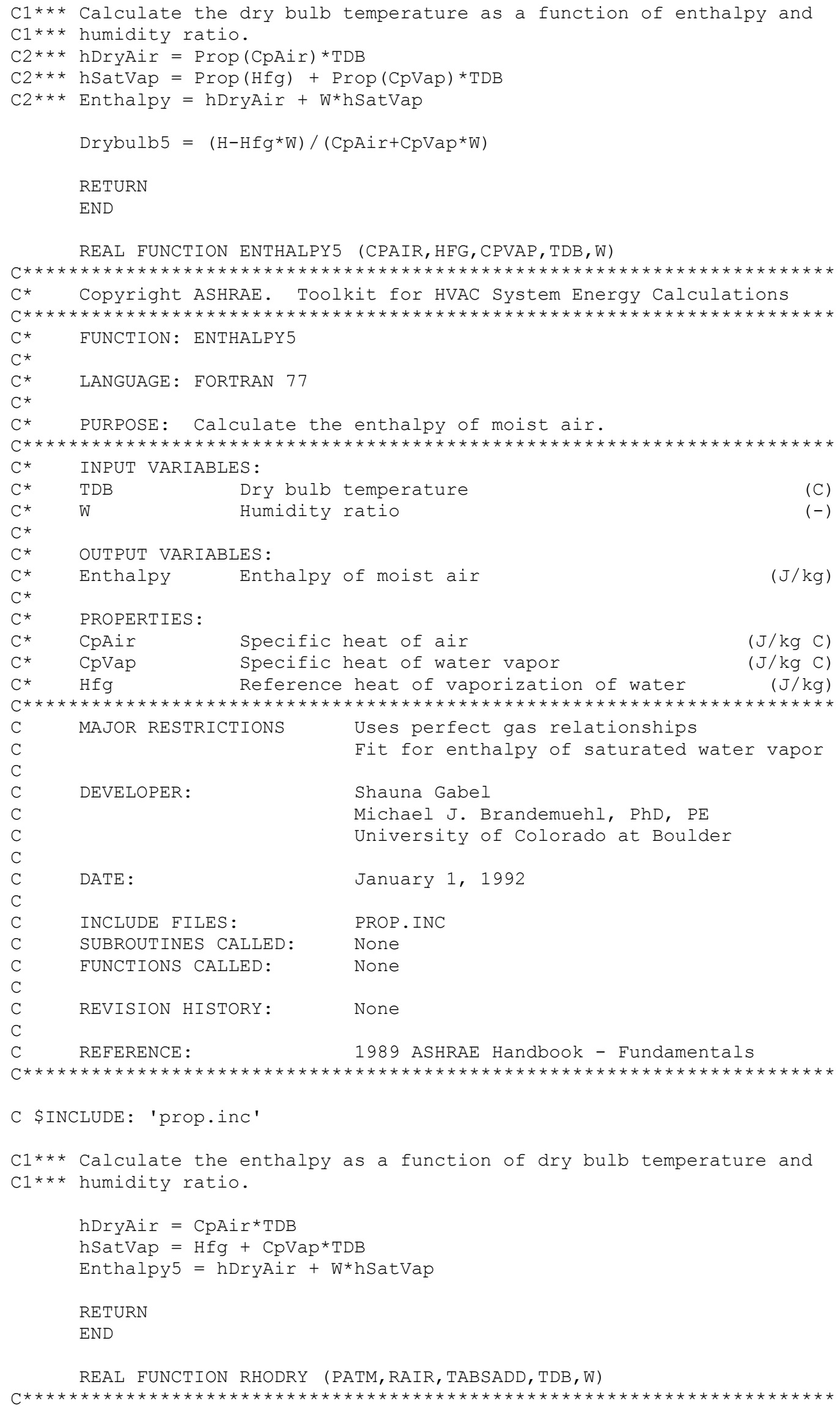




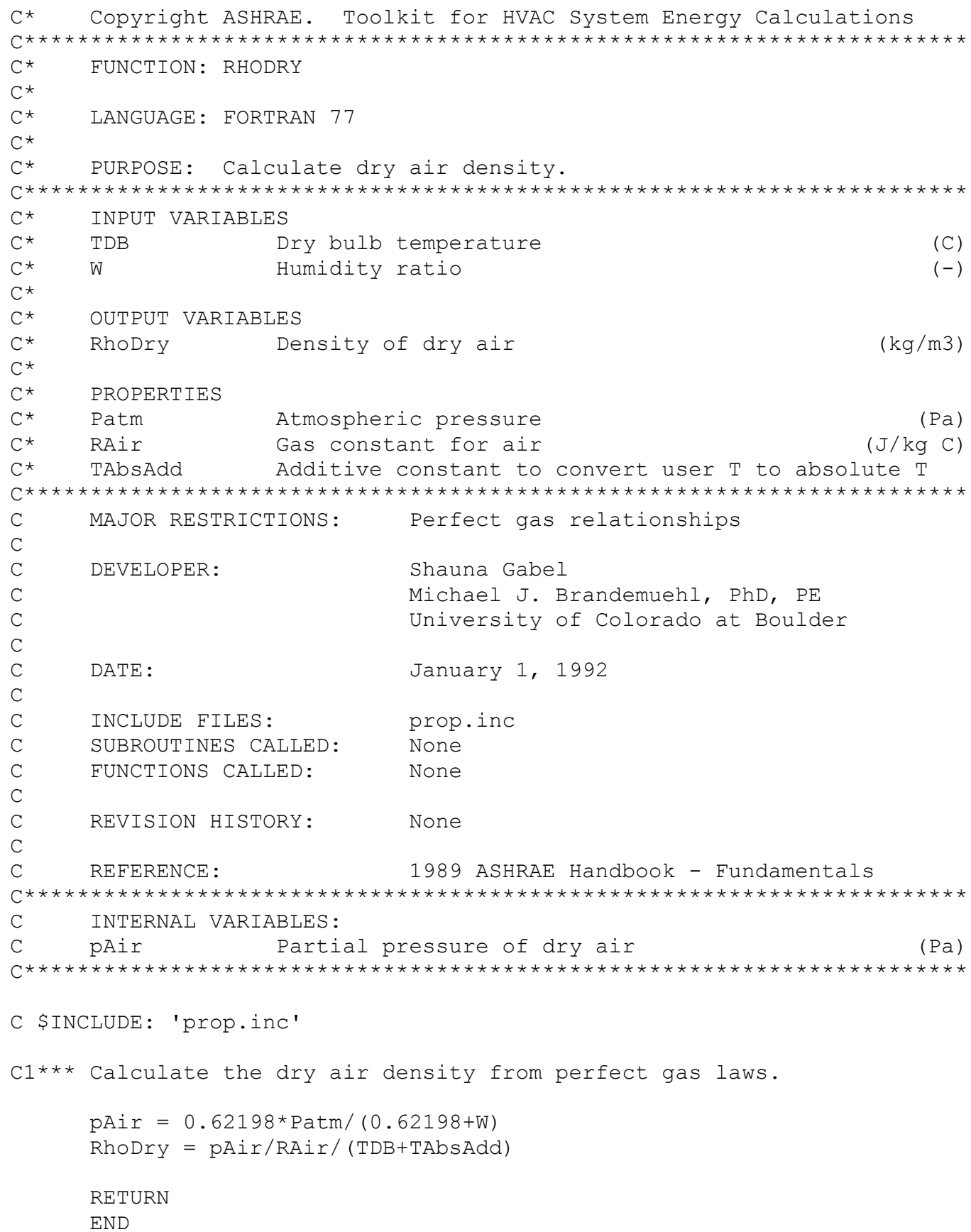




\section{Subroutine TYPE 75: Cooling Coil}

\section{SUBROUTINE AND FUNCTION CALL MAPPING}

Model the performance of a counterflow crossflow cooling coil. The model accounts for condensation on the outside surface. Three conditions are possible: all wet, partially wet or all dry. Input includes outlet air setpoint temperature. Water flow rate is changed until desired value is achieved. Output includes outlet air temperature and humidity, outlet water temperature, sensible and total cooling capacities and the wet fraction of air-side surface area. SUBROUTINE TYPE75 (TIME, XIN, OUT, T, DTDT, PAR, INFO, ICNTRL, *)

CALL TYPECK (IOPT, INFO,NI,NP,ND) -- subroutine in TRNWIN $\backslash$ Kernal $\backslash$ typeck. for CALL RCHECK (INFO, YCHECK, OCHECK) -- subroutine in TRNWIN $\backslash$ Kernal \rcheck.for

hAirRat = ENTHALPY3 (Prop,TAirRat,WAirRat) -- function F2 in type 75 hLiqRatSat = ENTHSAT (Prop, TLiqRat) -- function F4 in type 75 wAirLvgRat $=$ HUMTH (Prop, TAirRat, hDummy) -- function $F 6$ in type 75 tAirLvgRat = DRYBULB3 (Prop, hAirLvgRat, wAirLvgRat) -- function F13 in type

tDewRat $=$ DEWPOINT (Prop, WAirRat) -- function F3 in type 75 cpSat = (ENTHSAT (Prop, tDewRat)-hLiqRatSat) -- function F4 in type 75 / (tDewRat-TLiqRat) $\mathrm{uaH}=\operatorname{UAHX}(\mathrm{capAirH}$, hAirRat, capLiqH, hLiqRatSat, QTotRat, -- function F1 configHX, Errstat) in type 75 CALL BYPASS (Prop, TairRat, WAirRat, tAirLvgRat, wAirLvgRat, -- subroutine S5 in type 75

tAdpRat, wAdpRat, bfRat, ErrStat)

hAdpRat = ENTHALPY3 (Prop, tAdpRat, wAdpRat) -- function F2 in type 75 tDewPt $=$ DEWPOINT (Prop, WAirEnt) -- function F3 in type 75 CALL DRYCOIL (Prop, MLiq, TLiqEnt, MAir, TAirEnt, WAirEnt, -- subroutine S1 in type 75

UATot, configHX,

TLiqLvg, TAirLvg, WAirLvg, QTot, ErrStat)

CALL WETCOIL (Prop, MLiq, TLiqEnt, MAir, TAirEnt, WAirEnt, -- subroutine S2 in type 75

UAInt, UAExt, configHX, TLiqLvg, TAirLvg, WAirLvg, QTot, QSen, FWet, tSurfEnt, ErrStat) mLiq = XITERATE (mLiq, error,X1,F1,X2,F2, iter, icvg) -- function F14 in type 75

hAirEnt = MAIR * ENTHALPY3 (Prop, TAirEnt, WAirEnt) -- function F2 in type 75

S1 SUBROUTINE DRYCOIL (Prop,MLiq, TLiqEnt, MAir, TAirEnt, WAirEnt, UA, ConfigHX, TLiqLvg, TAirLvg, WAirLvg, Q, Errstat)

Calculate the performance of a sensible air-liquid heat exchanger. Calculated results include outlet air temperature and humidity, outlet water temperature, and heat transfer rate.

CALL HEATEX (capLiq, TLiqEnt, capAir, TAirEnt, UA, ConfigHX, -- subroutine s3

TLiqLvg, TAirLvg) in type 75

S2 SUBROUTINE WETCOIL (Prop, MLiq, TLiqEnt, MAir, TAirEnt, WAirEnt, UAIntTot, UAExtTot, ConfigHX, TLiqLvg, TAirLvg, WAirLvg, QTot, QSen, FWet, TSurfEnt, Errstat)

Calculate the performance of a cooling coil when the external fin surface is complete wet. Results include outlet air temperature and humidity, outlet water temperature, sensible and total cooling capacities, and the wet fraction of the air-side surface area.

hAirEnt = ENTHALPY3 (Prop,TAirEnt,WAirEnt) -- function F2 in type 75 hLiqEntSat = ENTHSAT (Prop, TLiqEnt) -- function F4 in type 75 tDewEnt $=$ DEWPOINT (Prop, WAirEnt) -- function F3 in type 75 
S3 SUBROUTINE HEATEX (Cap1, In1, Cap2, In2, UA, ConfighX, Out1, Out2)

Calculate the outlet states of a simple heat exchanger using the

effectiveness-Ntu method of analysis. / (tDewEnt-TLiqEnt)

CALL HEATEX (capAirWet, hAirEnt, capLiqWet, hLiqEntSat, uaH, -- subroutine S3 in type 75

TSurfEnt = TAIRSAT (Prop, hSurfEntSat) -- function F11 in type 75

CALL WCOILOUT (Prop, MAir, TAirEnt, WAirEnt, hAirEnt, hAirLvg, -- subroutine S4

cpSat $=($ ENTHSAT $($ Prop, tDewEnt) -hLiqEntSat) -- function F4 in type 75 in type 75

S4 SUBROUTINE WCOILOUT (Prop, MAir, TAirEnt, WAirEnt, HAirEnt, HAirLvg, UAExt, TAirLvg, WAirLvg, QSen, ErrStat)

Calculate the leaving air temperature, the leaving air humidity ratio and the sensible cooling capacity of wet cooling coil. tempCond = TAIRSAT (Prop, hCondSat) -- function F11 in type 75

IF (tempCond. LT. DEWPOINT (Prop, WAirEnt)) THEN -- function F3 in type 75 WAirLvg = HUMTH (Prop, TAirLvg, HAirLvg) -- function F6 in type 75

TAirLvg = DRYBULB3 (Prop, HAirLvg,WAirLvg) -- function F13 in type 75

S5 SUBROUTINE BYPASS(Prop, TEnt, WEnt, TLvg, WLvg, TAdp, WAdp, BF, ErrStat)

Calculate apparatus dew point and bypass factor given entering and leaving moist air conditions of cooling coil.

TAdp = DEWPOINT (Prop,WLvg) -- function F3 in type 75

WAdp $=\operatorname{HUMRATIO}(\operatorname{Prop}($ Patm), SATPRESS (Prop, TAdp)) -- function F5 \& F9

in type 75

TAdp = XITERATE (TAdp, error, X1,F1,X2,F2, iter, icvg) -- function F14 in type 75

hLvg = ENTHALPY3 (Prop, TLvg, WLvg) -- function in F2 type 75

hEnt = ENTHALPY3 (Prop, TEnt, WEnt) -- function F2 in type 75

hAdp = ENTHALPY3 (Prop, TAdp, WAdp) -- function F2 in type 75

F1 REAL FUNCTION UAHX (Cap1, In1, Cap2, In2, Q, ConfigHX,ErrStat)

Calculate the UA of a heat exchanger using the effectiveness-Ntu relationships given the entering capacity rate and temperature of each flow stream, the heat transfer rate under these conditions and the heat exchanger configuration.

CALL HEATEX (Cap1, In1, Cap2, In2, ua, ConfigHx, out1, out2) -- subroutine S3

in type 75

ua = XITERATE (ua, error,X1,F1,X2,F2, iter, icvg) -- function F14 in type 75

F2 REAL FUNCTION ENTHALPY3 (Prop, TDB,W)

Calculate the enthalpy of moist air.

F3 REAL FUNCTION DEWPOINT (Prop, W)

Calculate the dewpoint temperature given humidity ratio

DewPoint $=$ SATTEMP (Prop,pw) -- function F10 in type 75

F4 REAL FUNCTION ENTHSAT (Prop, TDB)

Calculate the enthalpy at saturation for given dry bulb temperature psat = SATPRESS (Prop, TDB) -- function F9 in type 75

$\mathrm{w}=$ HUMRATIO (Prop (Patm), psat) -- function F5 in type 75

ENTHSAT $=$ ENTHALPY3 (Prop, TDB, w) -- function F2 in type 75

F5 REAL FUNCTION HUMRATIO (Patm, Pw)

Calculate the humidity ratio from water vapor pressure and atmospheric Pressure

F6 REAL FUNCTION HUMTH (Prop, TDB, H)

Calculate the humidity ratio of moist air from dry bulb temperature and enthalpy. 
F7 REAL FUNCTION RELHUM (Patm, Psat, HumRatio)

Calculate the relative humidity from saturation and atmospheric Pressures

F8 REAL FUNCTION RHOMOIST (RhoDry, W)

Calculate moist air density from dry air density and humidity ratio

F9 REAL FUNCTION SATPRESS (Prop,T)

Calculate saturation pressure of water vapor as a function of temperature

F10 REAL FUNCTION SATTEMP (Prop, P)

Calculate the saturation (boiling) temperature of water given pressure pSat = SATPRESS (Prop, tSat) -- function F9 in type 75

tSat = XITERATE (tSat, error, X1,F1,X2,F2, iter,icvg) -- function F14 in type 75

F11 REAL FUNCTION TAIRSAT (Prop, HSat)

Calculate the dry bulb temperature given enthalpy at saturation. error = HSat - ENTHSAT (Prop, tSat) -- function F4 in type 75 tSat = XITERATE (tSat, error,X1,F1,X2,F2, iter, icvg) -- function F14 in type 75

F12 REAL FUNCTION WETBULB (Prop, TDB, W)

Calculate wet bulb temperature from dry bulb temperature and humidity ratio

tBoil = SATTEMP (Prop, Prop (Patm)) -- function F10 in type 75 psatStar = SATPRESS (Prop, WetBulb) -- function F9 in type 75 wStar $=$ HUMRATIO (Prop (Patm), psatStar) -- function F5 in type 75

WetBulb = XITERATE (WetBulb, error,X1,F1,X2,F2, iter, icvg) -- function F14

in type 75

F13 REAL FUNCTION DRYBULB3 (Prop, $\mathrm{H}, \mathrm{W}$ )

Calculate the dry bulb temperature of moist air from enthalpy and humidity.

F14 REAL FUNCTION XITERATE (X0,F0,X1,F1, X2, F2, ICount, ICvg)

Iterately solves for the value of $X$ which satisfies $F(X)=0$. Given $\mathrm{Xi}, \mathrm{F}(\mathrm{Xi})$ pairs, the subroutine tests for convergence and provides a new guess for the value of the independent variable $\mathrm{X}$.

\begin{tabular}{|c|c|c|}
\hline $1 \mathrm{PROP}(\mathrm{PATM})$ & 101325.0 & Atmospheric pressure ( $\mathrm{Pa})$ \\
\hline $2 \mathrm{PROP}(\mathrm{CPAIR})$ & 1006.0 & Specific heat of dry air (J/kg C) \\
\hline $3 \mathrm{PROP}(\mathrm{CPWAT})$ & 4186.0 & Specific heat of liquid water $(\mathrm{J} / \mathrm{kg} \mathrm{C})$ \\
\hline $4 \mathrm{PROP}(\mathrm{CPVAP})$ & 1805.0 & $\begin{array}{l}\text { Specific heat of saturated water } \\
\text { vapor }(\mathrm{J} / \mathrm{kg} \mathrm{C})\end{array}$ \\
\hline 5 PROP (CPLIQ) & 4186.0 & \\
\hline 6 PROP (DVISCAIR) & .0000182 & Air dynamic viscosity ( $\mathrm{kg} / \mathrm{m} \mathrm{s})$ \\
\hline 7 PROP (DVISCLIQ) & .00144 & Liquid dynamic viscosity $(\mathrm{kg} / \mathrm{m} \mathrm{s})$ \\
\hline $8 \mathrm{PROP}(\mathrm{KAIR})$ & .026 & Air thermal conductivity $(\mathrm{W} / \mathrm{m} \mathrm{C})$ \\
\hline PROP (KLIQ) & .604 & Liquid thermal conductivity (W/m C) \\
\hline PROP (RHOLIQ) & 998.0 & Liquid density $(\mathrm{kg} / \mathrm{m} 3)$ \\
\hline $\mathrm{PROP}(\mathrm{HFG})$ & $=2501000.0$ & Latent heat of vaporization of water ( $/ \mathrm{kg})$ \\
\hline PROP (RAIR) & 287.055 & Gas constant for air ( J/kg C) \\
\hline PROP ( TKELMULT) & 1.0 & $\begin{array}{l}\text { Multiplying factor to convert user } \\
\mathrm{T} \text { to Kelvin }\end{array}$ \\
\hline $\mathrm{PROP}(\mathrm{TABSADD})$ & 273.15 & $\begin{array}{l}\text { Additive factor to convert user } \mathrm{P} \text { to Kelvin: } \\
\text { tKel }=\text { Prop (TKelMult)*T }+ \text { Prop (TKelAdd) }\end{array}$ \\
\hline PROP ( PAMULT) & 1.0 & $\begin{array}{l}\text { Multiplying factor to convert user } \mathrm{P} \text { to } \\
\text { Pascals }\end{array}$ \\
\hline PROP ( PABSADD) & 0.0 & $\begin{array}{l}\text { Additive factor to convert user } \mathrm{P} \text { to Pascals: } \\
\mathrm{Pa}=\operatorname{Prop}(\mathrm{PaMult}) * \mathrm{P}+\operatorname{Prop}(\mathrm{PaAdd})\end{array}$ \\
\hline
\end{tabular}


SOURCE CODE

SUBROUTINE TYPE75 (TIME, XIN, OUT, T, DTDT, PAR, INFO, ICNTRL, *)

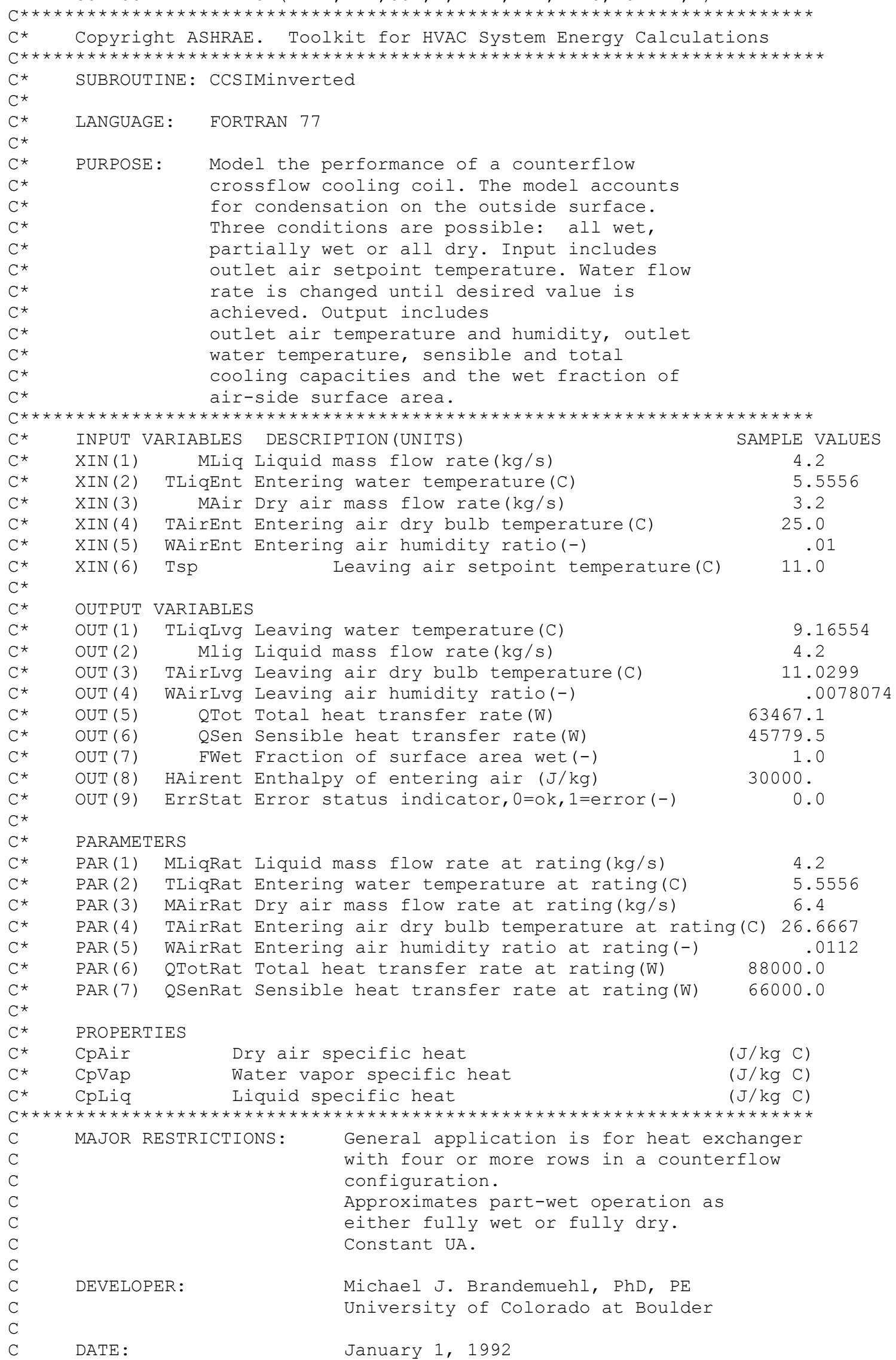




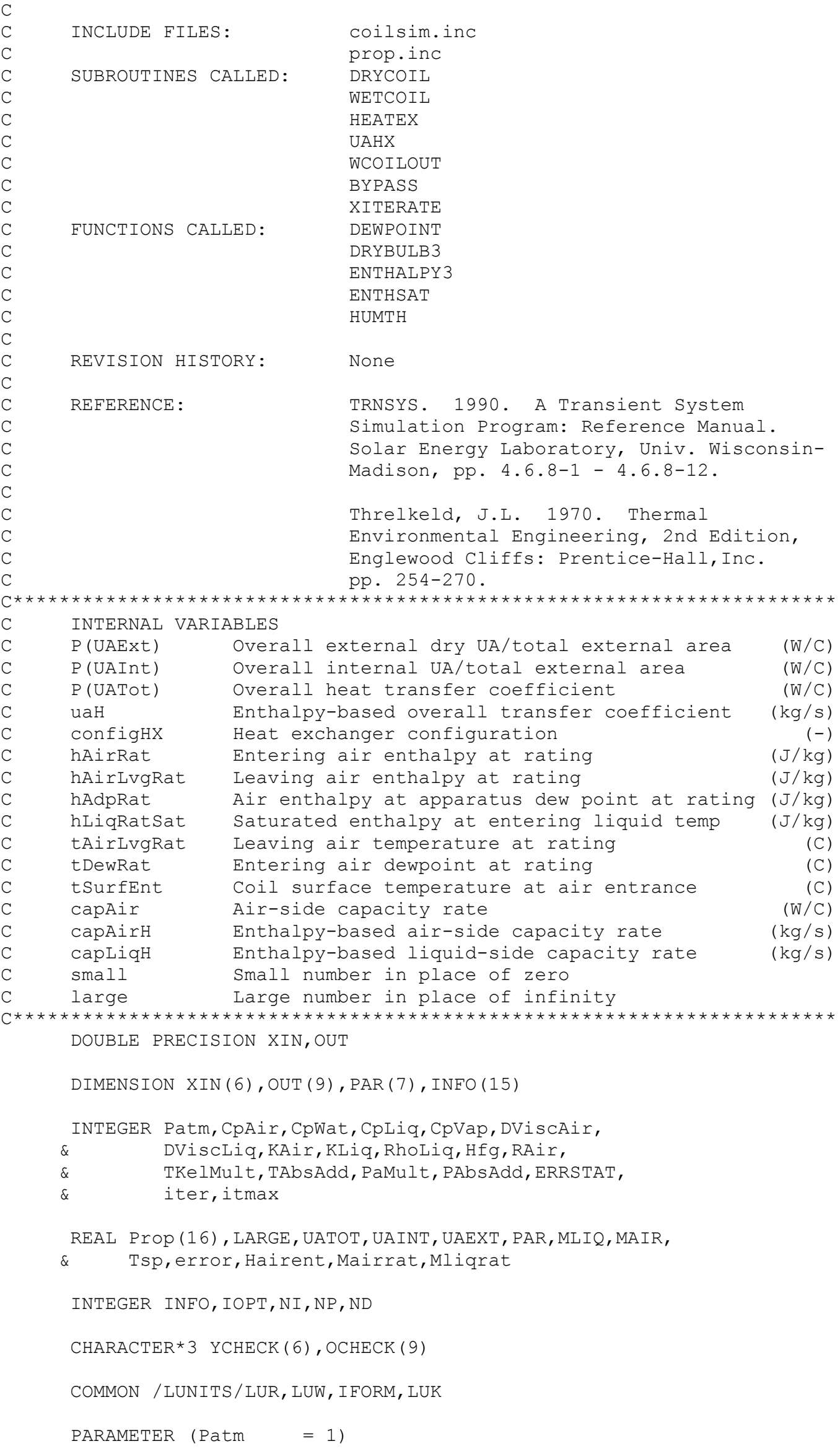




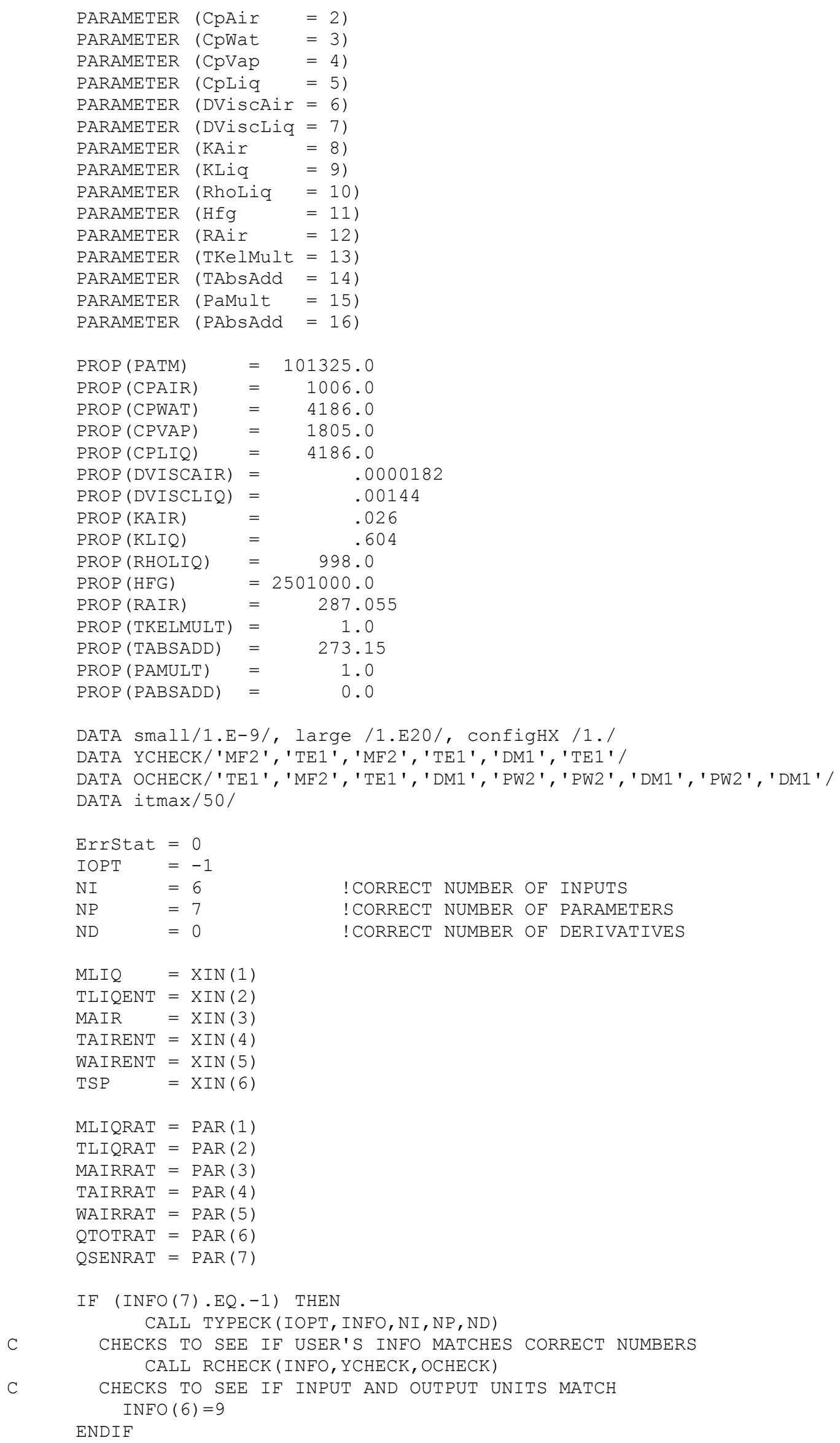




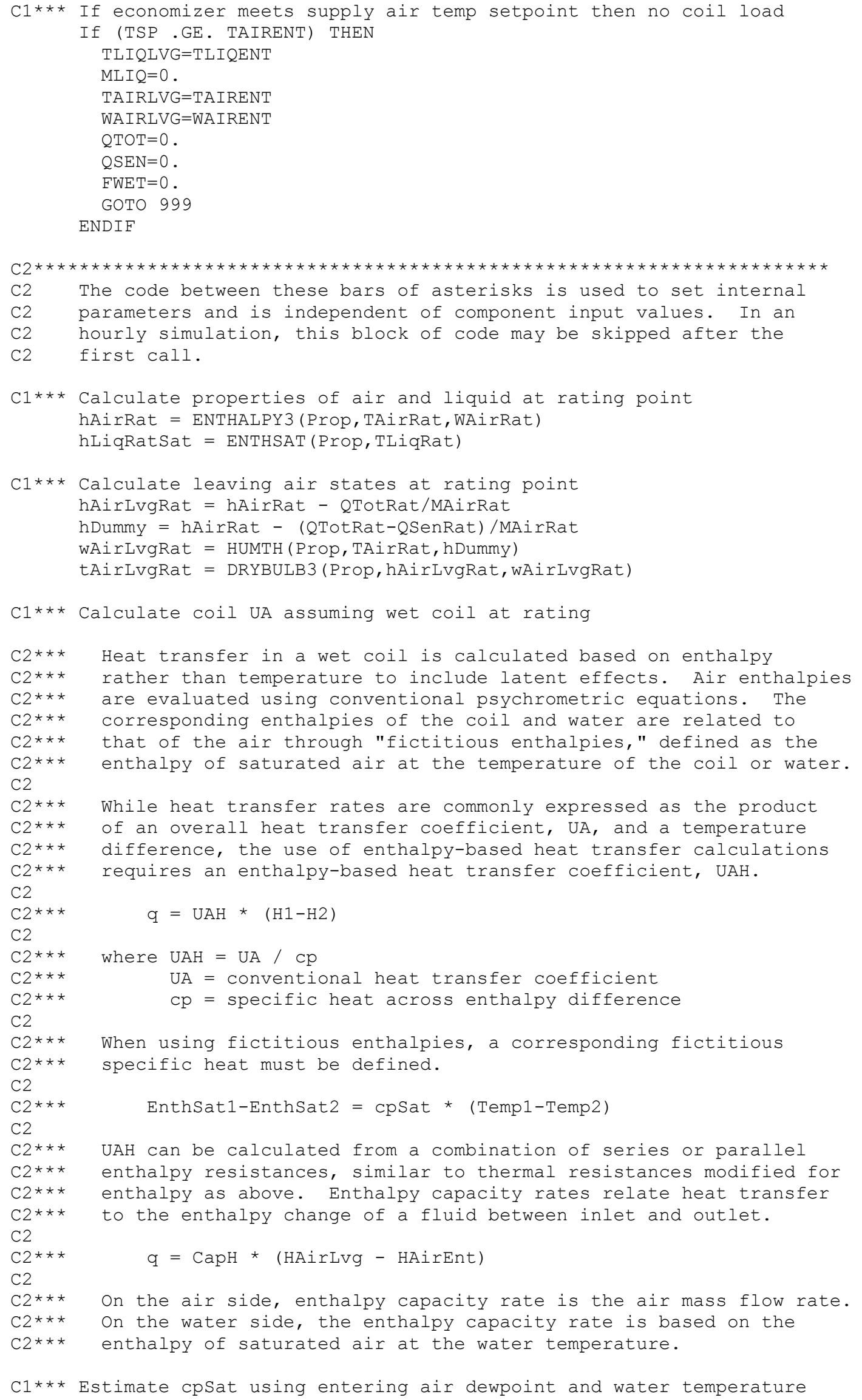




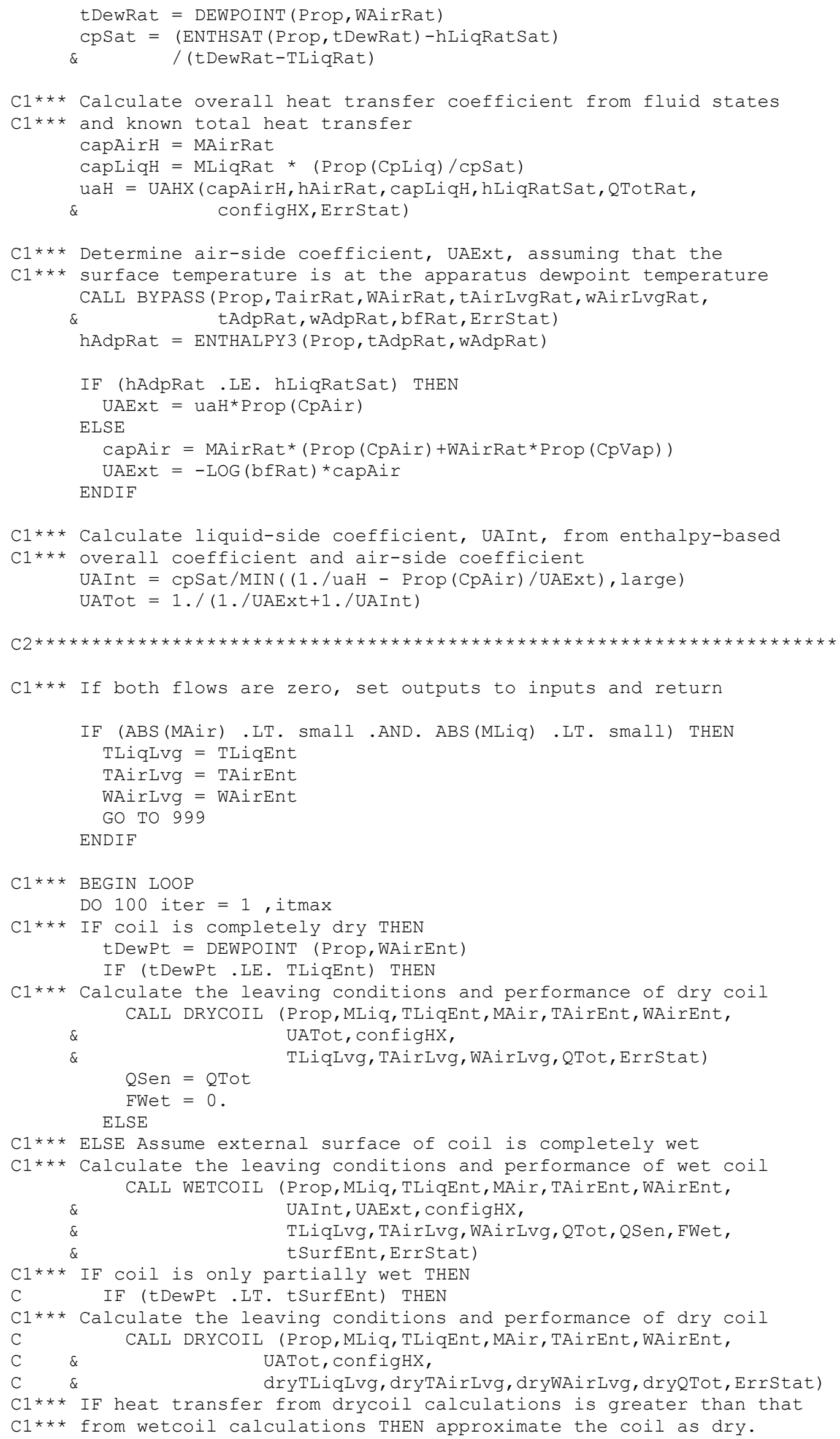




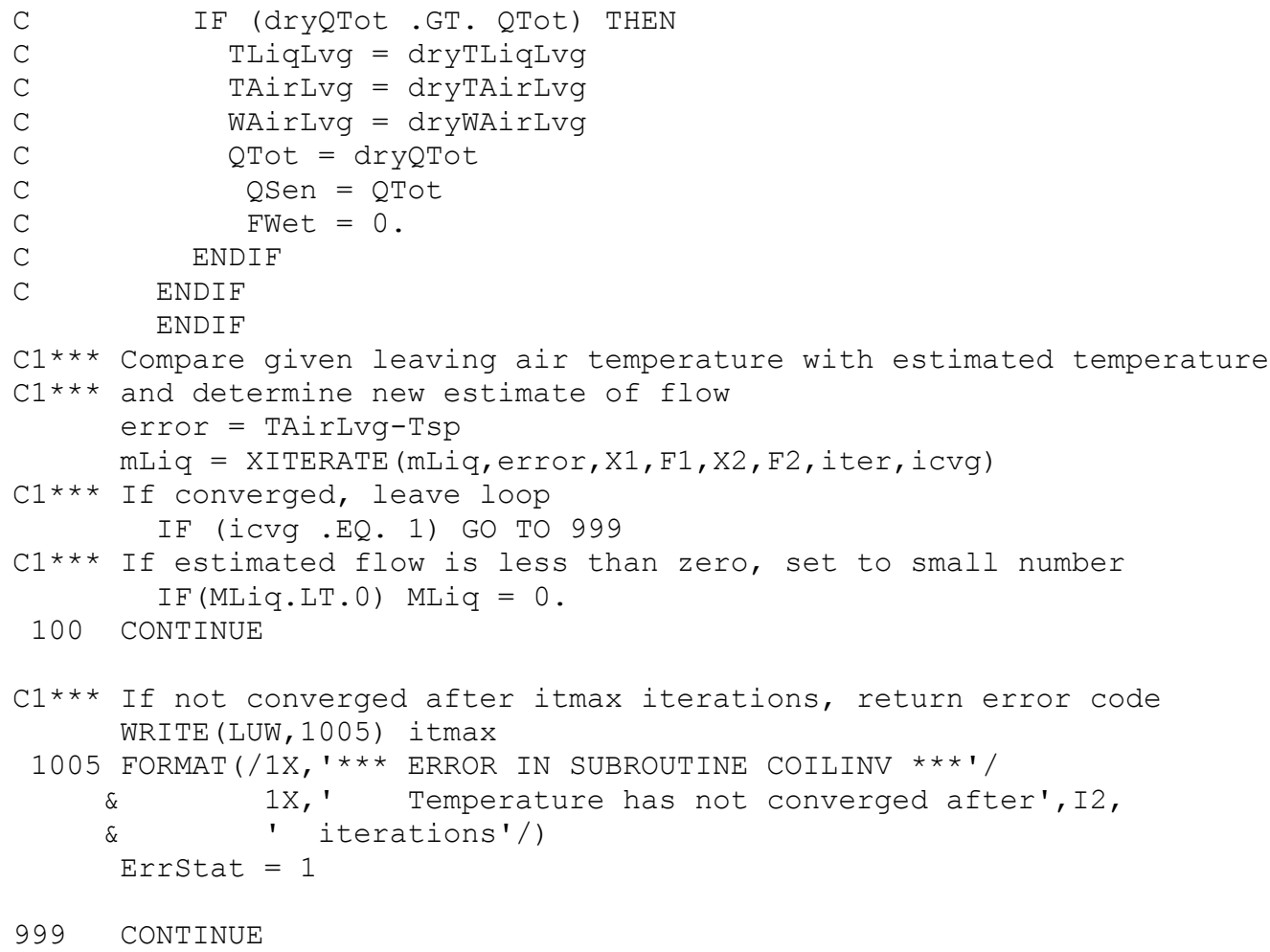




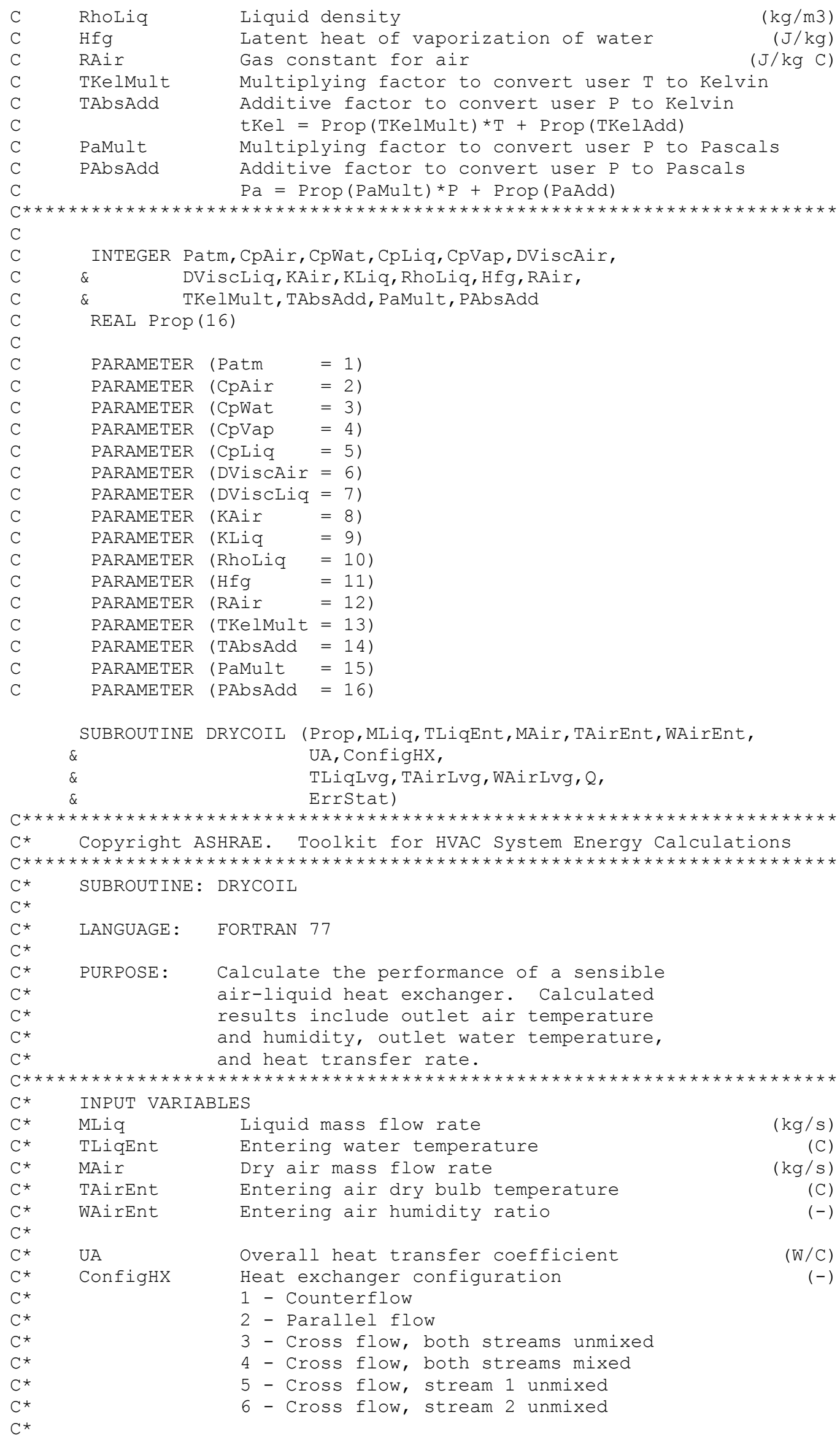




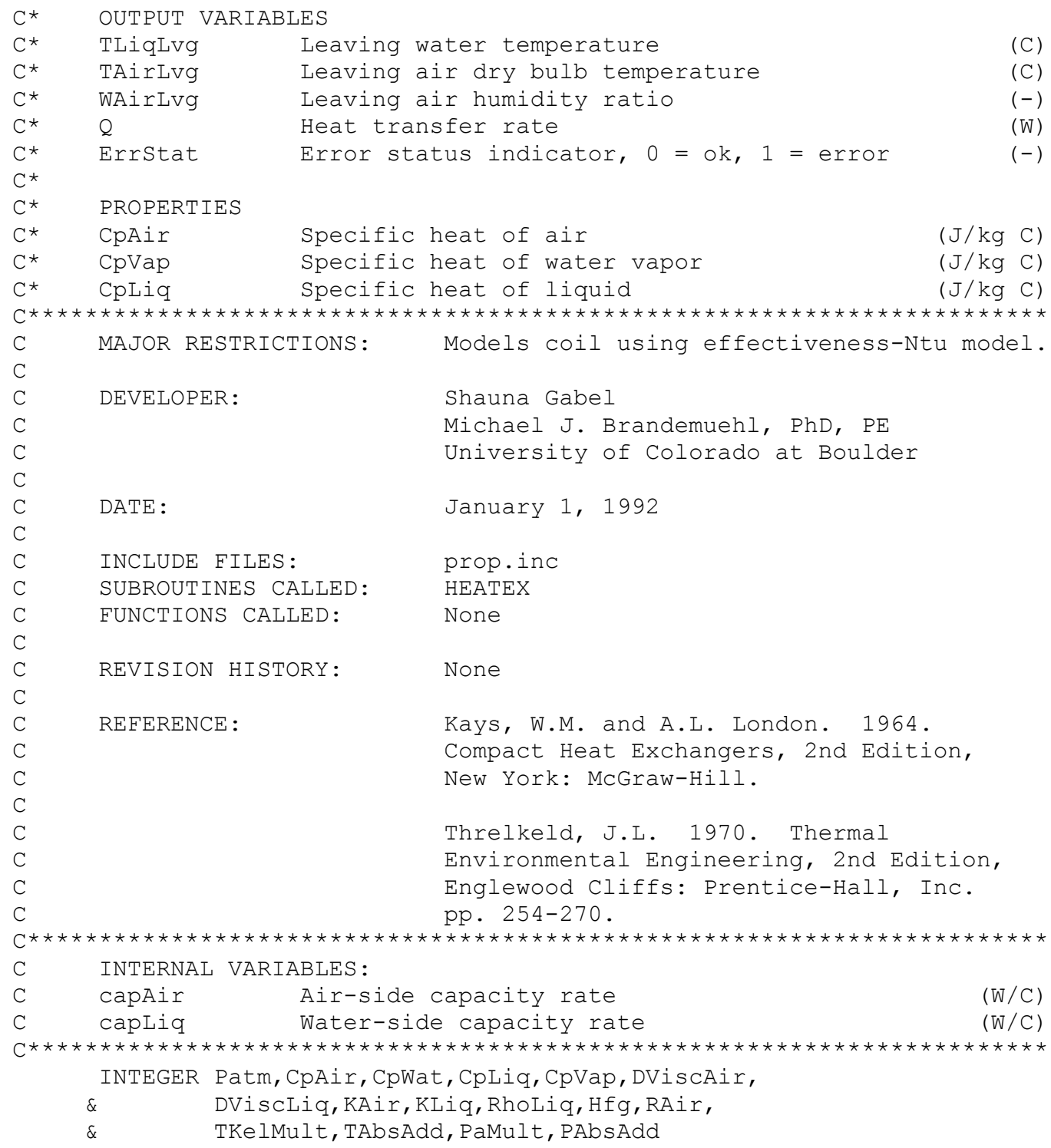

REAL Prop (16)

\begin{tabular}{|c|c|c|}
\hline 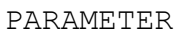 & & $=1)$ \\
\hline ARAMETER & (CpAir & $=2$ ) \\
\hline AMETER & (CpWat & $=$ \\
\hline METER & (CpVap & \\
\hline ARAMETER & (CpLiq & $=$ \\
\hline ETER & (DViscAir & $=$ \\
\hline ETER & (DViscLiq & $=$ \\
\hline ETER & $(\mathrm{K})$ & \\
\hline METER & ( KI & $=$ \\
\hline RAMETER & (RhoLiq & $=$ \\
\hline METER & & $=$ \\
\hline ETER & ir & $=$ \\
\hline $\mathrm{R}$ & lMult & $=$ \\
\hline AMETER & Add & $=$ \\
\hline AMETH & $1+$ & . \\
\hline RAME! & sAdd & \\
\hline
\end{tabular}

REAL MAir,MLiq

INTEGER Errstat 


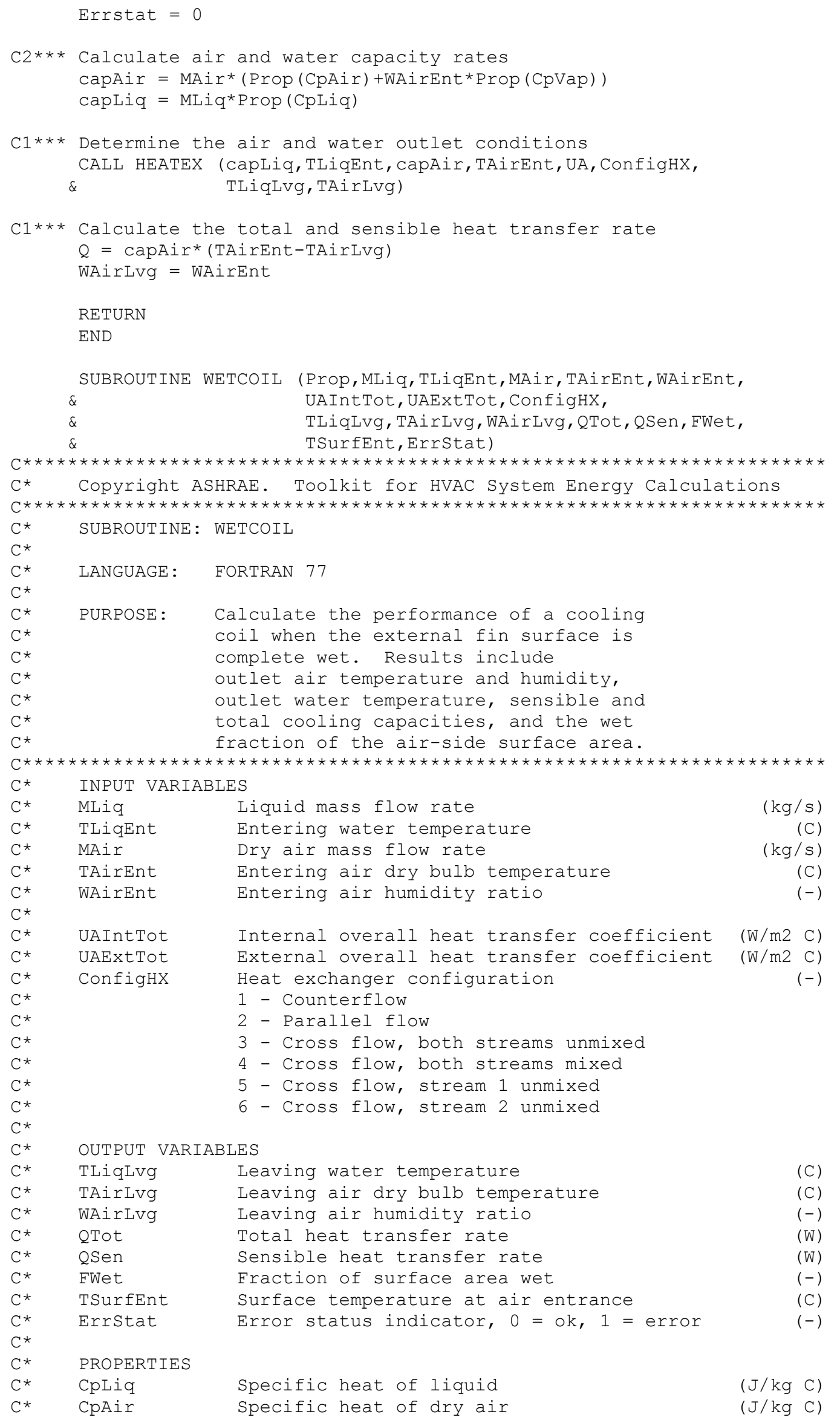

$\begin{array}{lll}C^{*} & \text { Cpliq } & \text { Specific heat of liquid } \\ C^{*} & \text { CpAir } & \text { Specific heat of dry ai }\end{array}$ 


\begin{tabular}{|c|c|c|c|c|}
\hline $\begin{array}{l}\text { C } \\
\text { C } \\
\text { C }\end{array}$ & \multirow{2}{*}{\multicolumn{2}{|c|}{ MAJOR RESTRICTIONS: }} & \multicolumn{2}{|c|}{$\begin{array}{l}\text { Models coil as counterflow heat exchanger } \\
\text { Approximates saturated air enthalpy as } \\
\text { a linear function of temperature }\end{array}$} \\
\hline $\mathrm{C}$ & & & & \\
\hline $\mathrm{C}$ & \multicolumn{2}{|l|}{ DEVELOPER: } & \multicolumn{2}{|l|}{ Shauna Gabel } \\
\hline C & & & \multicolumn{2}{|l|}{ Michael J. Brandemuehl, PhD, PE } \\
\hline $\mathrm{C}$ & & & \multirow{2}{*}{\multicolumn{2}{|c|}{ University of Colorado at Boulder }} \\
\hline $\mathrm{C}$ & & & & \\
\hline C & DATE : & & \multicolumn{2}{|l|}{ January 1, 1992} \\
\hline C & & & & \\
\hline $\mathrm{C}$ & \multicolumn{2}{|c|}{ INCLUDE FILES: } & \multicolumn{2}{|l|}{ prop.inc } \\
\hline C & \multirow{2}{*}{\multicolumn{2}{|c|}{ SUBROUTINES CALLED: }} & \multicolumn{2}{|l|}{ HEATEX } \\
\hline C & & & \multicolumn{2}{|l|}{ WCOILOUT } \\
\hline $\mathrm{C}$ & \multirow{3}{*}{\multicolumn{2}{|c|}{ FUNCTIONS CALLED: }} & \multicolumn{2}{|l|}{ ENTHALPY3 } \\
\hline $\mathrm{C}$ & & & \multicolumn{2}{|l|}{ ENTHSAT } \\
\hline $\mathrm{C}$ & & & \multicolumn{2}{|l|}{ TAIRSAT } \\
\hline $\mathrm{C}$ & & & & \\
\hline $\mathrm{C}$ & \multicolumn{2}{|c|}{ REVISION HISTORY: } & None & \\
\hline C & & & & \\
\hline $\begin{array}{l}\mathrm{C} \\
\mathrm{C}\end{array}$ & REFERENCE : & & $\begin{array}{l}\text { Elmahdy, A.H. and Mitalas, G.P. } \\
\text { "A Simple Model for Cooling and }\end{array}$ & 977 \\
\hline $\mathrm{C}$ & & & Dehumidifying Coils for Use In Ca & culating \\
\hline C & & & Energy Requirements for Buildings & \\
\hline $\mathrm{C}$ & & & ASHRAE Transactions, Vol.83 Part 2 & \\
\hline $\mathrm{C}$ & & & pp. $103-117$ & \\
\hline C & & & & \\
\hline $\mathrm{C}$ & & & TRNSYS. 1990. A Transient Syste & \\
\hline C & & & Simulation Program: Reference Mar & al. \\
\hline C & & & Solar Energy Laboratory, Univ. Wi & consin- \\
\hline $\mathrm{C}$ & & & Madison, pp. 4.6.8-1-4.6.8-12. & \\
\hline C & & & & \\
\hline C & & & Threlkeld, J.L. 1970. Thermal & \\
\hline $\mathrm{C}$ & & & Environmental Engineering, 2nd Ec & tion, \\
\hline $\mathrm{C}$ & & & Englewood Cliffs: Prentice-Hall, I & \\
\hline $\mathrm{C}$ & & & pp. $254-270$ & \\
\hline $\mathrm{C}^{*}$ & 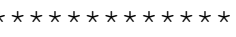 & 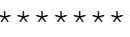 & 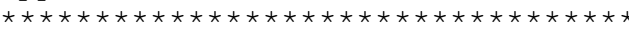 & 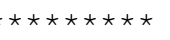 \\
\hline $\mathrm{C}$ & INTERNAL VAR & IABLES: & & \\
\hline C & extResist & Air-s & resistance to heat transfer & $(\mathrm{m} 2 \mathrm{C} / \mathrm{W})$ \\
\hline C & intResist & Liqui & de resistance to heat transfer & $(\mathrm{m} 2 \mathrm{C} / \mathrm{W})$ \\
\hline C & tDewEnt & Enter & air dew point & $(\mathrm{C})$ \\
\hline C & $\mathrm{uaH}$ & Overa & nthalpy heat transfer coefficient & $(\mathrm{kg} / \mathrm{s})$ \\
\hline C & capAirWet & Air-s & capacity rate & $(\mathrm{kg} / \mathrm{s})$ \\
\hline $\mathrm{C}$ & capLiqWet & Liqui & de capacity rate & $(\mathrm{kg} / \mathrm{s})$ \\
\hline $\mathrm{C}$ & resistRatio & Ratio & resistances & $(-)$ \\
\hline C & hAirLvg & Outle & r enthalpy & \\
\hline $\mathrm{C}$ & hLiqEntSat & Satur & enthalpy of air at & $(\mathrm{J} / \mathrm{kg})$ \\
\hline $\mathrm{C}$ & & enter & water temperature & \\
\hline $\begin{array}{l}\mathrm{C} \\
\mathrm{C}\end{array}$ & hLiqLvgSat & $\begin{array}{l}\text { Satur } \\
\text { water }\end{array}$ & $\begin{array}{l}\text { enthalpy of air at exit } \\
\text { perature }\end{array}$ & $(\mathrm{J} / \mathrm{kg})$ \\
\hline $\mathrm{C}$ & hSurfentSat & Satur & enthalpy of air at & $(\mathrm{J} / \mathrm{kg})$ \\
\hline C & & enter & surface temperature & \\
\hline $\begin{array}{l}\text { C } \\
\text { C }\end{array}$ & hSurfLvgSat & $\begin{array}{l}\text { Satur } \\
\text { surfa }\end{array}$ & $\begin{array}{l}\text { enthalpy of air at exit } \\
\text { emperature }\end{array}$ & $(\mathrm{J} / \mathrm{kg})$ \\
\hline C & cpsat & Coeff & nt for equation below & $(\mathrm{J} / \mathrm{kg} \quad \mathrm{C})$ \\
\hline C & & EnthS & EnthSat2 $=$ cpSat* $($ TSat $1-$ TSat 2$)$ & \\
\hline $\mathrm{C}$ & & (all & r and surface temperatures are & \\
\hline C & & relat & o saturated air enthalpies for & \\
\hline C & & wet $s$ & ce heat transfer calculations) & \\
\hline & 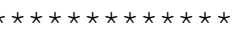 & 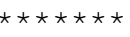 & 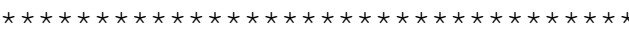 & 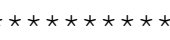 \\
\hline & INTEGER Patm & , CpAir, & t, CpLiq, CpVap, DViscAir, & \\
\hline & $\quad$ DVis & CLiq, KA & Liq, RhoLiq, Hfg, RAir, & \\
\hline & TKell & Mult, TA & d, PaMult, PAbsAdd & \\
\hline
\end{tabular}




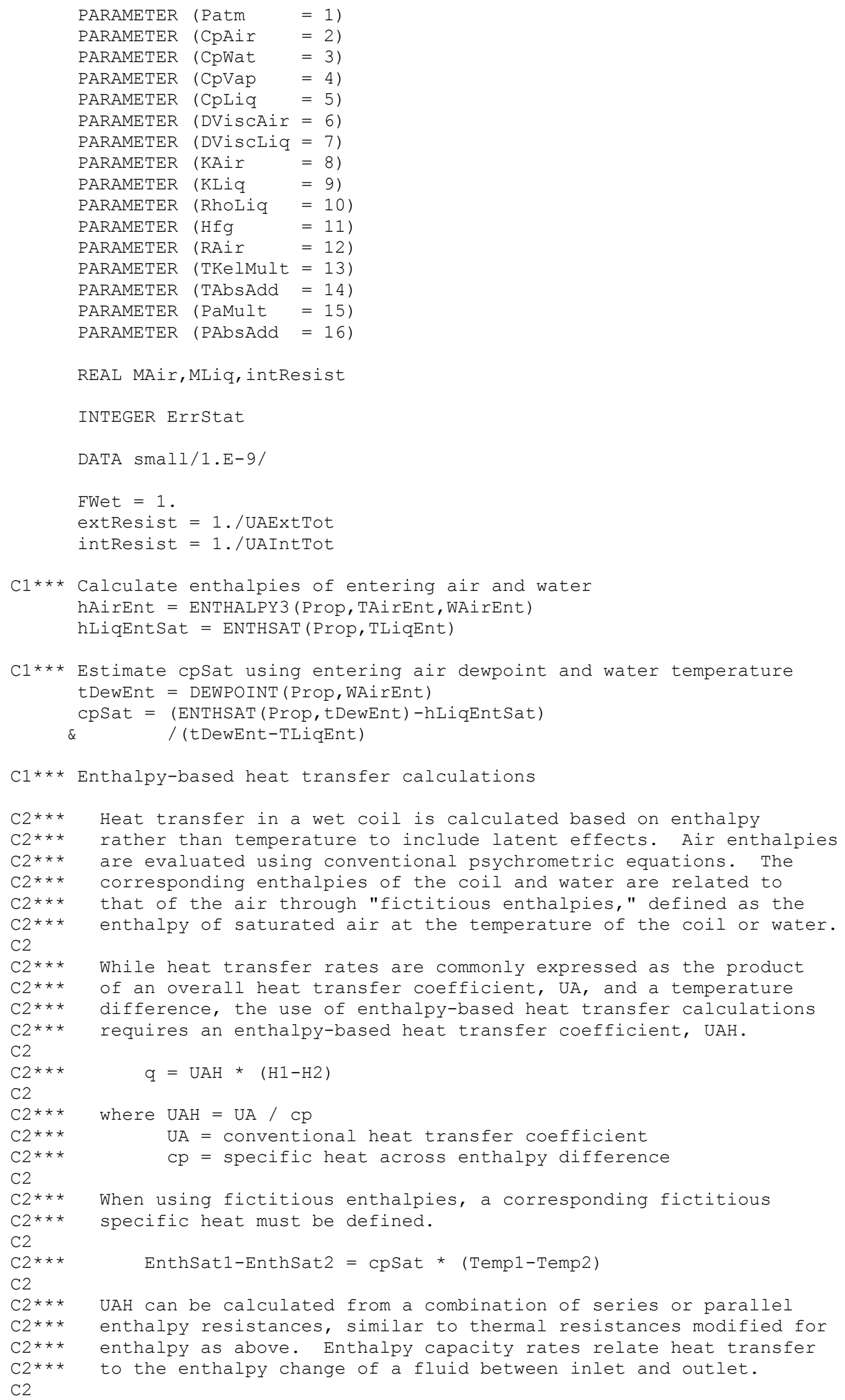




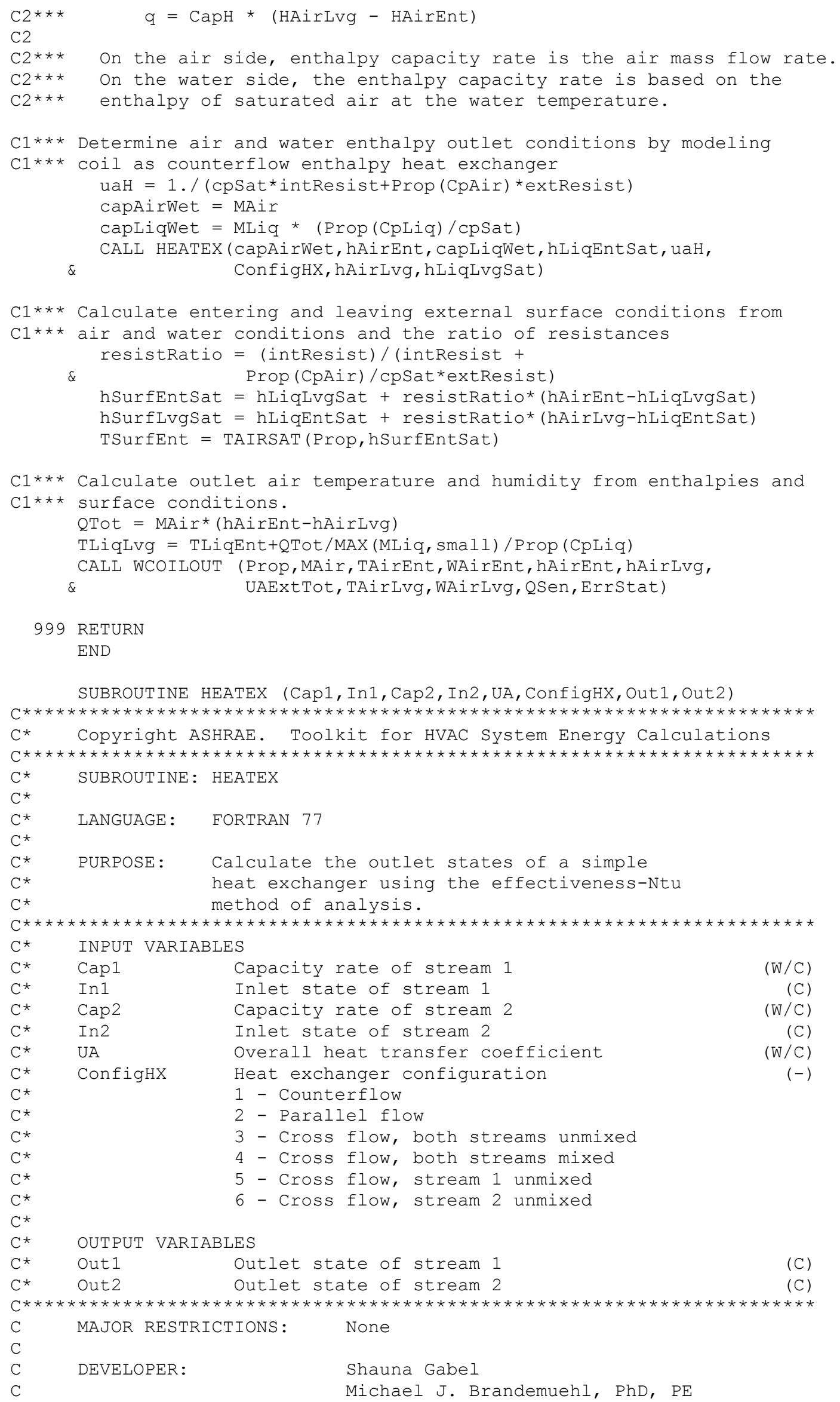




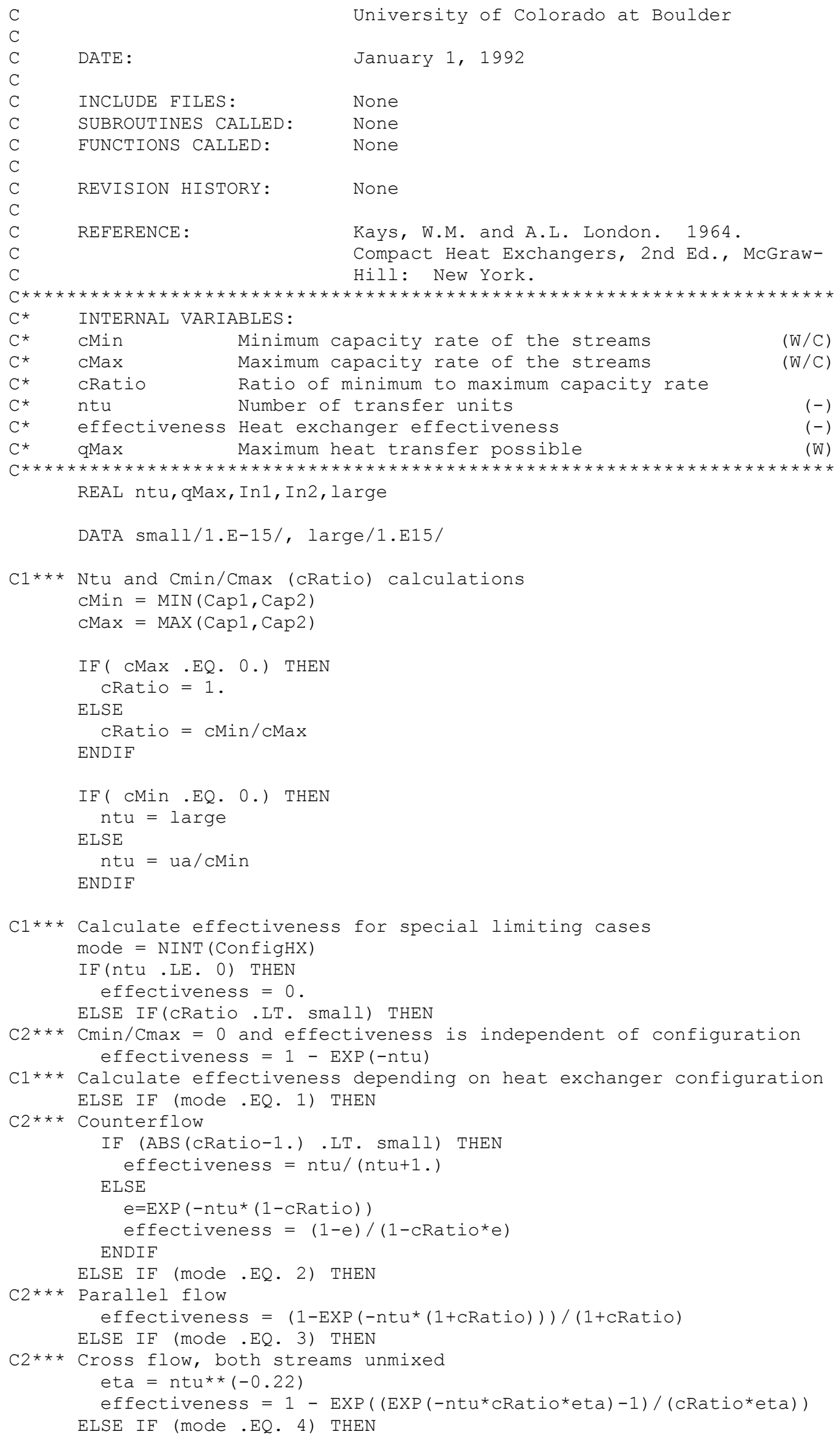




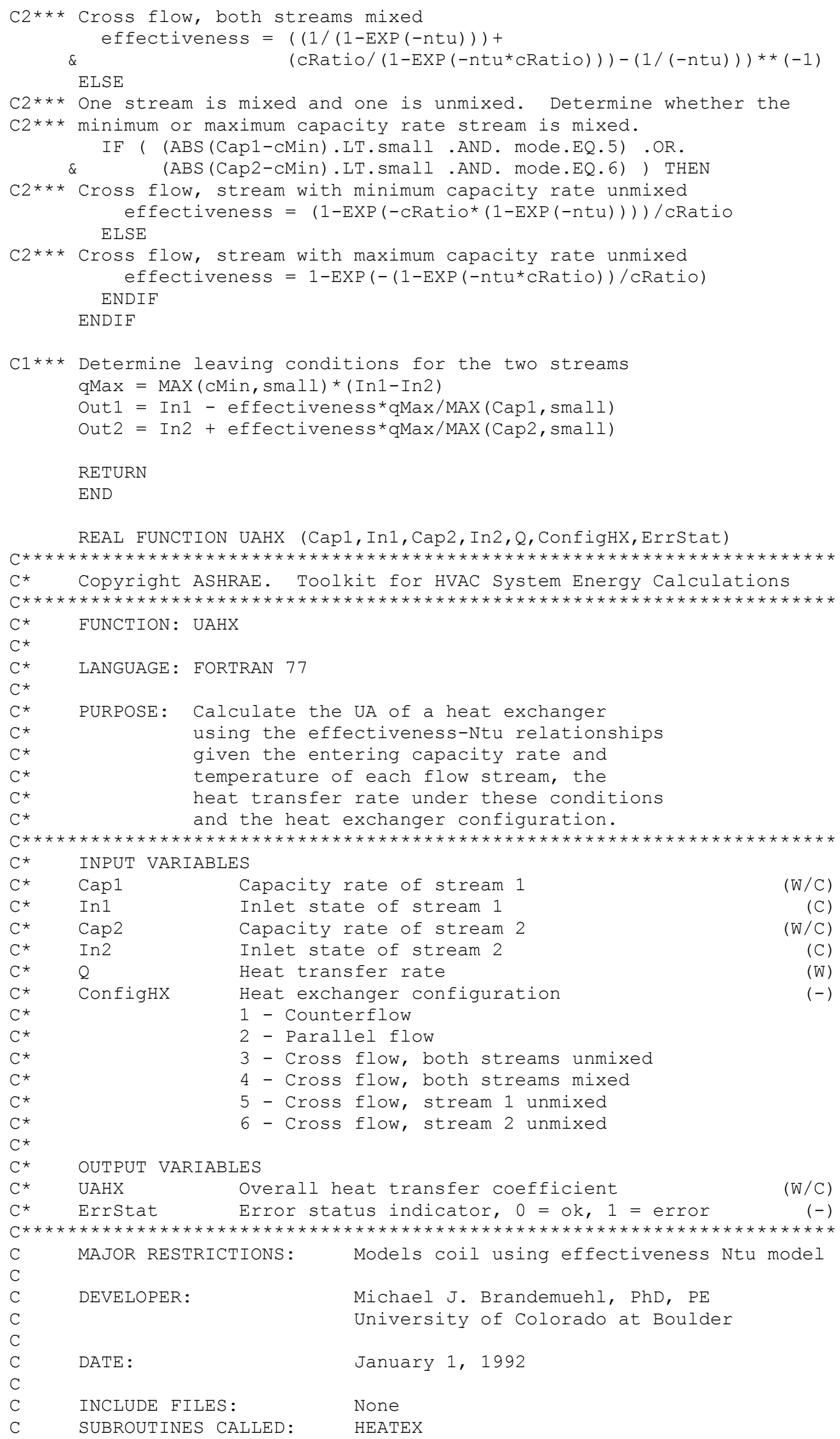




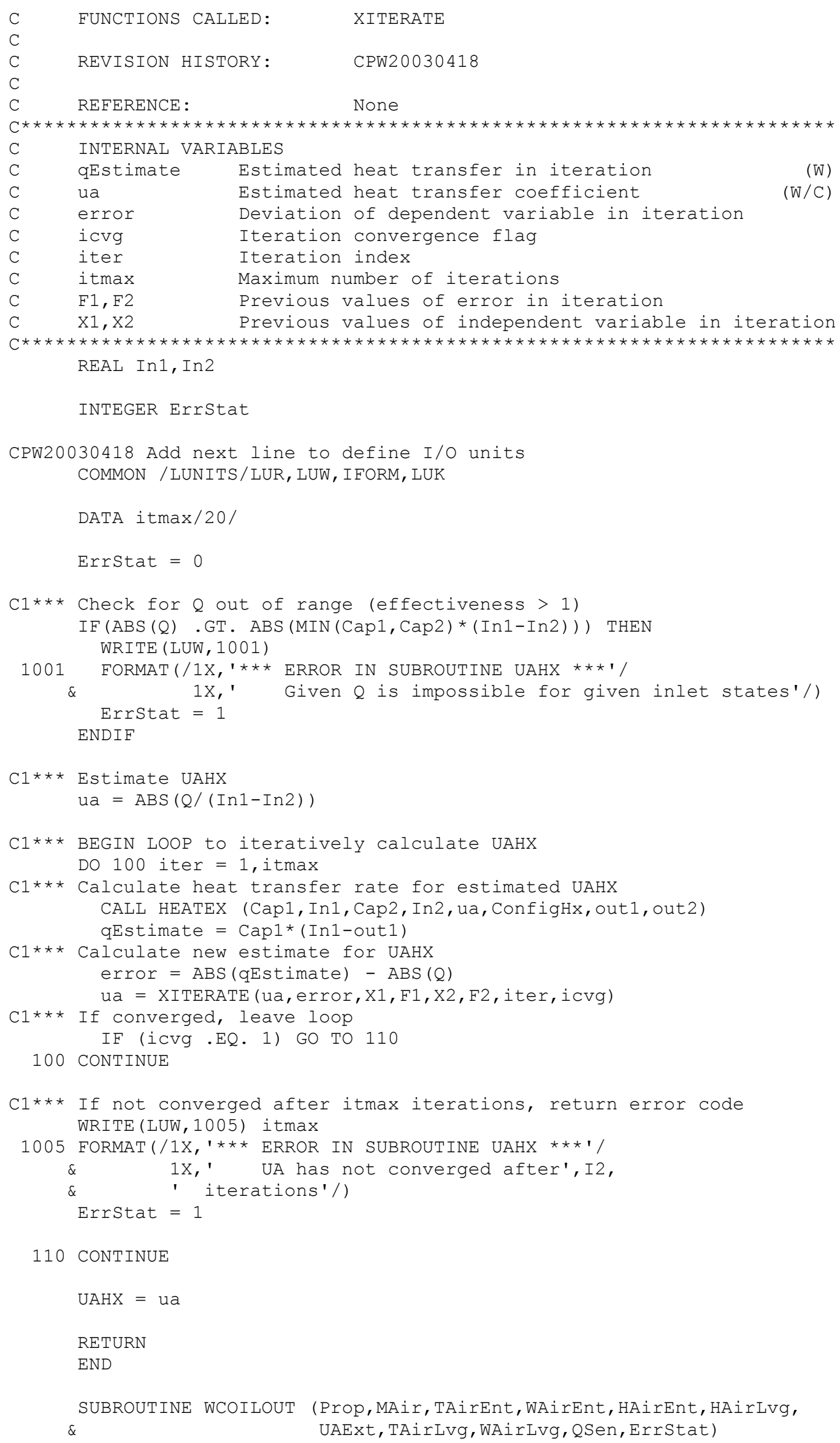

110 CONTINUE

$\mathrm{UAHX}=\mathrm{ua}$

RETURN

END

SUBROUTINE WCOILOUT (Prop, MAir, TAirEnt, WAirEnt, HAirEnt, HAirLvg, UAExt, TAirLvg, WAirLvg, eSen, ErrStat) 


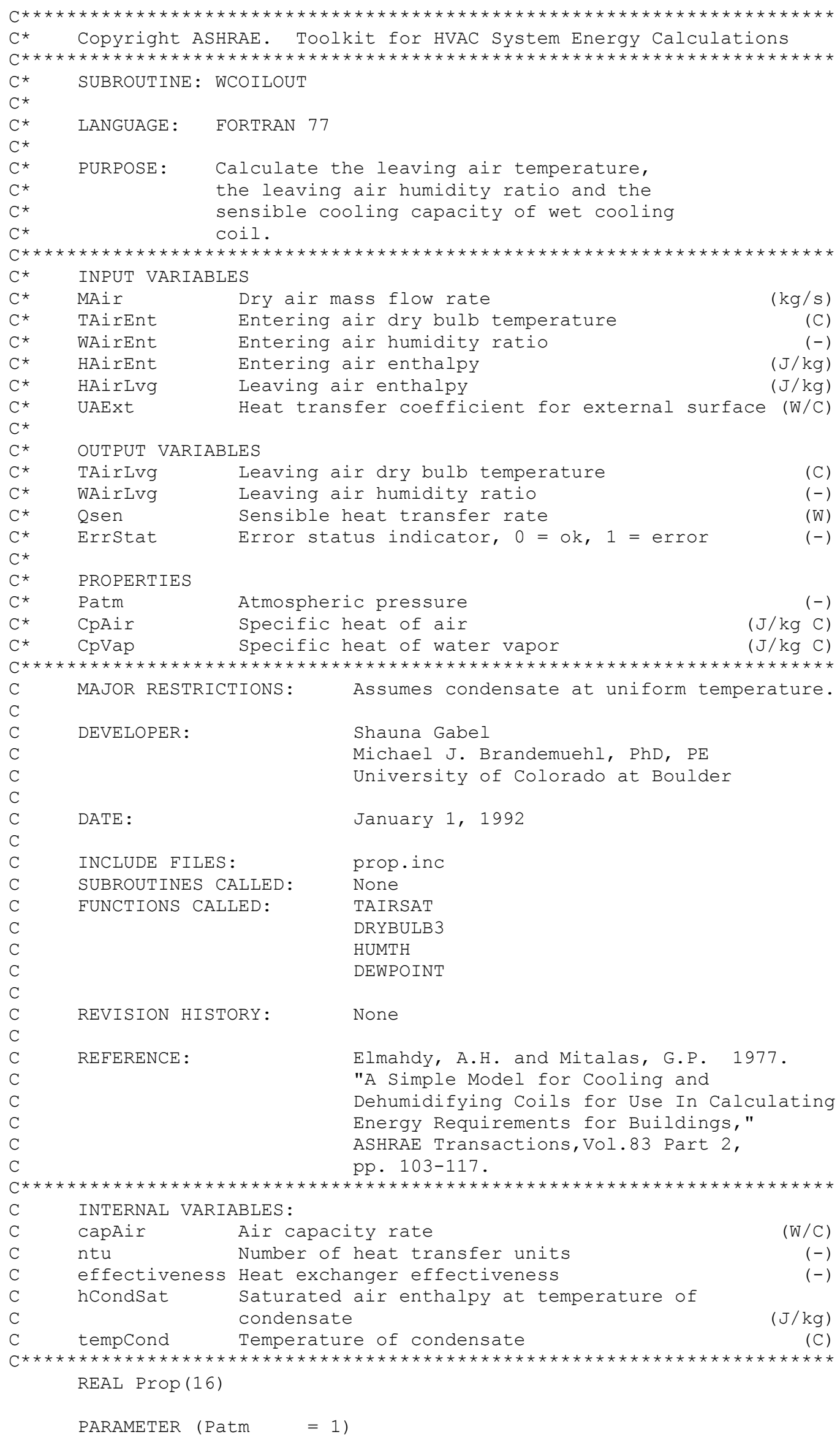




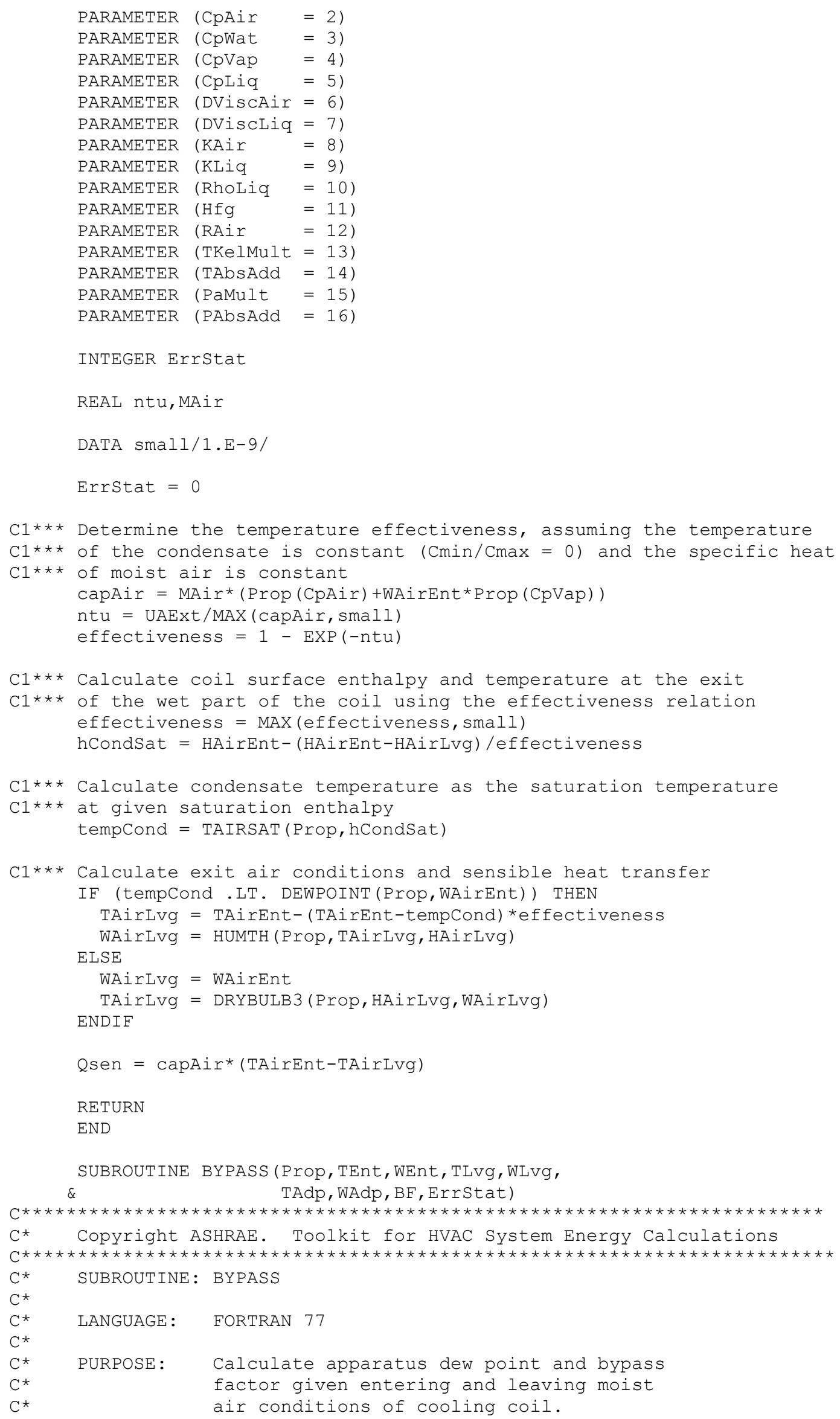




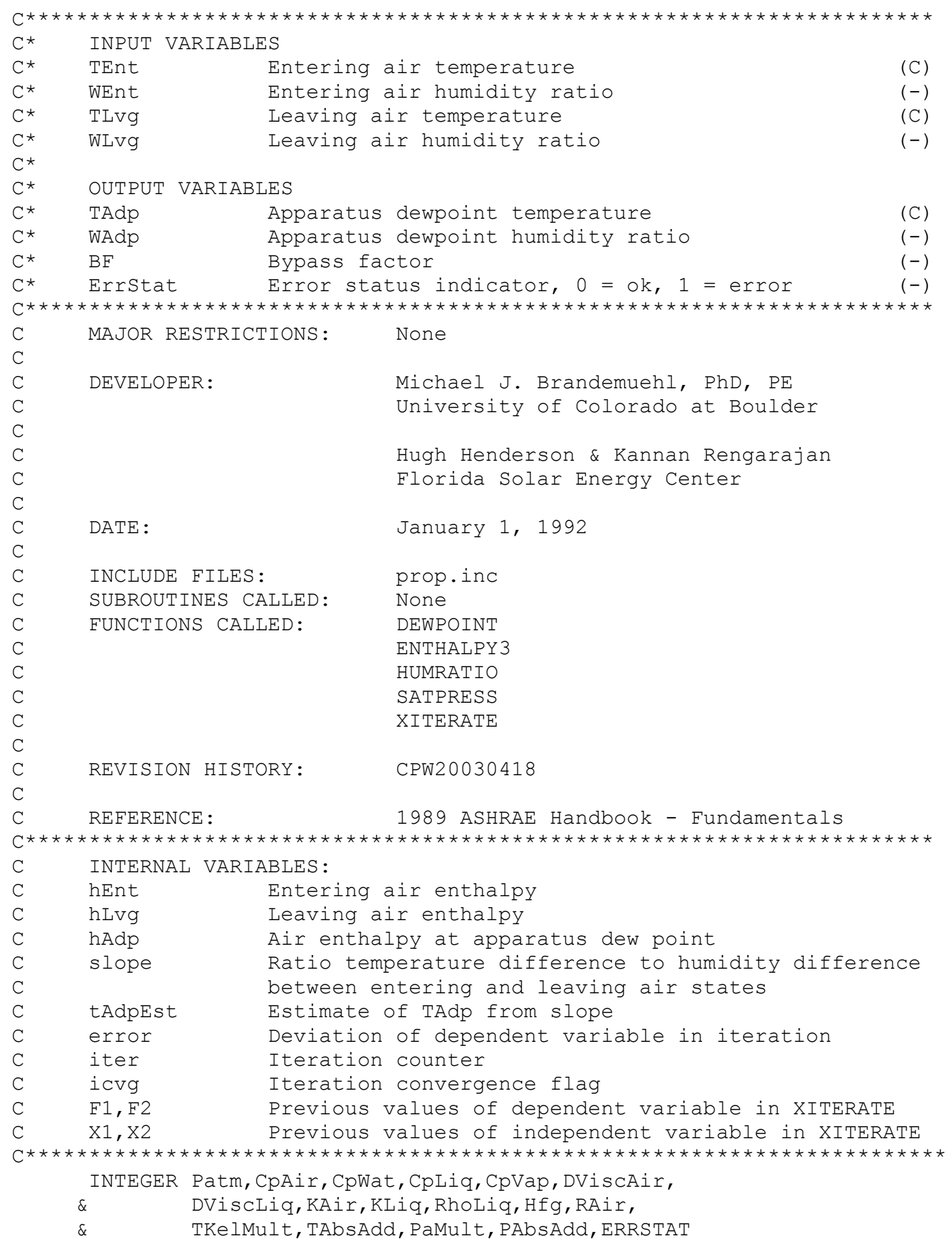

REAL Prop (16)

CPW20030418 Add next line to define I/O units COMMON /LUNITS/LUR, LUW, IFORM, LUK

$\begin{array}{lll}\text { PARAMETER } & (\text { Patm } & =1) \\ \text { PARAMETER } & \text { (CpAir } & =2 \text { ) } \\ \text { PARAMETER } & \text { (CpWat } & =3 \text { ) } \\ \text { PARAMETER } & \text { (CpVap } & =4) \\ \text { PARAMETER } & \text { (CpLiq } & =5 \text { ) } \\ \text { PARAMETER } & \text { (DViscAir }=6) \\ \text { PARAMETER } & \text { (DViscLiq }=7) \\ \text { PARAMETER } & (\text { KAir } & =8) \\ \text { PARAMETER } & (\text { KLiq } & =9)\end{array}$




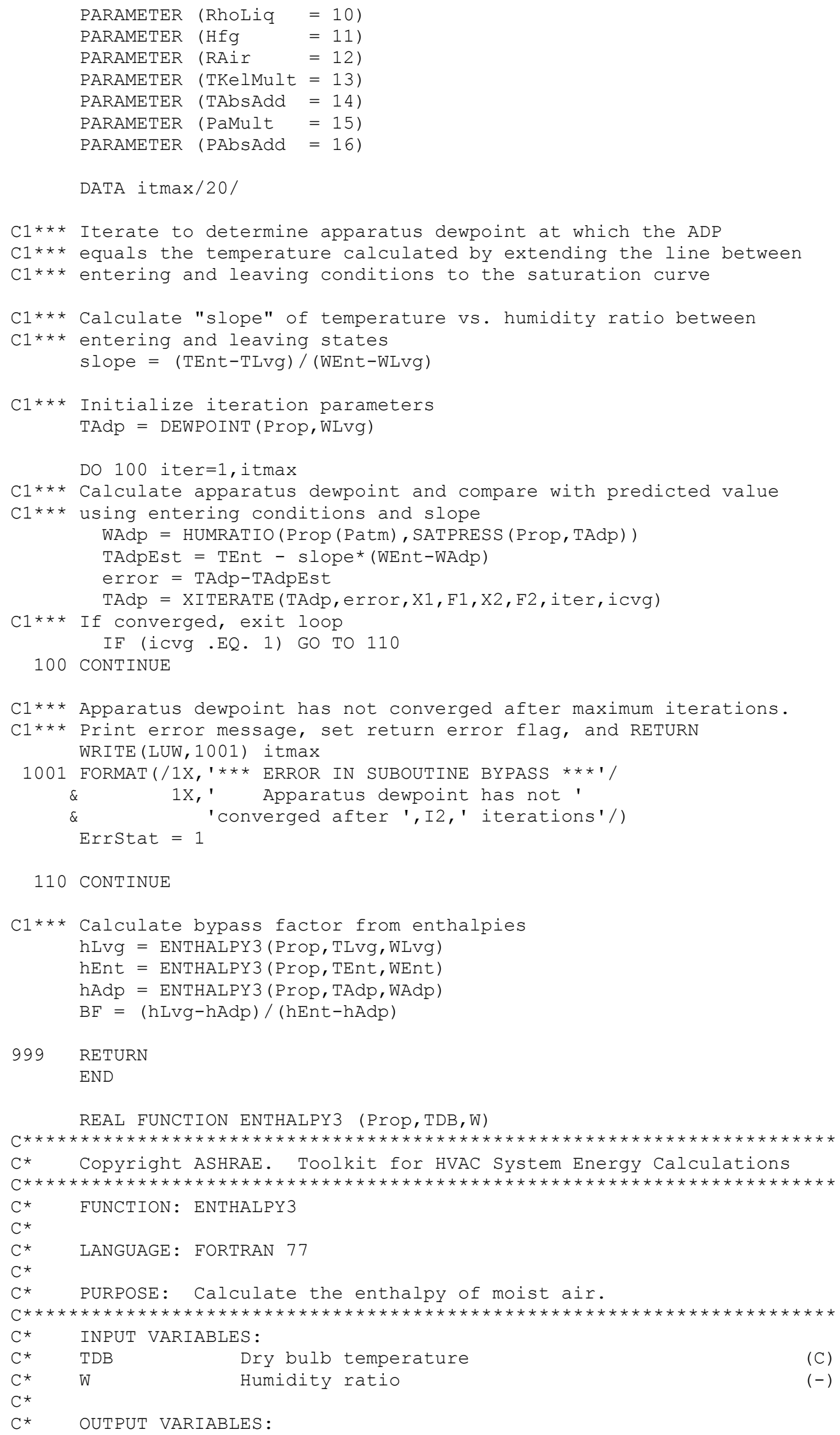




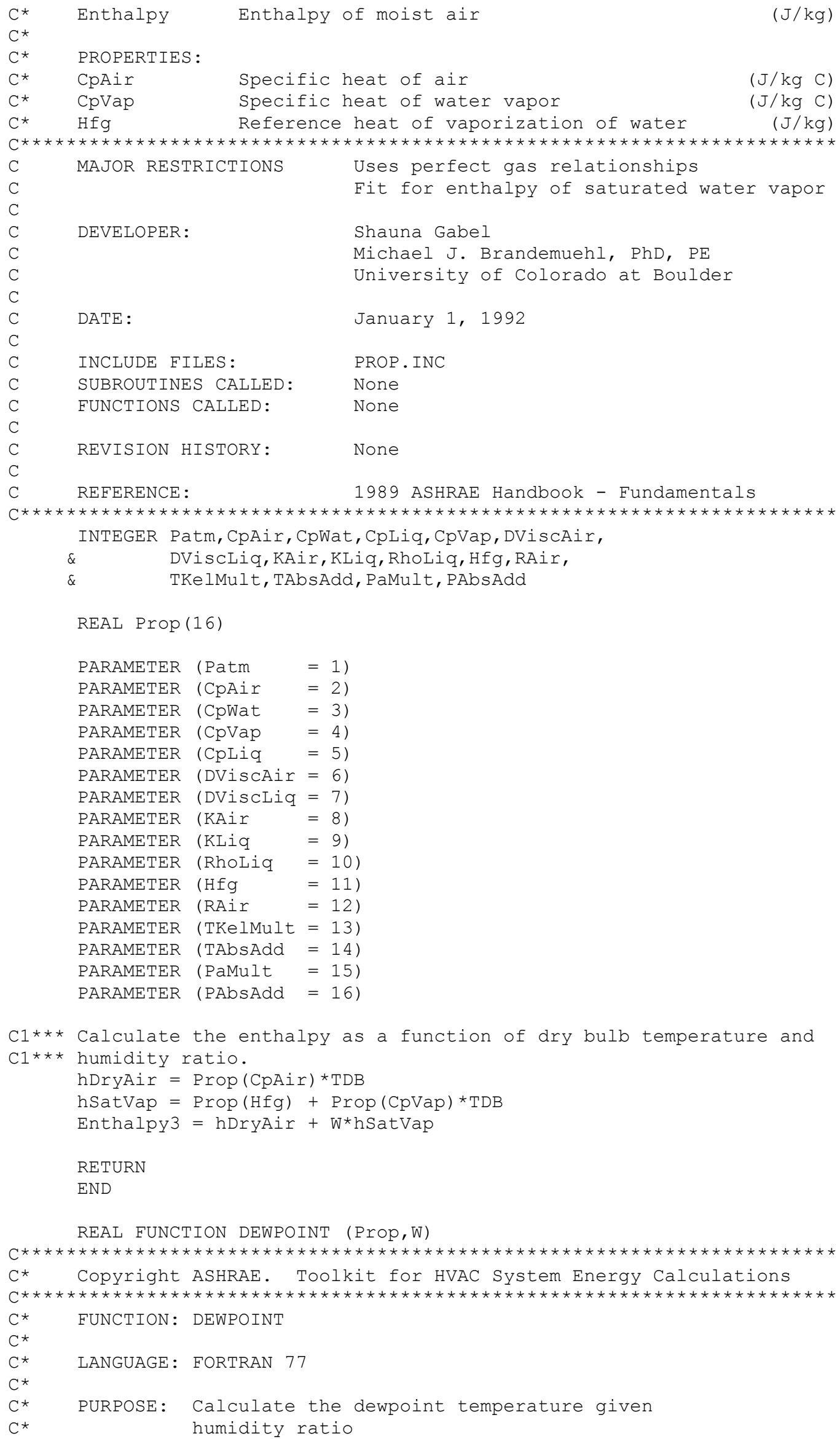




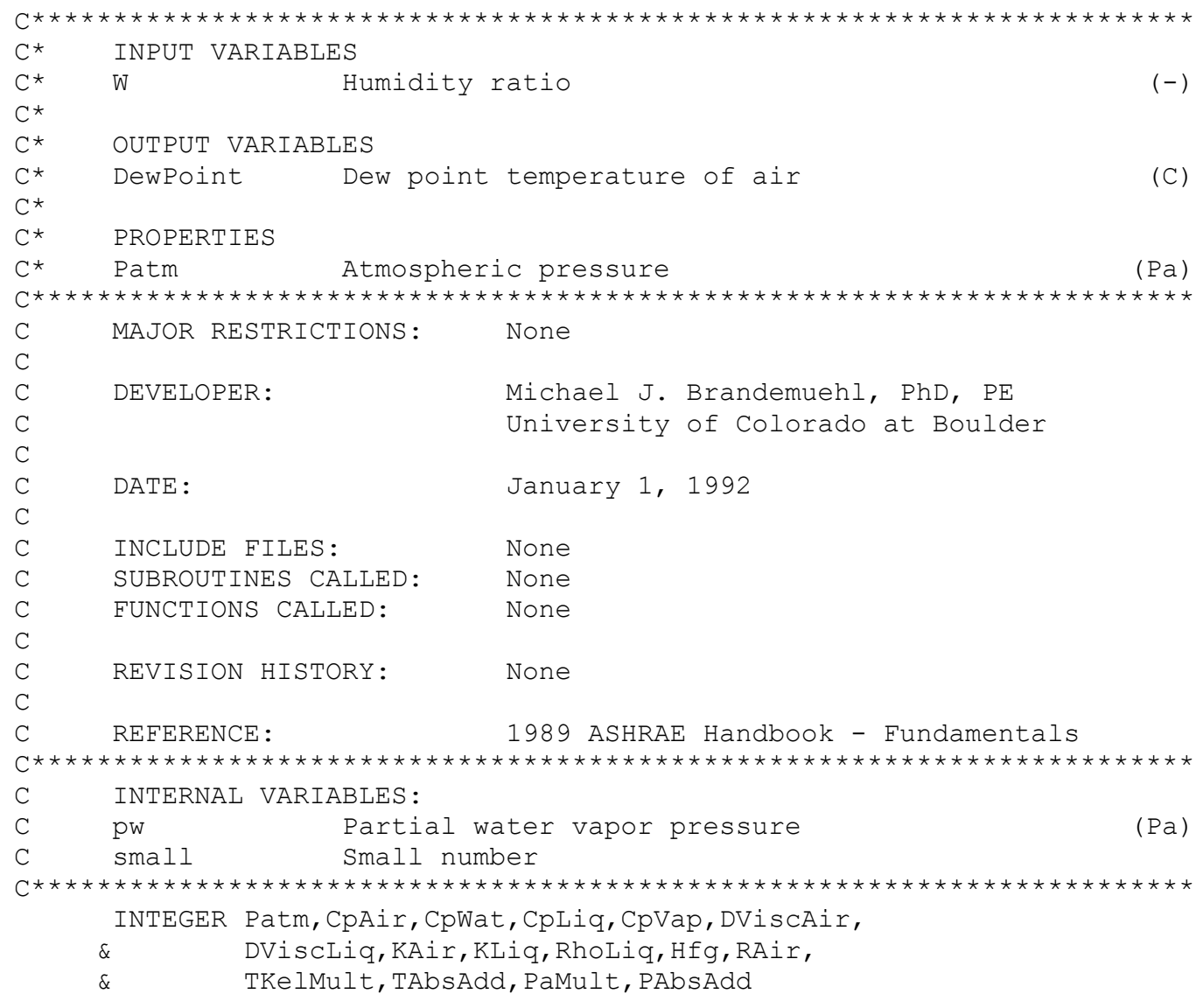

REAL Prop (16)

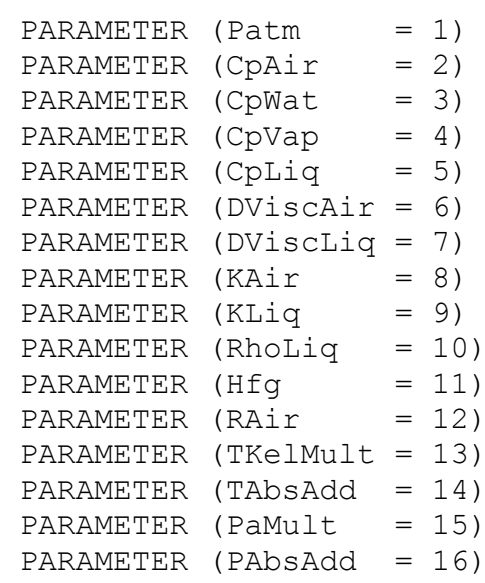

DATA small/1.E-9/

C1*** Test for "dry" air

IF (W.LT. Small) THEN

DewPoint $=-999$

ELSE

C1*** Calculate the partial water vapor pressure as a function of

$\mathrm{C} 1 * * *$ humidity ratio. $\mathrm{pw}=\operatorname{Prop}($ Patm $) * \mathrm{~W} /(.62198+\mathrm{W})$

C1*** Calculate dewpoint as saturation temperature at water vapor

C1*** partial pressure DewPoint $=$ SATTEMP (Prop, pw)

ENDIF 


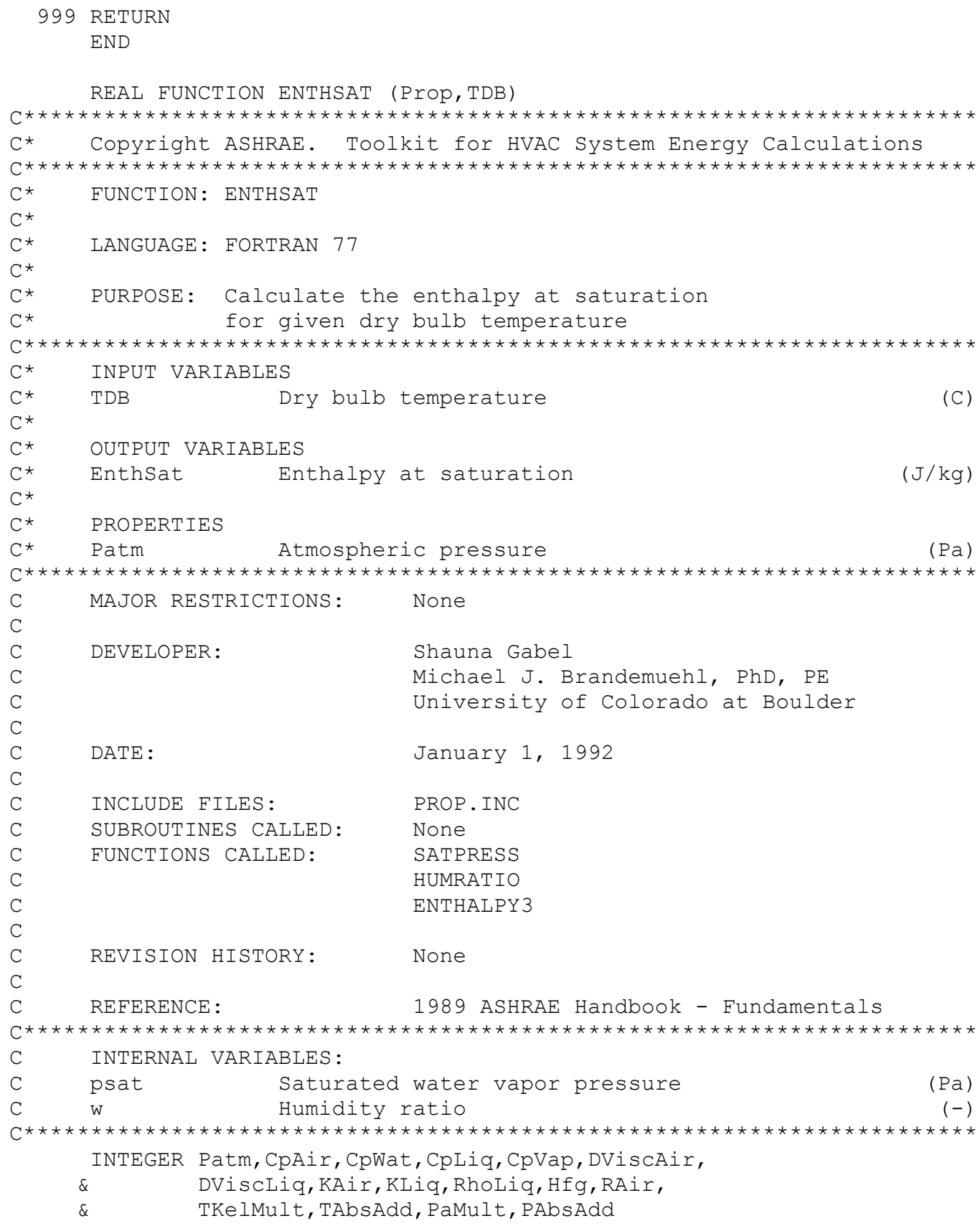




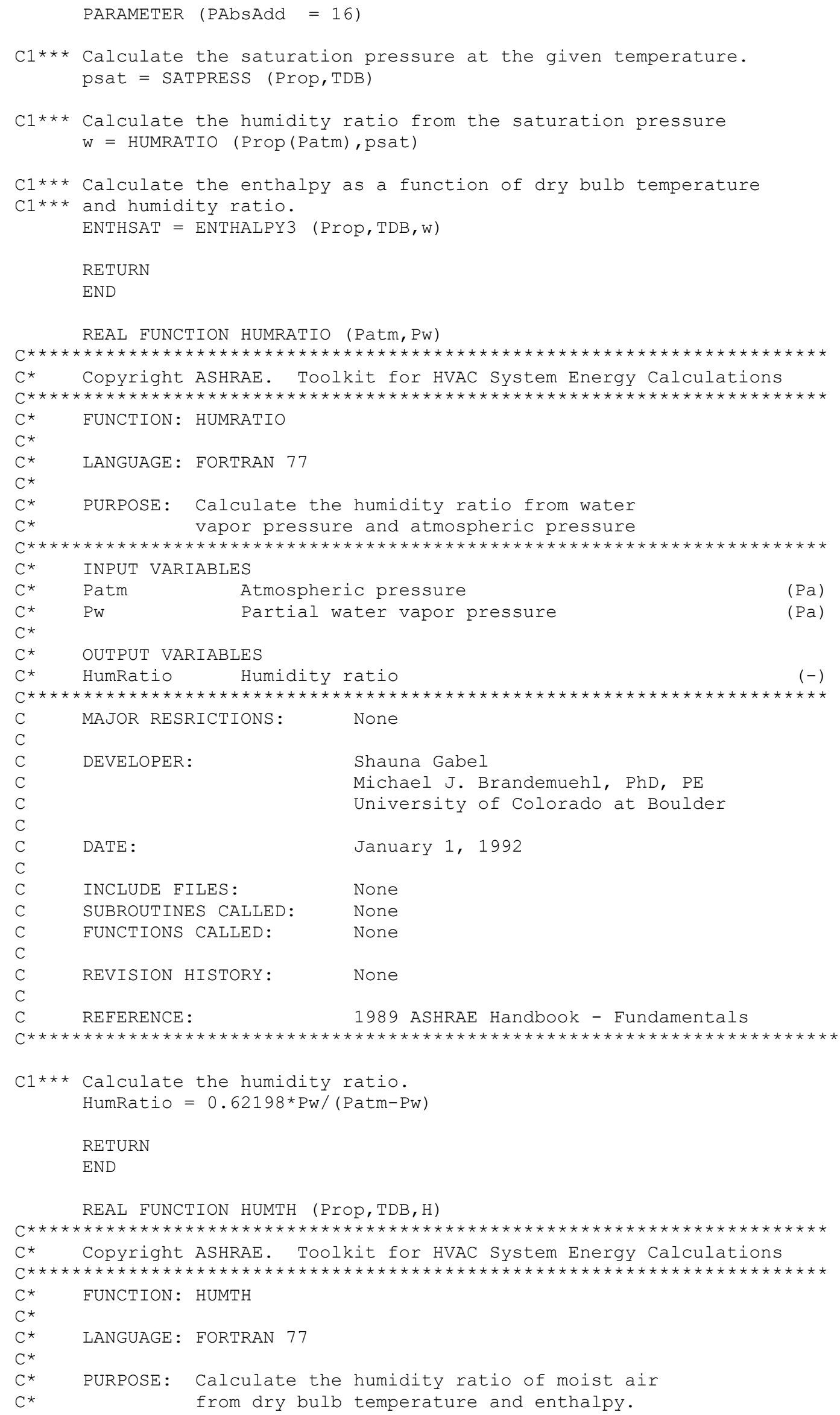




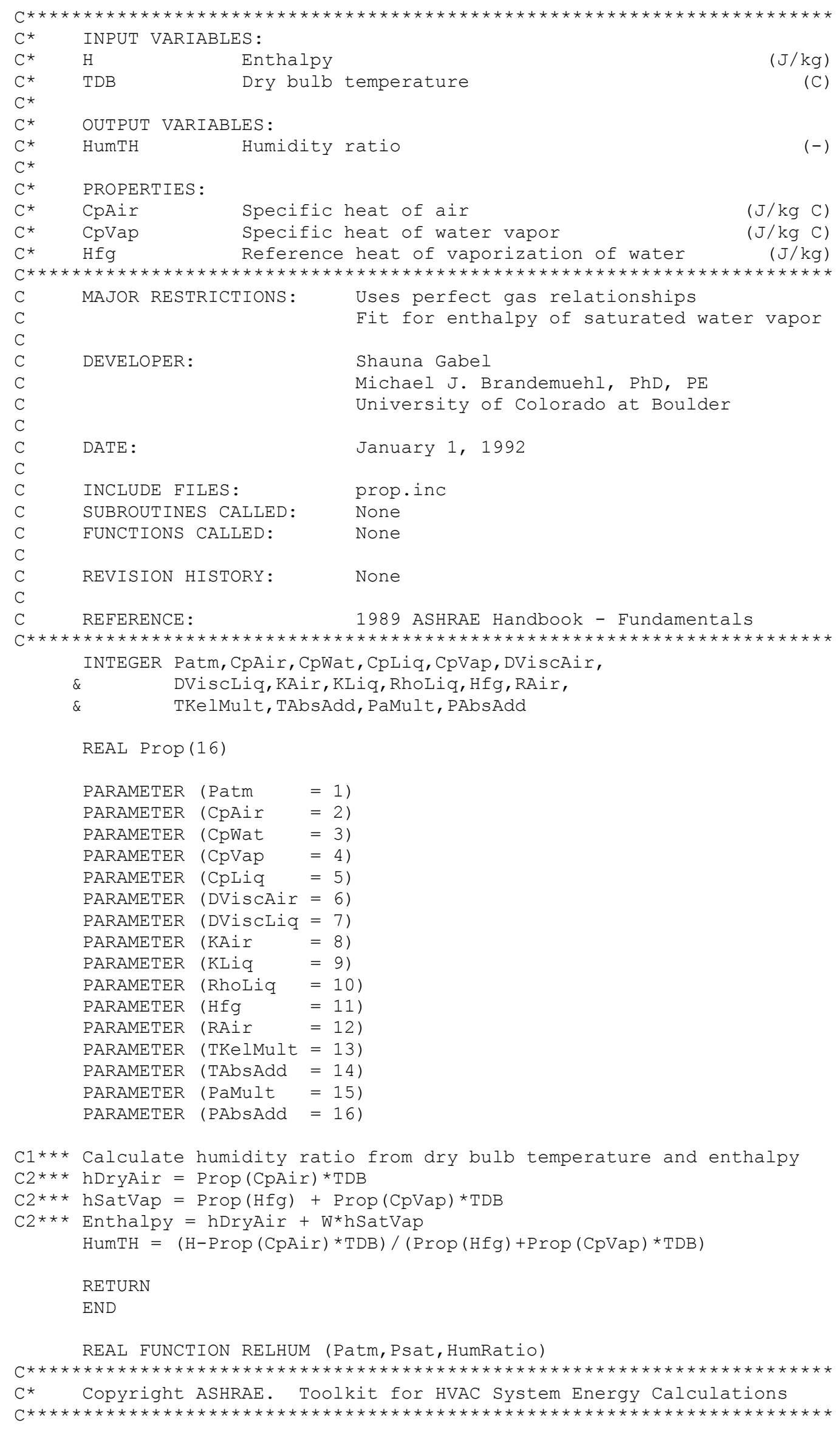




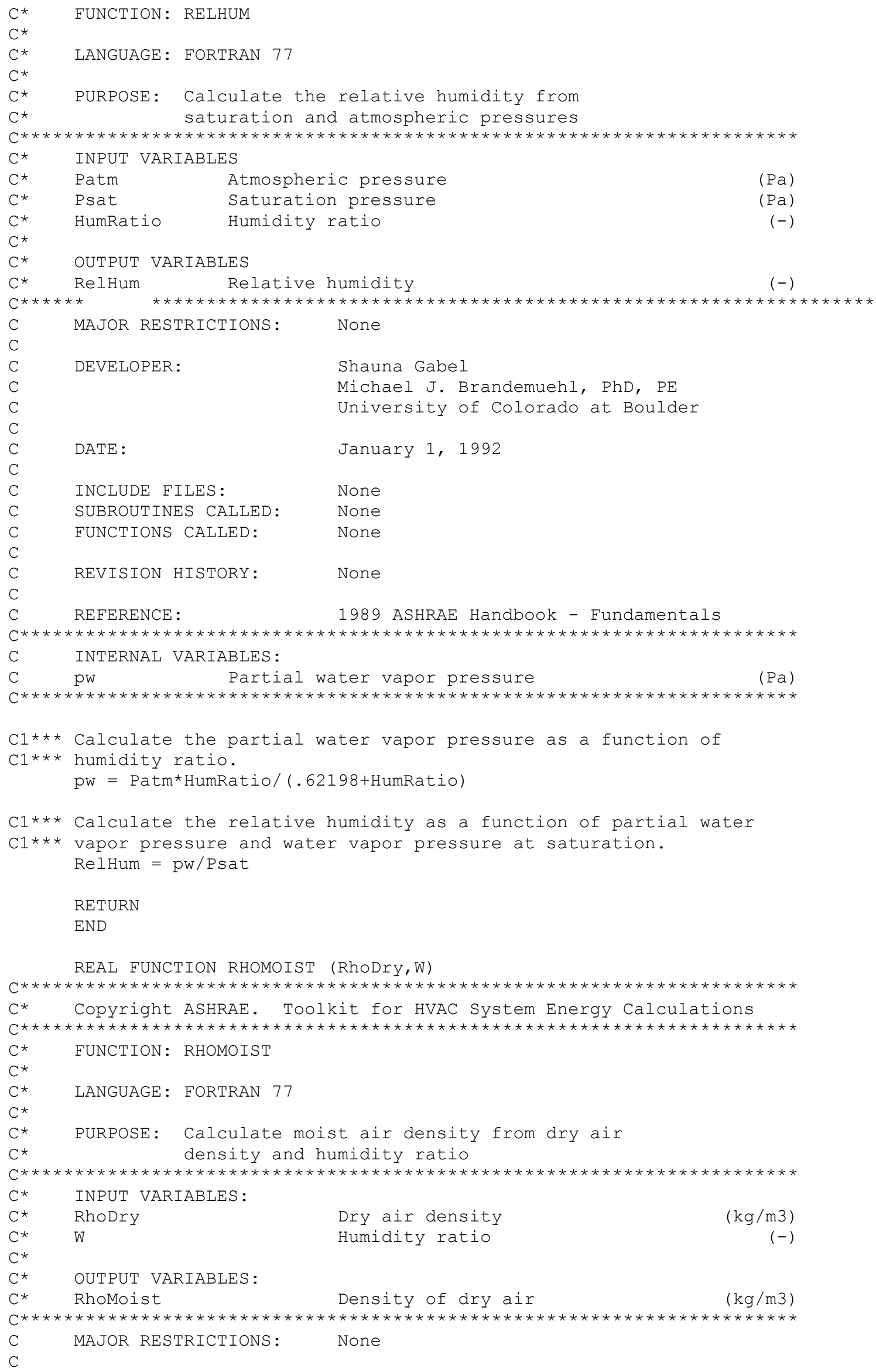




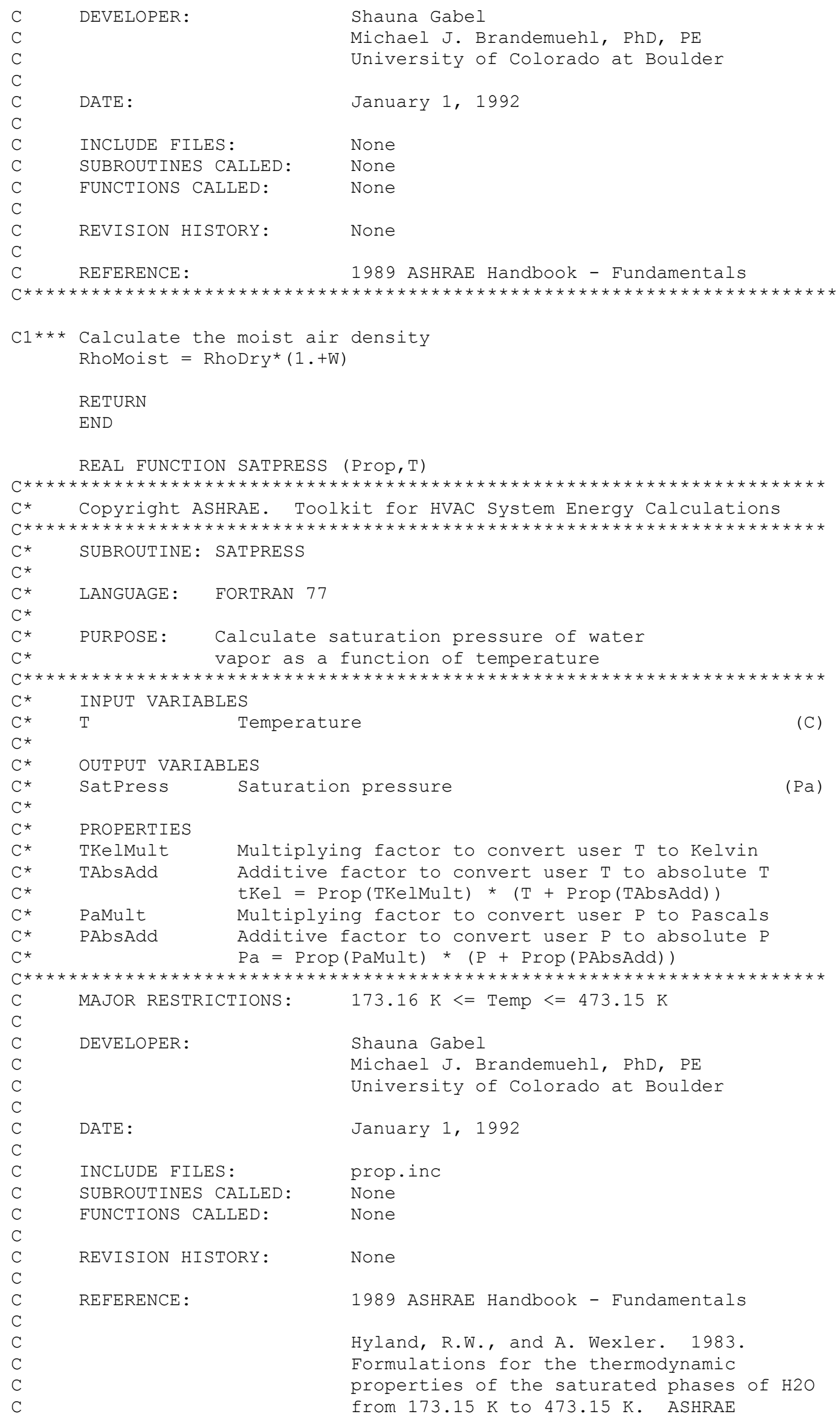




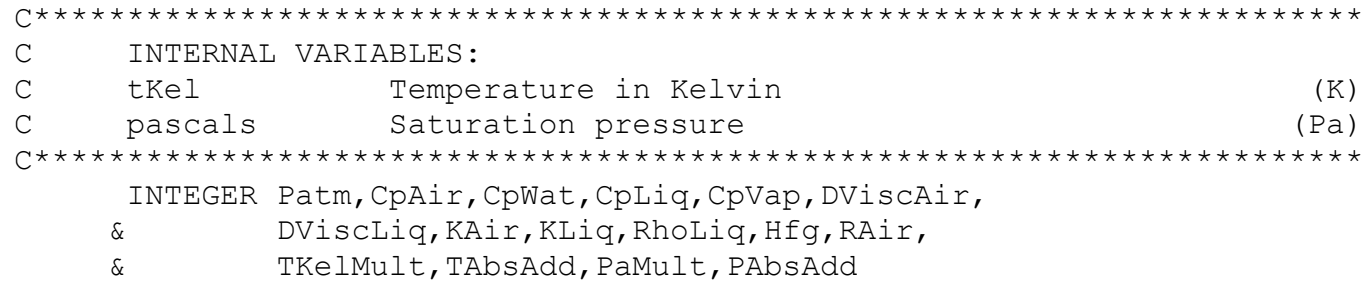




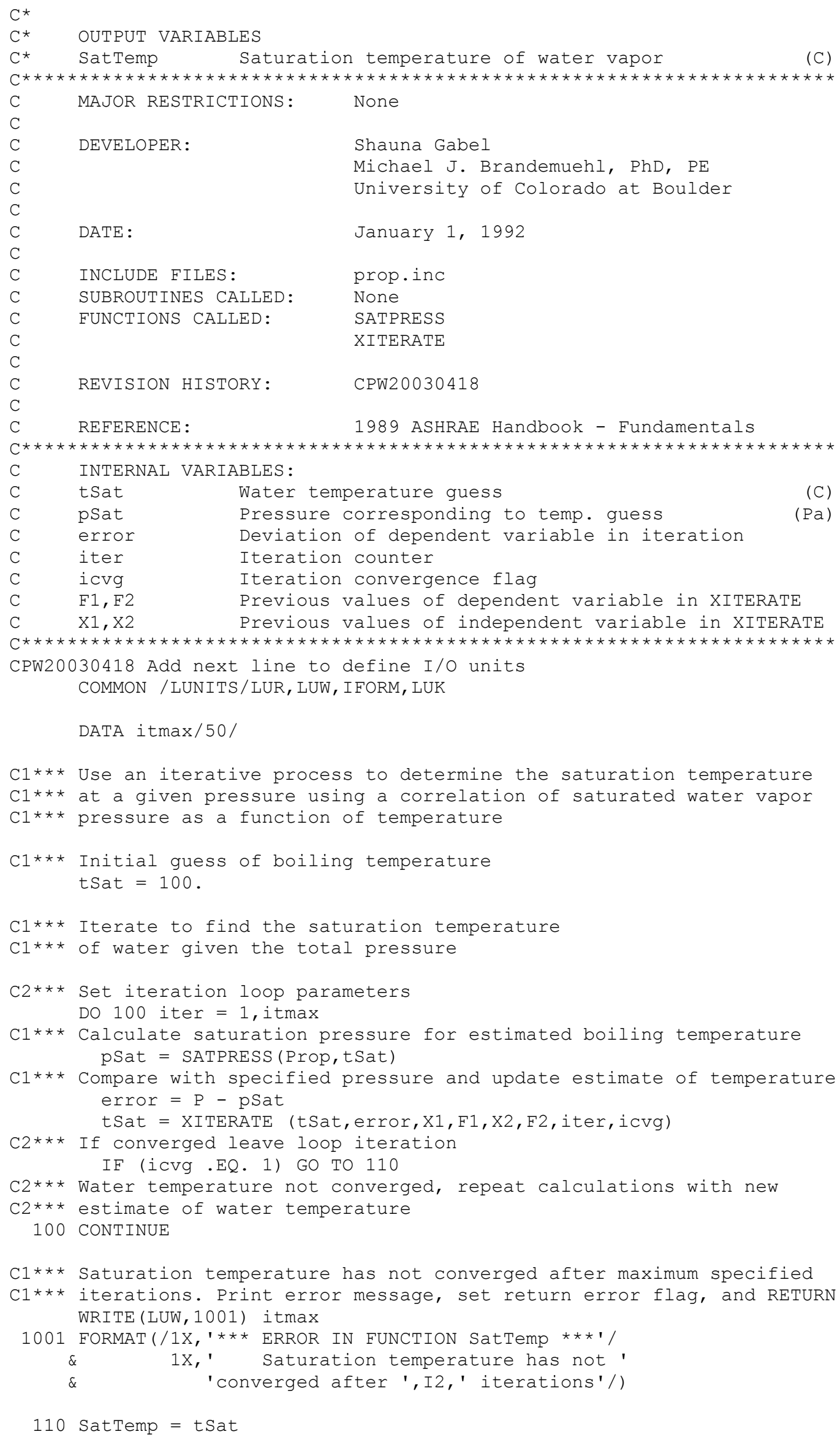




\section{RETURN}

END

REAL FUNCTION TAIRSAT (Prop, HSat)

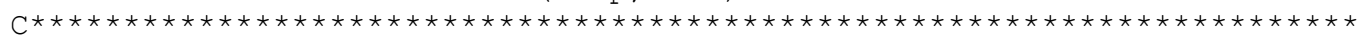

C* Copyright ASHRAE. Toolkit for HVAC System Energy Calculations

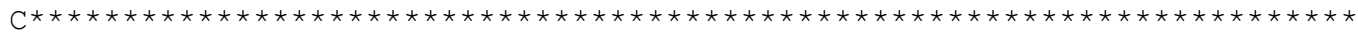

C* FUNCTION: ENTHSAT

$C^{*}$

C* LANGUAGE: FORTRAN 77

$C^{\star}$

$C^{*} \quad$ PURPOSE: Calculate the dry bulb temperature given

$C^{*} \quad$ enthalpy at saturation.

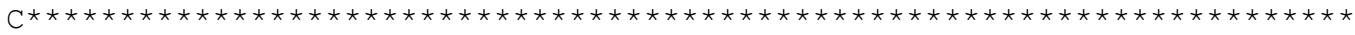

C* INPUT VARIABLES:

$\mathrm{C}^{*}$ HSat Enthalpy at saturation (J/kg)

$\mathrm{C}^{\star}$ OUTPUT VARTABIES:

C* TAirsat Dry bulb temperature (C)

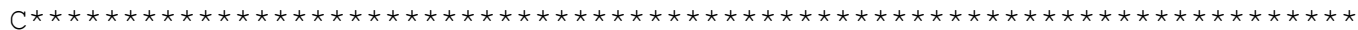

C MAJOR RESTRICTIONS: None

$\mathrm{C}$

$\mathrm{C}$

$\mathrm{C}$

C

$\mathrm{C}$

C

C

C

1989 ASTRAF Handbook - Fundamentals

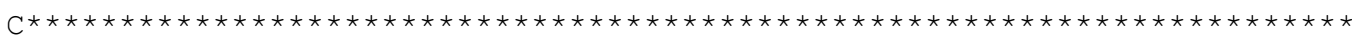

C INTERNAL VARIABLES:

C error Deviation of dependent variable in iteration

C iter Iteration counter

C icvg Iteration convergence flag

C F1,F2 Previous values of dependent variable in XITERATE

C $\mathrm{X} 1, \mathrm{x} 2 \quad$ Previous values of independent variable in XITERATE

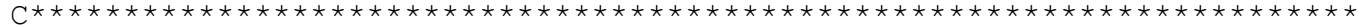

CPW20030418 Add next line to define I/O units COMMON /LUNITS/LUR, LUW, IFORM, LUK

DATA itmax/20/, tSat/50./

C1*** Estimate saturation temperature if reasonable value not available IF (tSat.LT. -200. .OR. tSat.GT. 1000.) tSat $=50$.

C1*** Calculate saturation temperature by iteration using function to

C1*** calculate saturation enthalpy from temperature Do 100 iter=1,itmax

error $=$ HSat - ENTHSAT (Prop, tSat)

tSat = XITERATE (tSat, error, X1, F1, X2,F2, iter, icvg)

C1*** If converged, leave iteration loop. IF (icvg .EQ. 1) GO TO 110

C1*** Temperature not converged, repeat calculation with new

C1*** estimate of temperature.

100 CONTINUE

C1*** Temperature has not converged after maximum specified

C1*** iterations. Print error message and RETURN WRITE (LUW, 1001) itmax 


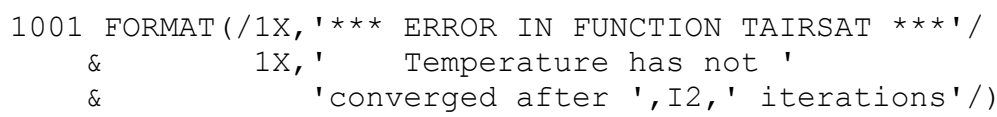

110 CONTINUE

TAirSat $=$ tSat

RETURN

END

REAL FUNCTION WETBULB (Prop, TDB,W)

\begin{tabular}{|c|c|c|c|}
\hline$C^{*}$ & \multirow{2}{*}{\multicolumn{3}{|c|}{ 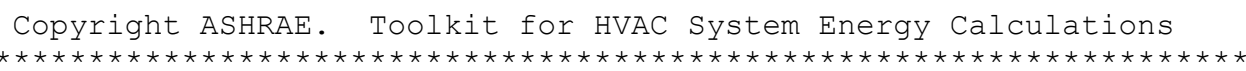 }} \\
\hline$C^{\star \star}$ & & & \\
\hline$C^{*}$ & \multirow{2}{*}{\multicolumn{3}{|c|}{ FUNCTION: WETBULB }} \\
\hline$C^{*}$ & & & \\
\hline$C^{*}$ & \multicolumn{3}{|c|}{ LANGUAGE: FORTRAN 77} \\
\hline$C^{\star}$ & & & \\
\hline $\mathrm{C}^{*}$ & \multirow[t]{2}{*}{ PURPOSE : } & \multirow{2}{*}{\multicolumn{2}{|c|}{$\begin{array}{l}\text { Calculate wet bulb temperature from dry } \\
\text { bulb temperature and humidity ratio }\end{array}$}} \\
\hline$C^{*}$ & & & \\
\hline \multicolumn{4}{|c|}{ 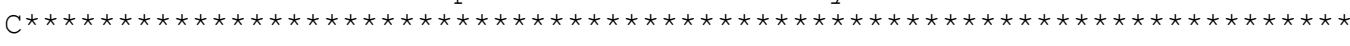 } \\
\hline$C^{*}$ & \multicolumn{3}{|c|}{ INPUT VARIABLES } \\
\hline$C^{*}$ & \multicolumn{2}{|r|}{ Dry bulb temperature } & (C) \\
\hline$C^{*}$ & \multirow{2}{*}{\multicolumn{2}{|c|}{ Humidity ratio of air }} & $(-)$ \\
\hline $\mathrm{C}^{*}$ & & & \\
\hline$C^{*}$ & \multicolumn{3}{|c|}{ OUTPUT VARIABLES } \\
\hline $\mathrm{C}^{*}$ & \multirow[t]{2}{*}{ WetBulb } & Wet bulb temperature & (C) \\
\hline $\mathrm{C}^{*}$ & & & \\
\hline$C^{*}$ & \multicolumn{2}{|c|}{ PROPERTIES: } & \\
\hline$C^{*}$ & \multicolumn{2}{|r|}{ Atmospheric pressure } & $(\mathrm{Pa})$ \\
\hline$C^{*}$ & \multirow{2}{*}{$\begin{array}{l}\text { Hfg } \\
\text { CpAir }\end{array}$} & Latent heat of vaporization of water & $(\mathrm{J} / \mathrm{kg})$ \\
\hline$C^{*}$ & & Specific heat of air & $(\mathrm{J} / \mathrm{kg} \quad \mathrm{C})$ \\
\hline $\mathrm{C}^{*}$ & CpVap & Specific heat of water vapor & $(\mathrm{J} / \mathrm{kg} \mathrm{C})$ \\
\hline$C^{*}$ & CpWat & Specific heat of water & $(\mathrm{J} / \mathrm{kg} \quad \mathrm{C})$ \\
\hline
\end{tabular}

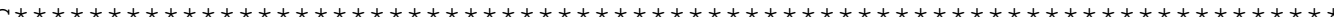

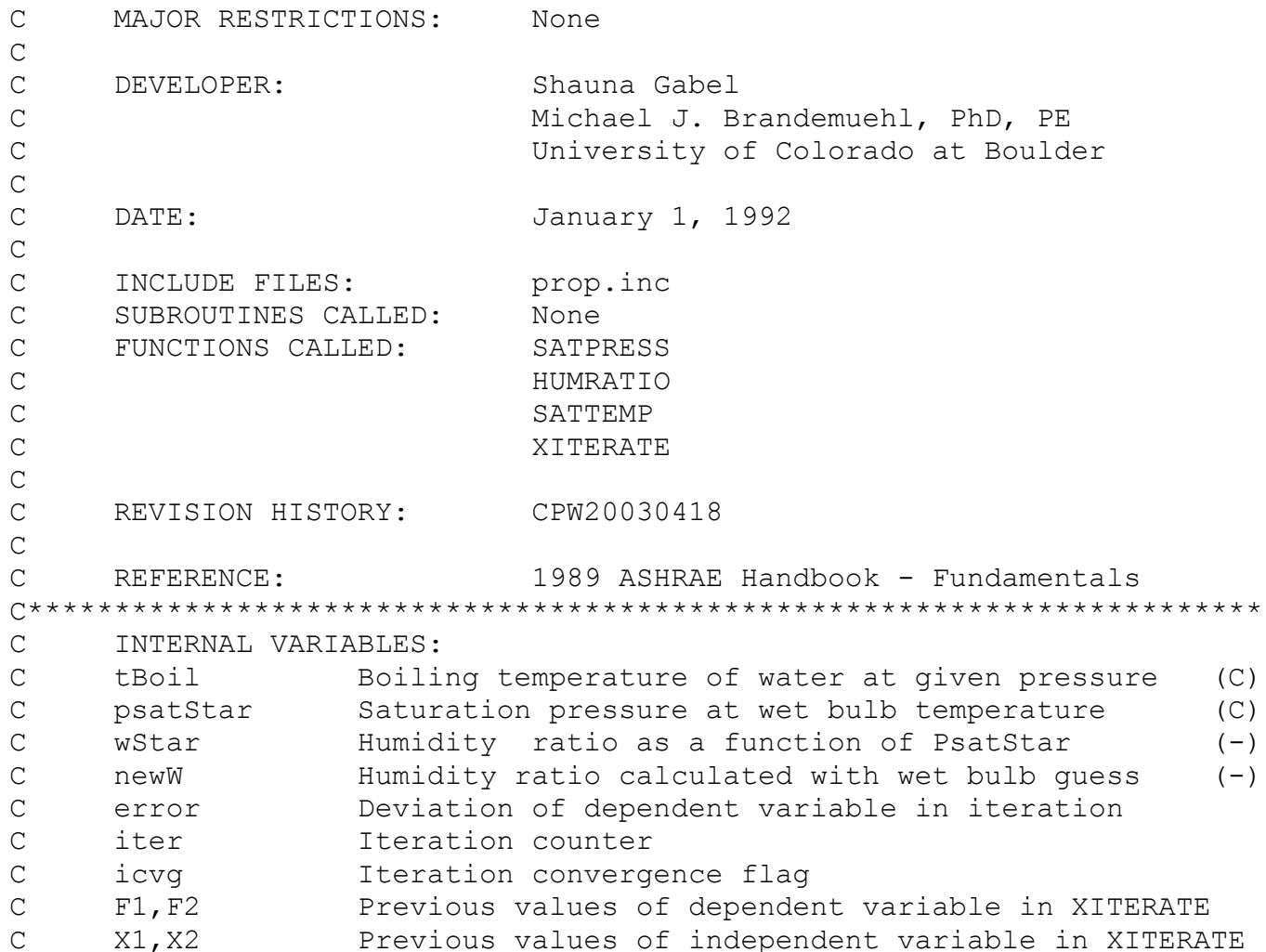




\begin{tabular}{|c|c|c|}
\hline INTEGER & \multirow{2}{*}{\multicolumn{2}{|c|}{ Patm, CpAir, CpWat, }} \\
\hline$\&$ & & \\
\hline$\&$ & \multicolumn{2}{|c|}{ TKelMult, TAbsAdd, } \\
\hline \multicolumn{3}{|c|}{ REAL Prop (16) } \\
\hline PARAMETE & (Patm & $=1)$ \\
\hline PARAMETE & (CpAir & $=21$ \\
\hline PARAMETE & (CpWat & $=31$ \\
\hline PARAMETE & (CpVap & $=4)$ \\
\hline PARAMETE & (CpLiq & $=5)$ \\
\hline PARAMETE & (DViscAir & $=6)$ \\
\hline PARAMETE & (DViscLiq & $=7)$ \\
\hline PARAMETE & (KAir & $=81$ \\
\hline PARAMETE & (KLiq & $=9)$ \\
\hline PARAMETE & (RhoLiq & $=10)$ \\
\hline PARAMETE & ( Hfg & $=11)$ \\
\hline PARAMETE & (RAir & $=12)$ \\
\hline PARAMETE & (TKelMult & $=13)$ \\
\hline PARAMETE & (TAbsAdd & $=14)$ \\
\hline PARAMETE & (PaMult & $=15)$ \\
\hline PARAMETE & (PAbsAdd & $=16)$ \\
\hline
\end{tabular}

REAL newW

CPW20030418 Add next line to define I/O units COMMON /LUNITS/LUR, LUW, IFORM, LUK

DATA itmax/20/

C1*** Initial temperature guess

tBoil = SATTEMP (Prop, Prop (Patm))

WetBulb = MAX ( MIN (WetBulb,TDB, (tBoil-0.1)), 0.)

C1*** Begin iteration loop

DO 100 iter $=1$, itmax

IF (WetBulb.GE. (tBoil-0.09) ) WETBULB = tBoil-0.1

C1*** Determine the saturation pressure for wet bulb temperature psatstar = SATPRESS (Prop, WetBulb)

C1*** Determine humidity ratio for given saturation pressure wStar = HUMRATIO (Prop (Patm), psatStar)

C1*** Calculate new humidity ratio and determine difference from known

C1*** humidity ratio

newW $=(($ Prop $($ Hfg $)-($ Prop $($ CpWat $)-\operatorname{Prop}($ CpVap $)) *$ WetBulb $) *$ WStar -

$\& \quad \operatorname{Prop}($ CpAir $) *($ TDB - WetBulb $)) /($ Prop $($ Hfg $)+\operatorname{Prop}($ CpVap $) * T D B$

$\& \quad-\operatorname{Prop}($ CpWat $) *$ WetBulb)

C1*** Check error, if not satisfied, calculate new guess and iterate error $=W$-newW

WetBulb = XITERATE (WetBulb, error, X1, F1, X2, F2, iter, icvg)

C1*** If converged, leave iteration loop.

IF (icvg .EQ. 1) GO TO 900

C1*** Wet bulb temperature not converged, repeat calculation with new

$\mathrm{C} 1 * * \star$ estimate of wet bulb temperature.

100 CONTINUE

C1*** Wet bulb temperature has not converged after maximum specified

C1*** iterations. Print error message, set return error flag, and RETURN WRITE (LUW, 1009) itmax

1009 FORMAT(/IX, '*** ERROR IN FUNCTION WetBulb $* * * 1 /$

\& 1X,' Wet bulb temperature has not '

\& 'converged after ',I2,' iterations'/)

900 IF (WetBulb.GT. TDB) WetBulb = TDB

999 RETURN 
END

REAL FUNCTION DRYBULB3 (Prop, H, W)

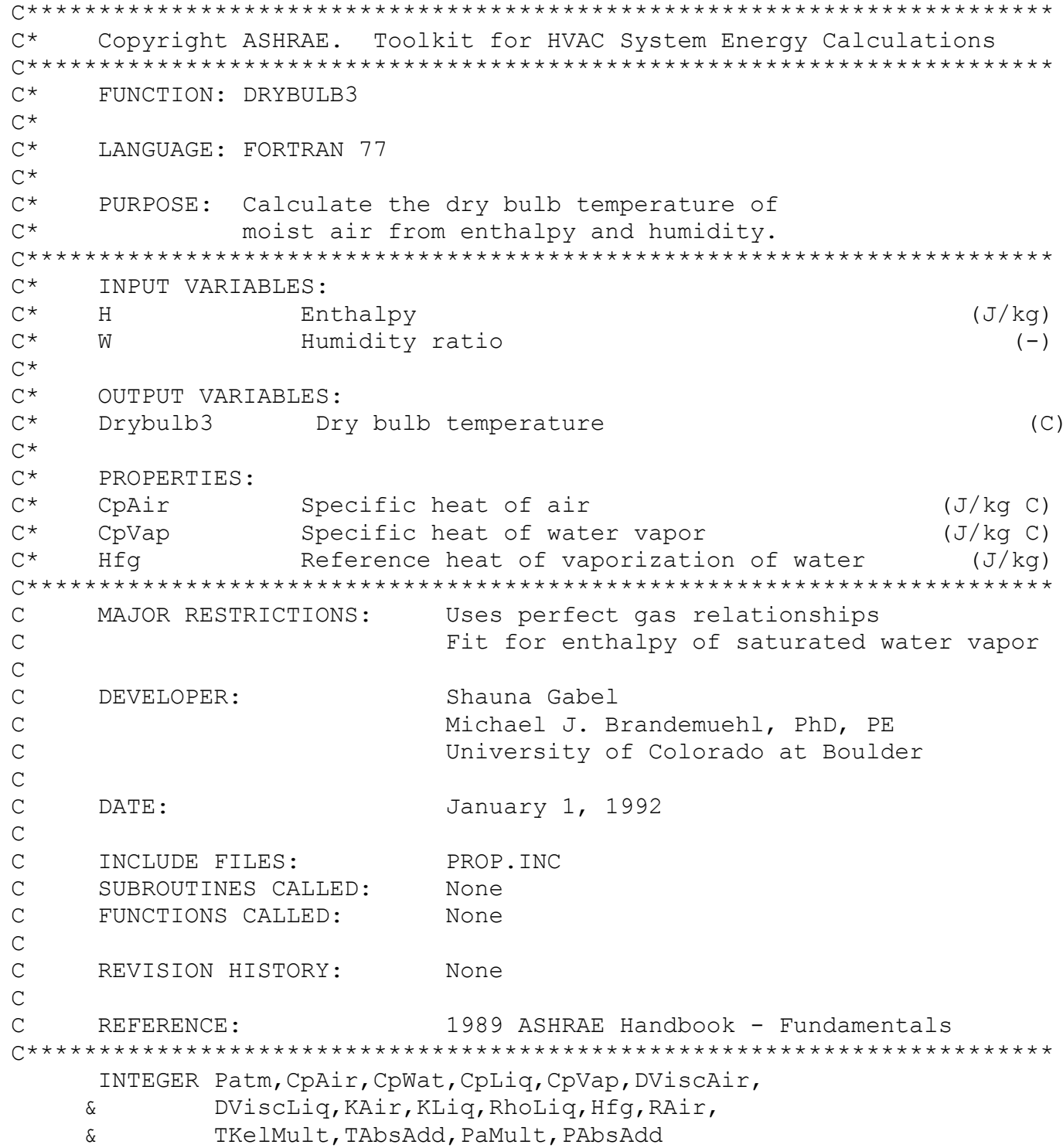




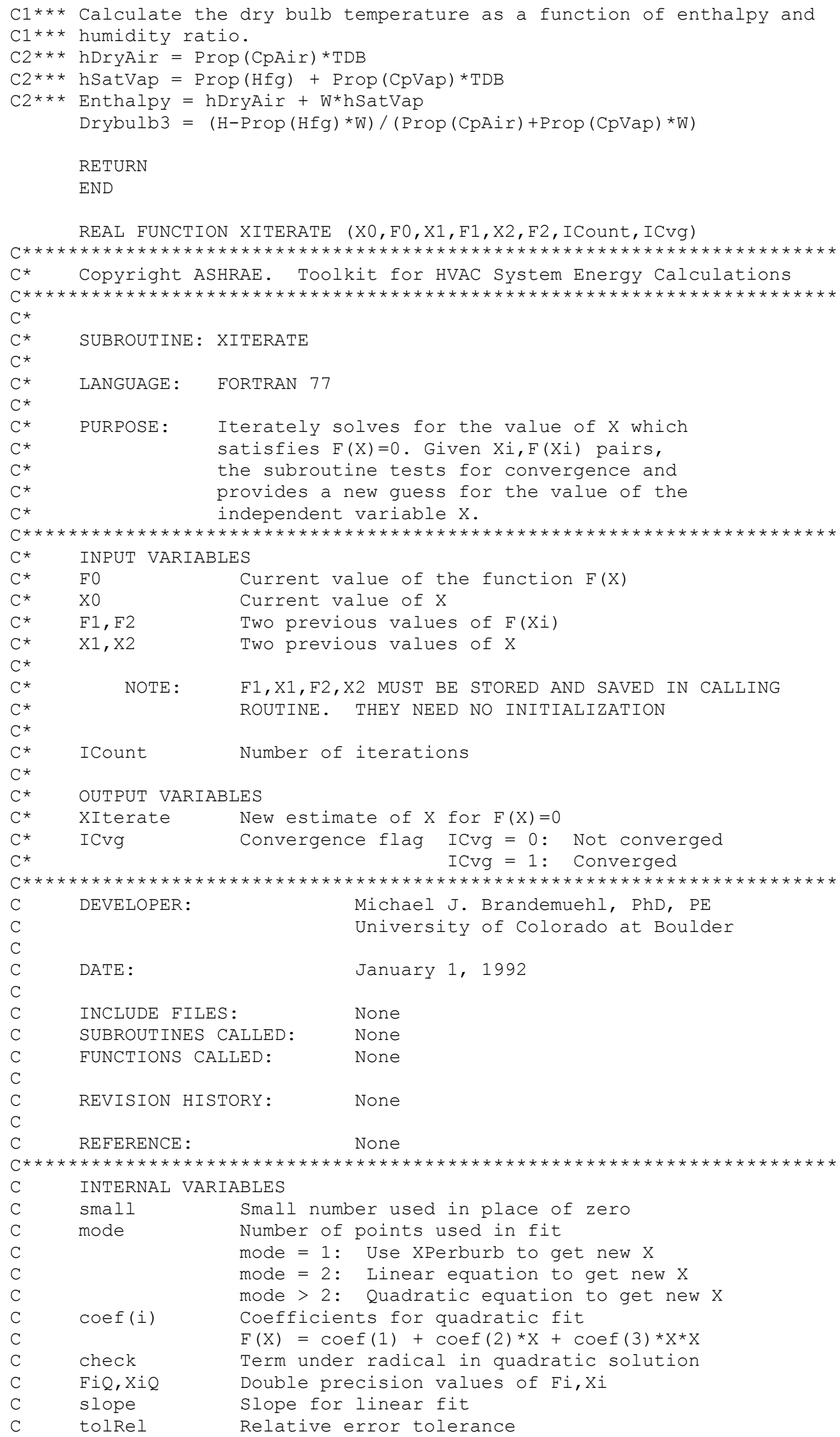




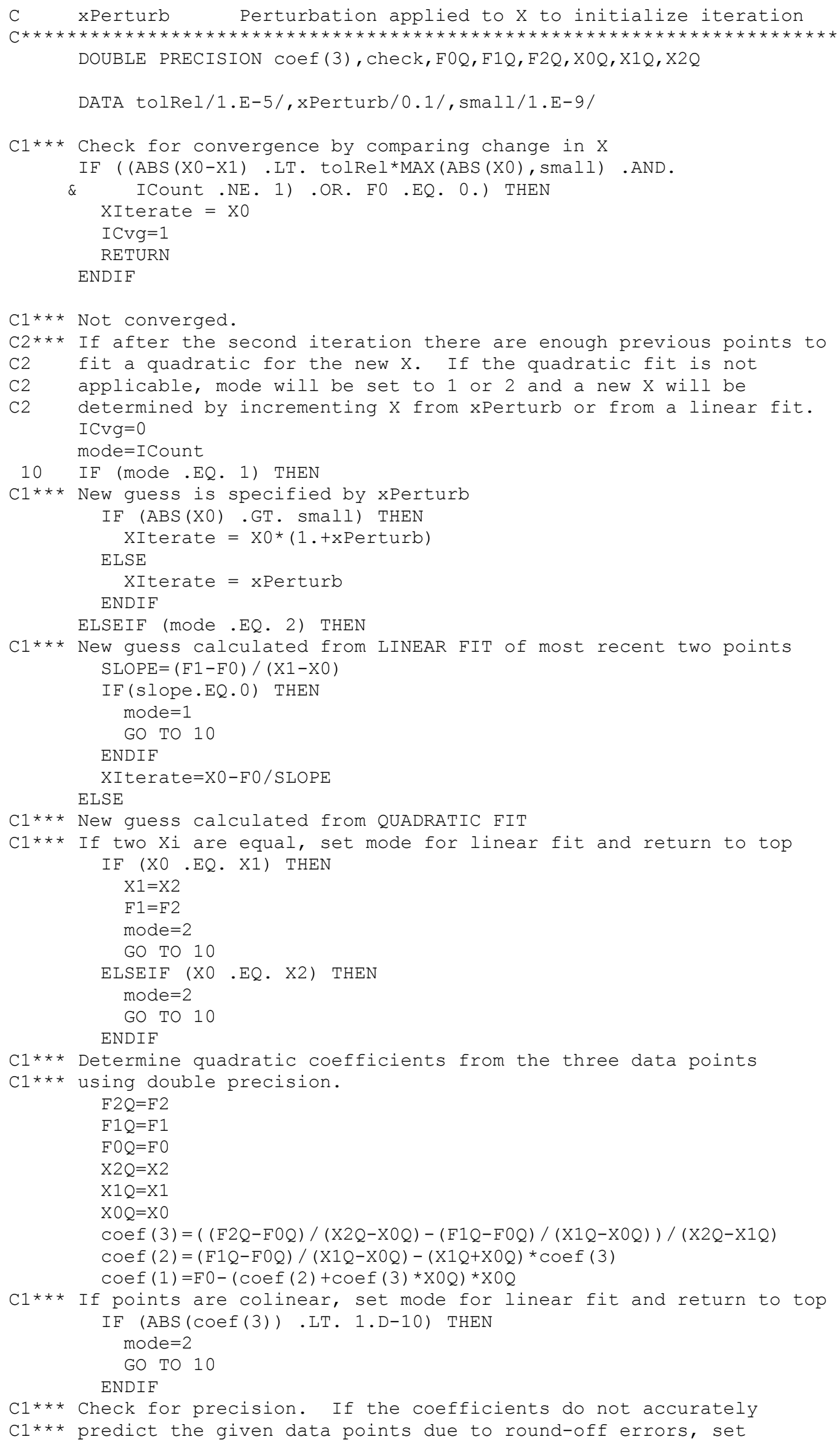




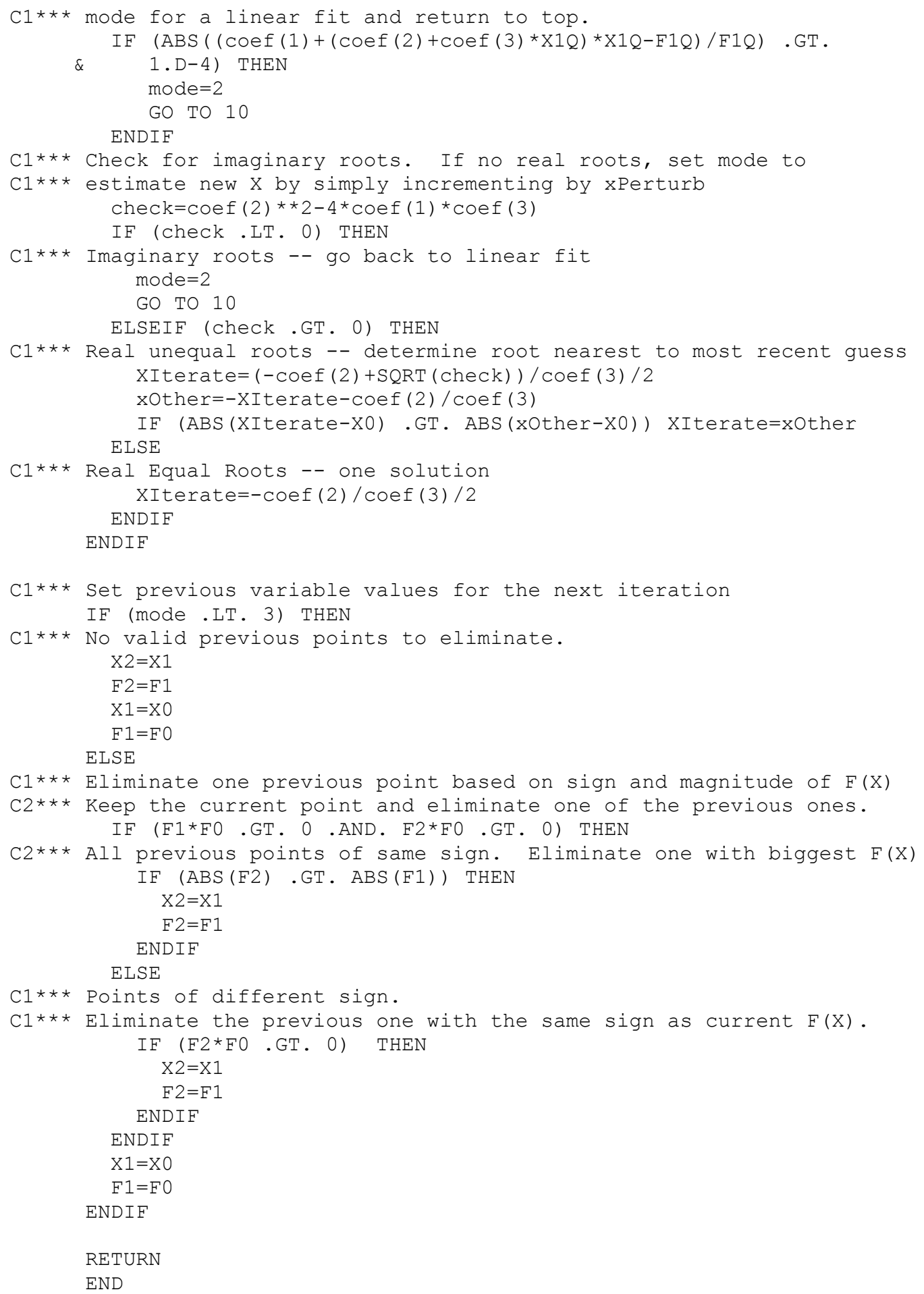




\section{Subroutine TYPE 77: Zone Return Air Mixing}

\section{SUBROUTINE AND FUNCTION CALL MAPPING}

Return Air Temp - Calculate the humidity ratio of the return air stream from zone latent loads

SUBROUTINE TYPE77 (TIME, XIN, OUT, T, DTDT, PAR, INFO, ICNTRL, *)

CALL TYPECK (IOPT, INFO, NI, NP, ND) -- subroutine in TRNWIN \Kernal typeck.for

CALL RCHECK (INFO, YCHECK, OCHECK) -- subroutine in TRNWIN \Kernal\rcheck. for

\section{SOURCE CODE}

SUBROUTINE TYPE77 (TIME, XIN, OUT, T, DTDT, PAR, INFO, ICNTRL, *)

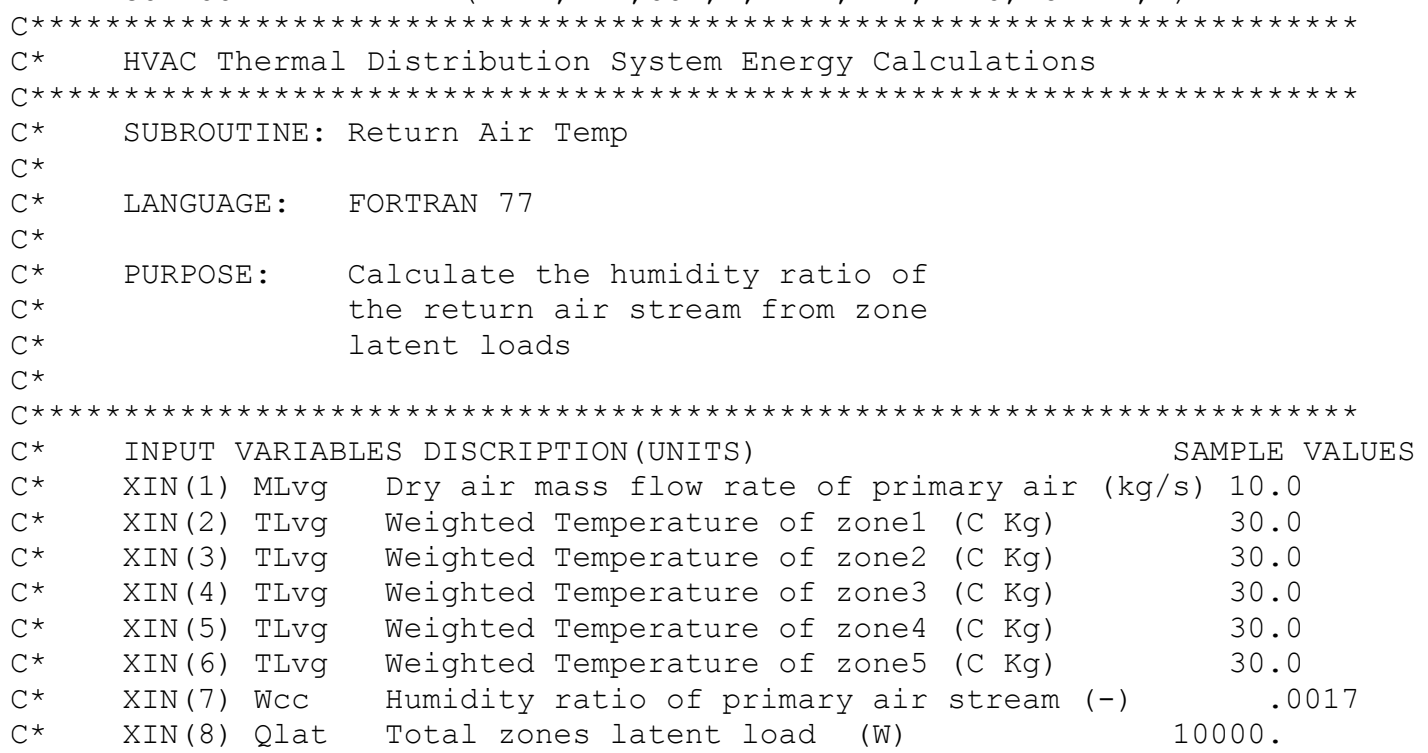

$C^{*}$ XIN(8) Qlat Total zones latent load (W) 10000.

C* OUTPUT VARIABLES

$C^{*} \quad$ OUT (1) MAirRet Dry air mass flow rate of return (kg/s) 3.65

C* OUT (2) TAirRet Temperature of zones (C) 11.7877

$C^{*}$ OUT (3) WAirRet Humidity ratio of return air stream (-) $\quad .00508950$

$\mathrm{C}^{*} \quad$ OUT (4) ErrStat Error flag (0=0k, l=error) (-) 0.0

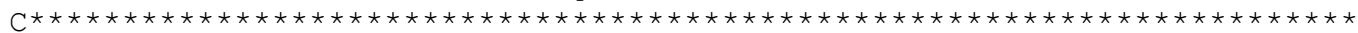

\begin{tabular}{|c|c|c|}
\hline 0 & MAJOR RESTRICTIONS: & None \\
\hline $\mathrm{C}$ & DEVELOPER: & Ellen Franconi \\
\hline $\mathrm{C}$ & & University of Colorado at Boulder \\
\hline $\mathrm{C}$ & & \\
\hline $\mathrm{C}$ & DATE : & November 1997 \\
\hline $\mathrm{C}$ & & \\
\hline $\mathrm{C}$ & INCLUDE FILES: & None \\
\hline $\mathrm{C}$ & SUBROUTINES REQUIRED: & None \\
\hline $\mathrm{C}$ & FUNCTIONS REQUIRED: & None \\
\hline $\mathrm{C}$ & & \\
\hline $\mathrm{C}$ & REVISION HISTORY: & None \\
\hline 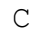 & & \\
\hline $\mathrm{C}$ & REFERENCE: & None \\
\hline & 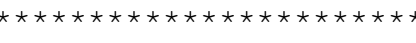 & 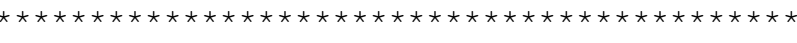 \\
\hline $\mathrm{C}$ & INTERNAL VARIABLES & \\
\hline $\mathrm{C}$ & none & \\
\hline & 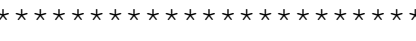 & 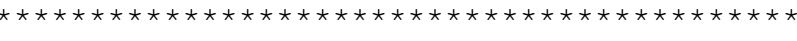 \\
\hline & DOUBLE PRECISION XIN, & $\mathrm{UT}$ \\
\hline
\end{tabular}

REAL MLVG, MAirRet, CPAIR, CPVAP, HFG

DIMENSION XIN (8), OUT (4), INFO (15) 


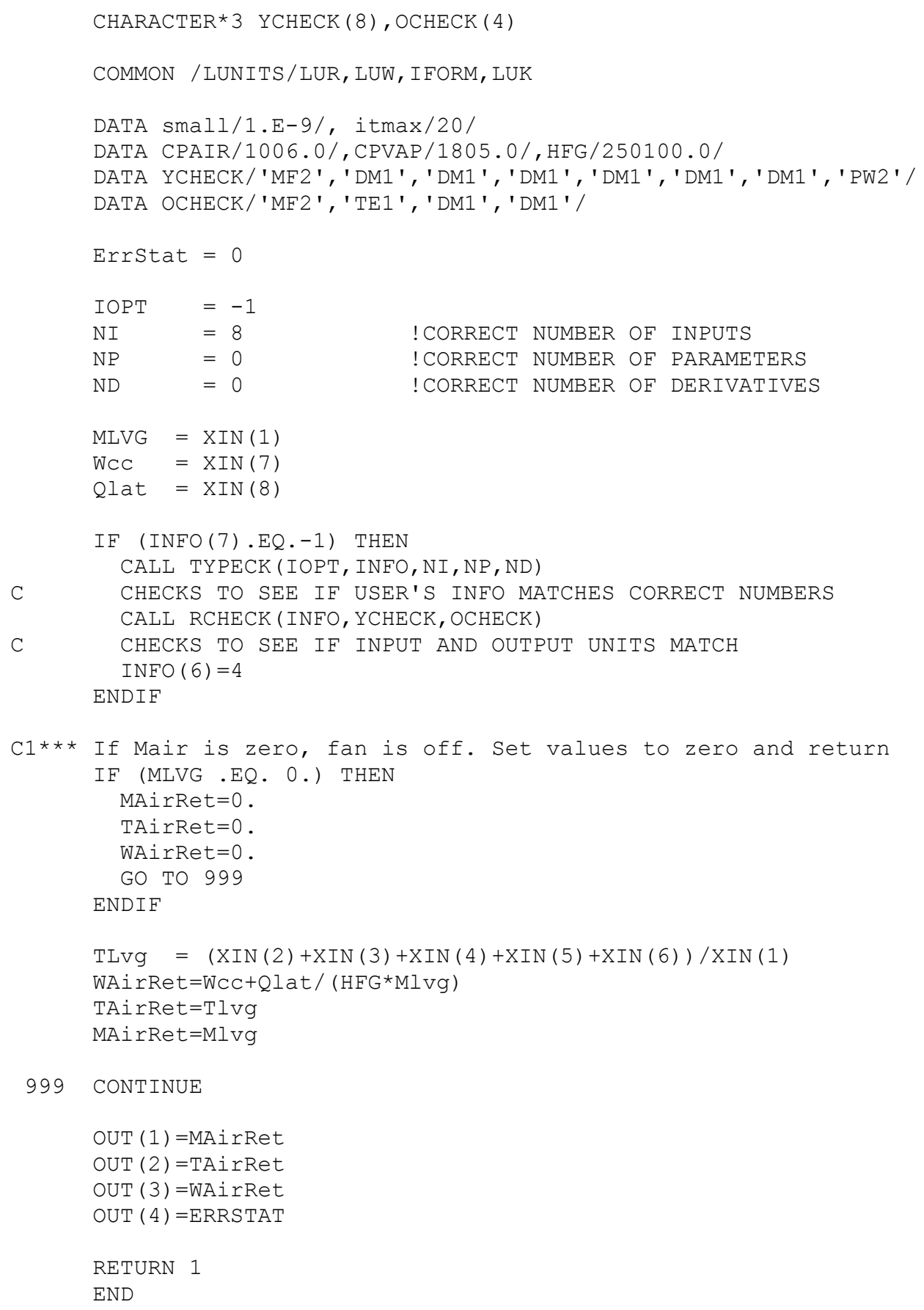




\section{Subroutine TYPE 80: Economizer}

\section{SUBROUTINE AND FUNCTION CALL MAPPING}

Model an outside air economizer controlled to mix outdoor and return air

$C^{*} \quad$ to a set mixed air temperature when

$C^{*} \quad$ the outside air conditions are beneficial

$C^{*} \quad$ for reducing cooling energy usage.

SUBROUTINE TYPE80 (TIME,XIN, OUT, T, DTDT, PAR, INFO, ICNTRL, *)

CALL TYPECK (IOPT, INFO, NI,NP,ND) -- subroutine in TRNWIN \Kernal typeck.for CALL RCHECK (INFO, YCHECK, OCHECK) -- subroutine in TRNWIN \Kernal \rcheck.for

CALL MIXOAIR (Prop,MAirAmb, TAirAmb, WAirAmb, MAirRet, TAirRet, -- subroutine

$\&$

$\&$

$\&$

$\&$

$\&$

$\&$

WAirRet, MAirMix, TAirMix, WAirMix, ErrStat)

S1 in type 80

CALL MIXIAIR (Prop, MAirMix, TSetMix, TAirAmb, WAirAmb, TAirRet, -- subroutine

s2 in type 80

WAirRet, MAirAmb, MAirRet, WAirMix, ErrStat)

CALL MIXOAIR (Prop, MAirAmb, TAirAmb, WAirAmb, MAirRet, TAirRet, -- subroutine

S1 in type 80

WAirRet, MAirMix, TAirMix, WAirMix, ErrStat)

hret $=$ ENTHALPY3 (Prop, TAirRet,WAirRet) -- function F2 in type 75

hmix = ENTHALPY3 (Prop, TAirMix, WAirMix) -- function F2 in type 75

hoa = ENTHALPY3 (Prop, TAirAmb, WAirAmb) -- function F2 in type 75

S1 SUBROUTINE MIXOAIR (Prop, M1Ent, T1Ent, W1Ent, M2Ent, T2Ent, w2Ent, MLvg, TLvg, WLvg, ErrStat)

Calculate the leaving temperature, humidity ratio and mass flow rate of two mixed air streams by simple conservation.

h1Ent = ENTHALPY3 (Prop, T1Ent,W1Ent) -- function F2 in type 75

h2Ent = ENTHALPY3(Prop, T2Ent,W2Ent) -- function F2 in type 75

TLVg = DRYBULB3 (Prop, hLvg, WLVg) -- function F13 in type 75

S2 SUBROUTINE MIXIAIR (Prop, MLvg, TLvg, T1Ent,w1Ent, T2Ent, w2Ent, M1Ent, M2Ent, WLvg, ErrStat)

Calculate the mass flow rate of two entering air streams of a mixing box with a known leaving mass flow rate and the temperatures of all the streams.

CALL MIXOAIR (PROP, M1Ent, T1Ent, W1Ent, M2Ent, T2Ent,W2Ent, -- subroutine S1

mEst, TLvg, WLvg, ErrStat)

M1Ent = XITERATE (M1Ent, error, X1, F1, X2, F2, iter,icvg) -- function F14 in type 75

\begin{tabular}{|c|c|c|}
\hline $1 \mathrm{PROP}(\mathrm{PATM})$ & 101325.0 & Atmospheric pressure ( $\mathrm{Pa})$ \\
\hline $2 \mathrm{PROP}(\mathrm{CPAIR})$ & 1006.0 & Specific heat of dry air (J/kg C) \\
\hline $3 \mathrm{PROP}(\mathrm{CPWAT})$ & 4186.0 & Specific heat of liquid water ( J/kg C) \\
\hline $4 \mathrm{PROP}(\mathrm{CPVAP})$ & 1805.0 & $\begin{array}{l}\text { Specific heat of saturated water } \\
\text { vapor }(\mathrm{J} / \mathrm{kg} \mathrm{C})\end{array}$ \\
\hline 5 PROP (CPLIQ) & 4186.0 & \\
\hline 6 PROP (DVISCAIR) & .0000182 & Air dynamic viscosity $(\mathrm{kg} / \mathrm{m} \mathrm{s})$ \\
\hline 7 PROP (DVISCLIQ) & .00144 & Liquid dynamic viscosity $(\mathrm{kg} / \mathrm{m} \mathrm{s})$ \\
\hline $8 \mathrm{PROP}(\mathrm{KAIR})$ & .026 & Air thermal conductivity (W/m C) \\
\hline PROP (KLIQ) & .604 & Liquid thermal conductivity (W/m C) \\
\hline PROP (RHOLIQ) & 998.0 & Liquid density $(\mathrm{kg} / \mathrm{m} 3)$ \\
\hline PROP ( HFG) & $=2501000.0$ & Latent heat of vaporization of water ( $/ \mathrm{kg})$ \\
\hline PROP (RAIR) & 287.055 & Gas constant for air ( $/ \mathrm{kg} \mathrm{C})$ \\
\hline PROP ( TKELMULT) & 1.0 & $\begin{array}{l}\text { Multiplying factor to convert user } \\
\mathrm{T} \text { to Kelvin }\end{array}$ \\
\hline PROP (TABSADD) & 273.15 & $\begin{array}{l}\text { Additive factor to convert user } \mathrm{P} \text { to Kelvin: } \\
\text { tKel }=\text { Prop (TKelMult)*T }+ \text { Prop (TKelAdd) }\end{array}$ \\
\hline PROP ( PAMULT) & 1.0 & $\begin{array}{l}\text { Multiplying factor to convert user } \mathrm{P} \text { to } \\
\text { Pascals }\end{array}$ \\
\hline PROP (PABSADD) & 0.0 & $\begin{array}{l}\text { Additive factor to convert user } \mathrm{P} \text { to Pascals: } \\
\mathrm{Pa}=\operatorname{Prop}(\mathrm{PaMult}) * \mathrm{P}+\operatorname{Prop}(\mathrm{PaAdd})\end{array}$ \\
\hline
\end{tabular}




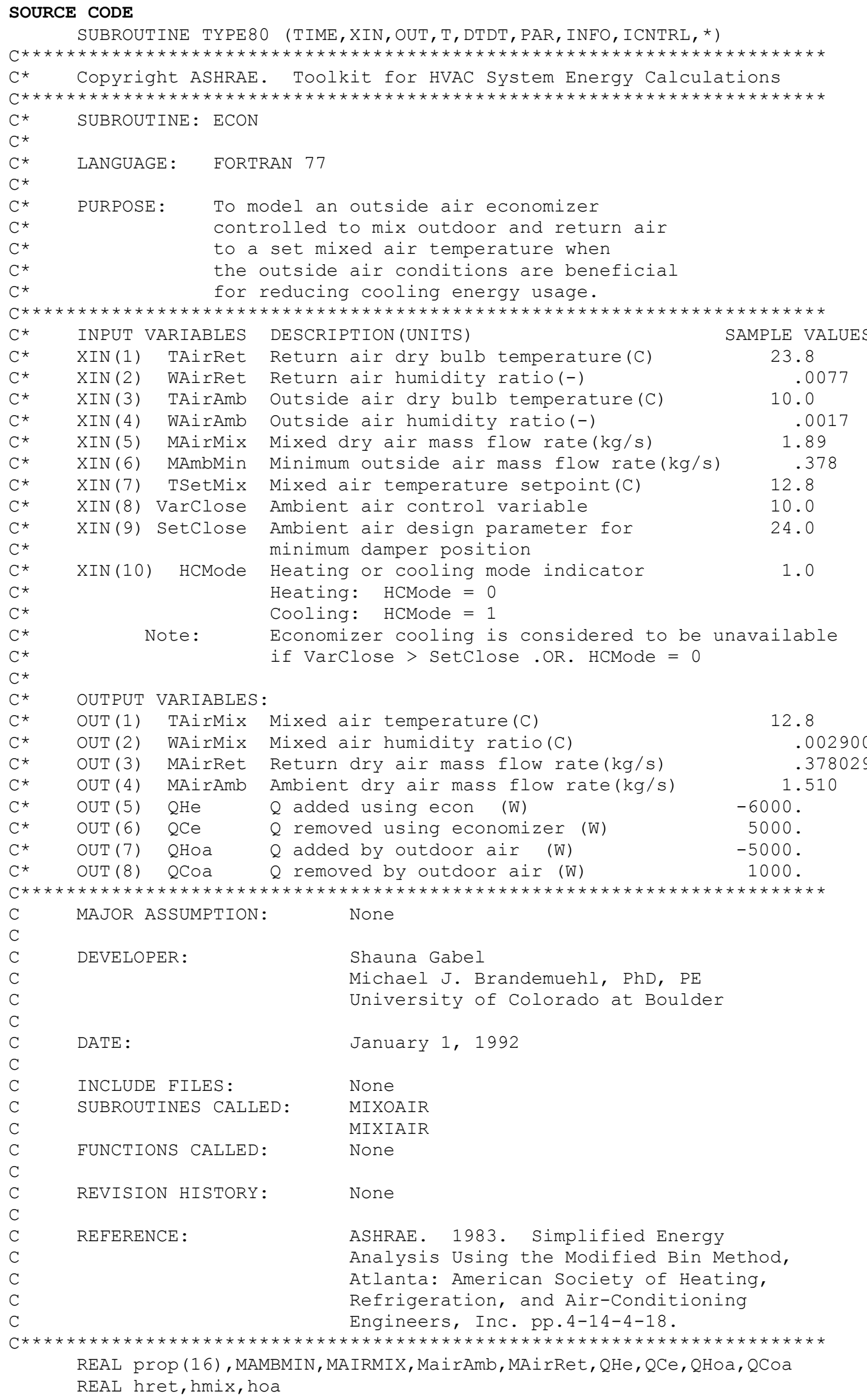




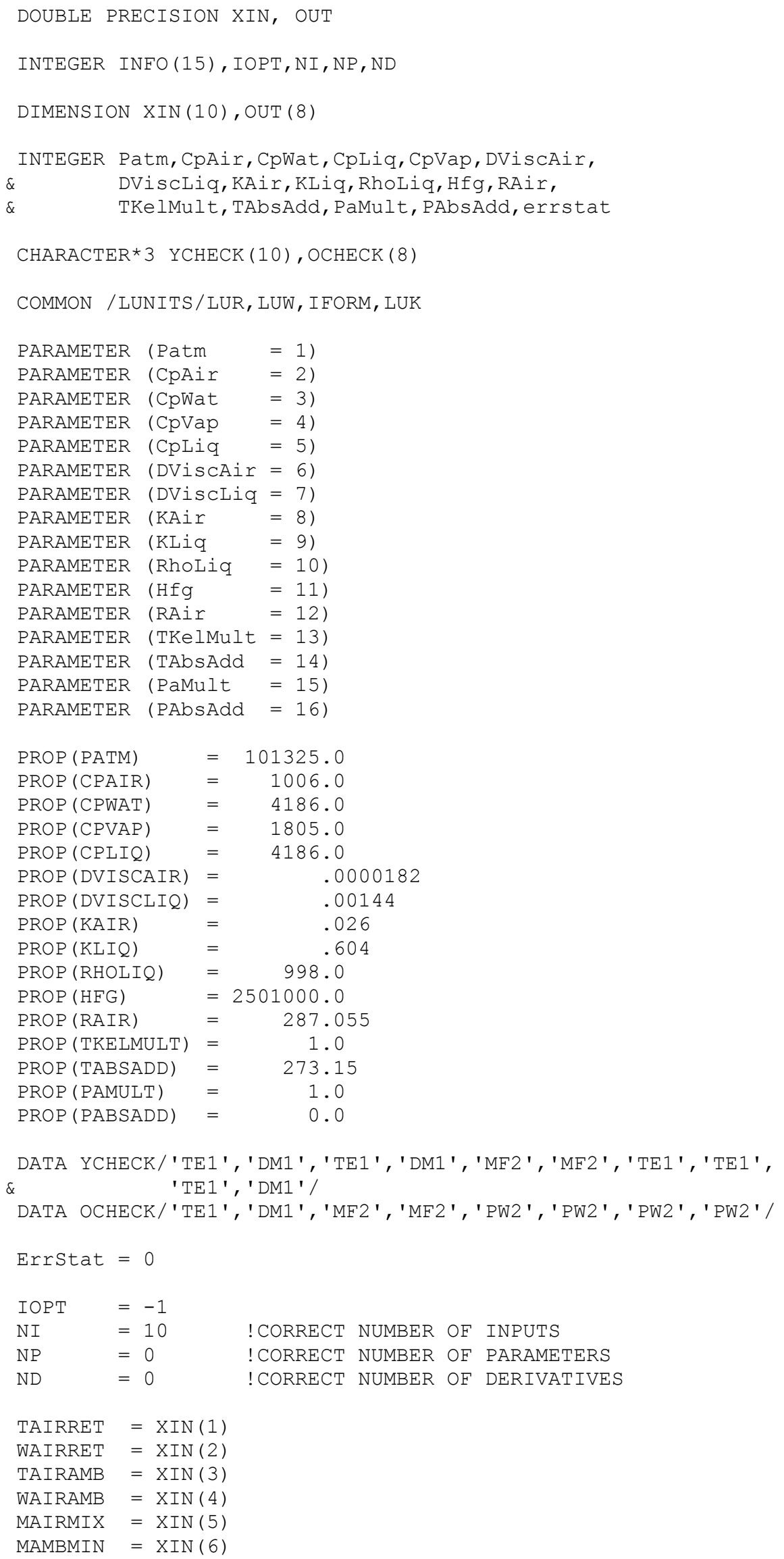




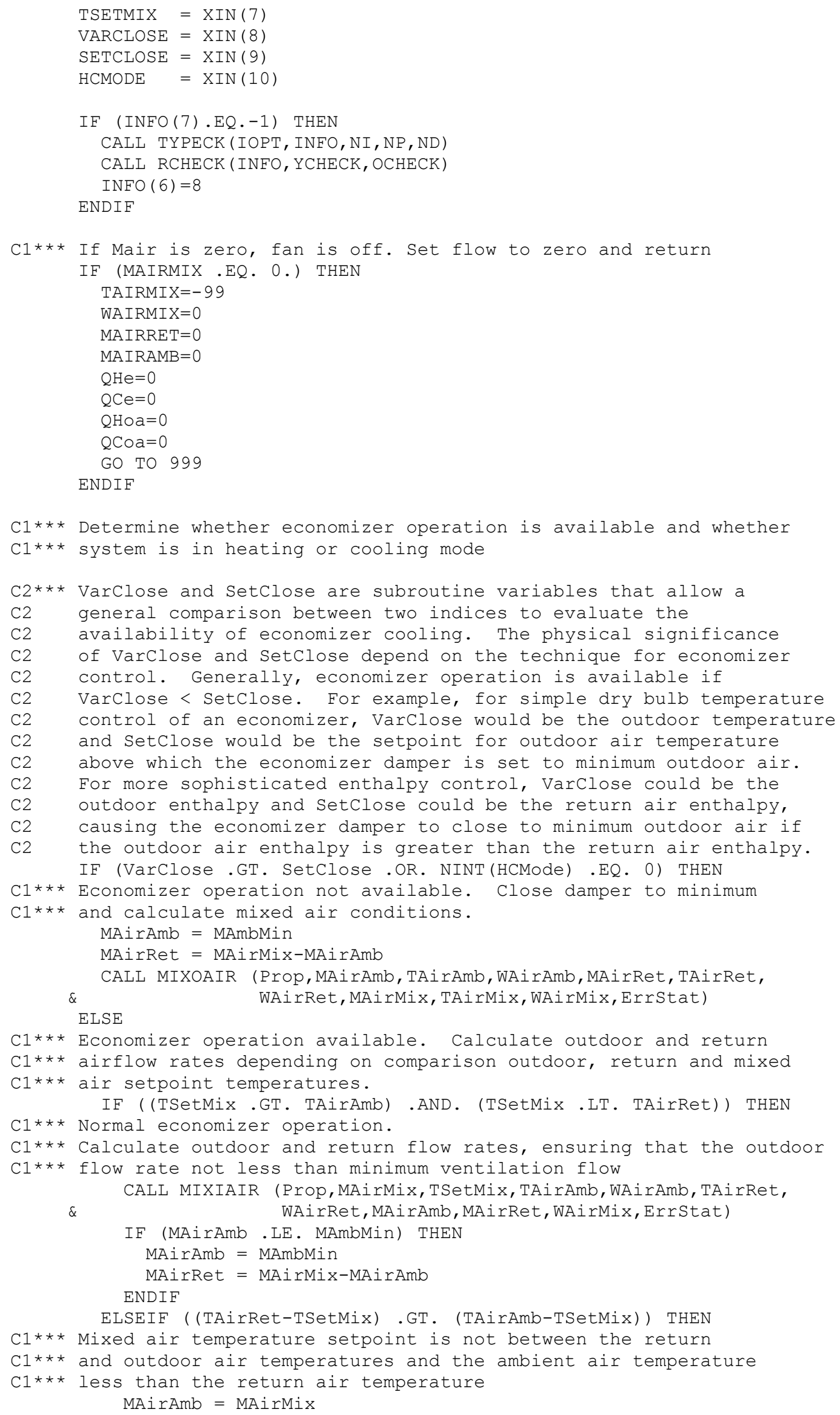




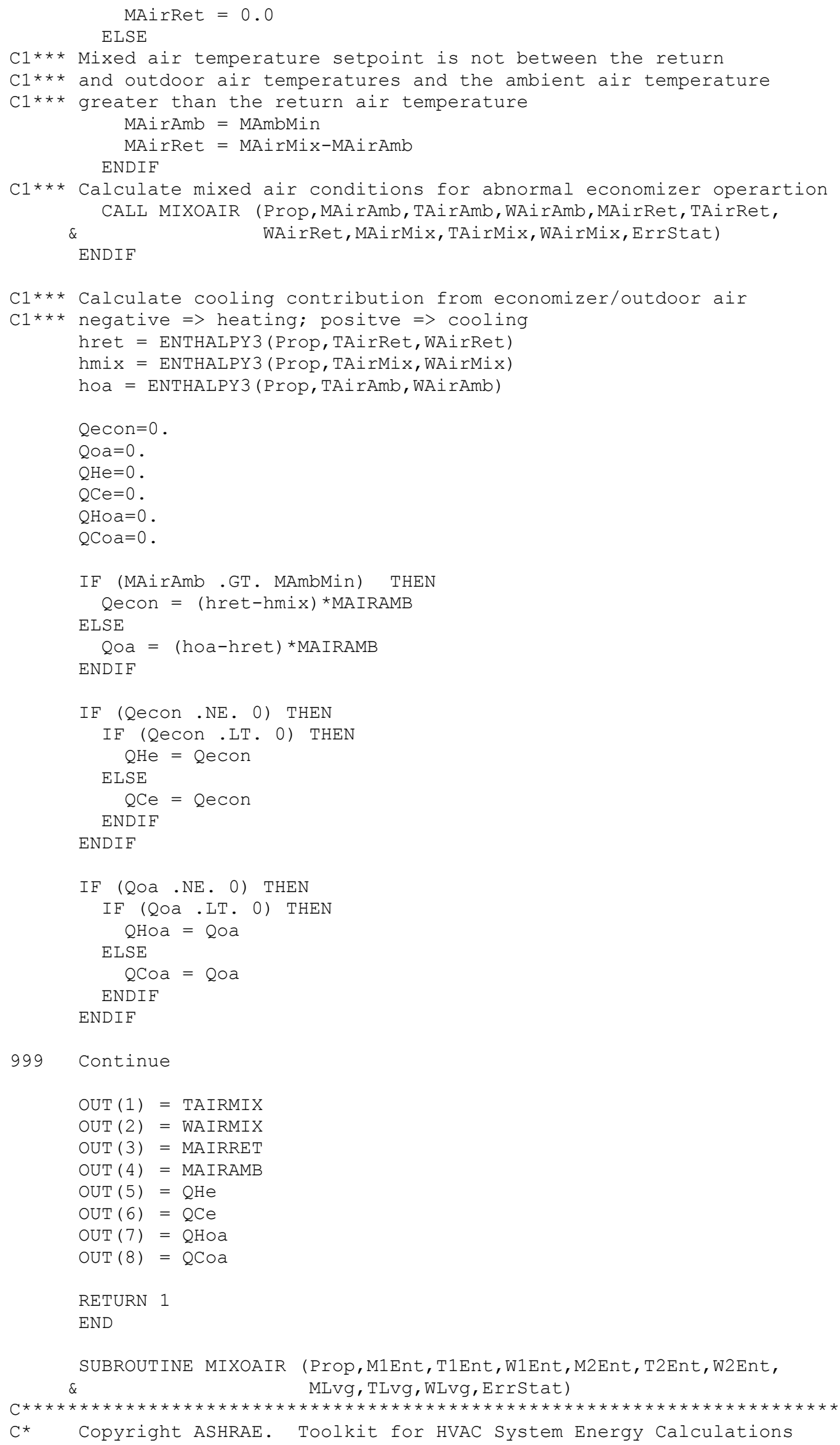




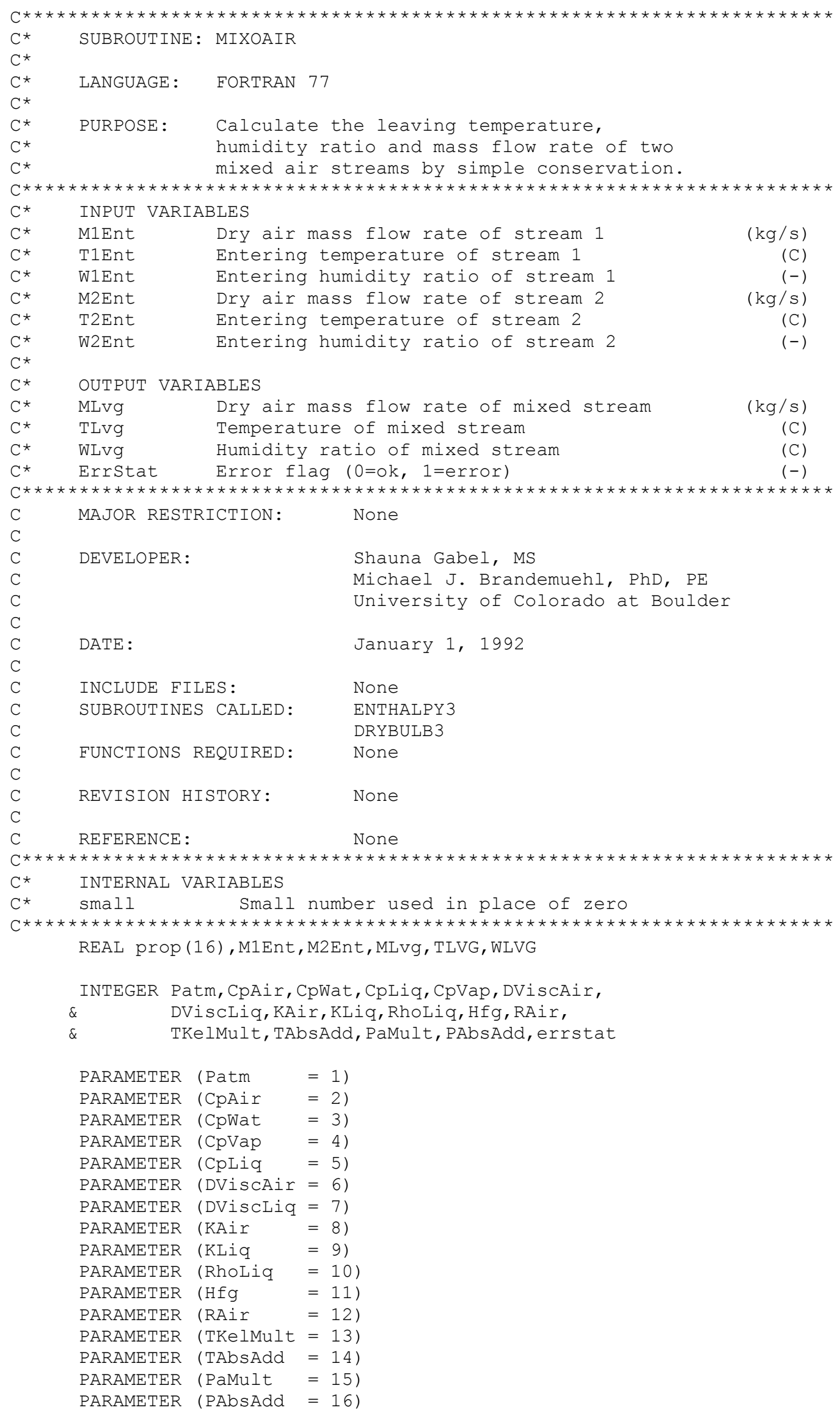


DATA small/1.E-9/

Errstat $=0$

C1*** Calculate the mass flow rate of the mixed stream.

$\mathrm{MLVg}=\mathrm{M} 1 \mathrm{Ent}+\mathrm{M} 2 \mathrm{Ent}$

C1*** If leaving flow is zero, set leaving conditions to those of

C1 stream 1 and RETURN.

IF (ABS (MLvg) . LE. Small) THEN

WLVg $=$ W1Ent

TLVg $=$ T1Ent

ELSE

C1*** Leaving flow is not zero. Proceed with calculations.

C1*** Calculate the humidity ratio of the mixed stream

$W L v g=($ M1Ent*W1Ent+M2Ent*W2Ent) $/$ MLvg

C1*** Calculate the mixed stream temperature from enthalpy and humidity

h1Ent = ENTHALPY3 (Prop, T1Ent, W1Ent)

h2Ent = ENTHALPY3 (Prop, T2Ent, W2Ent)

hLvg $=($ M1Ent*h1Ent+M2Ent*h2Ent) $/$ MLvg

TLVg $=$ DRYBULB3 (Prop, hLvg, WLvg)

ENDIF

RETURN

END

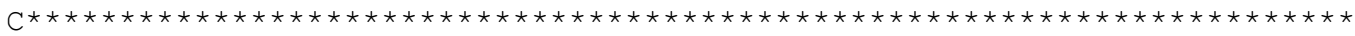

C* FILE: PROP.INC

$\mathrm{C}^{\star}$

$C^{*} \quad$ This file assigns a numbers to air and water property names to be

$C^{*} \quad$ used in the "Prop" array.

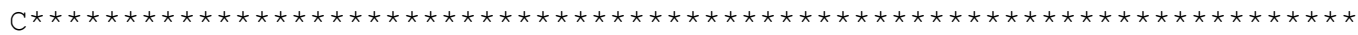

C DEVELOPER: Inger Andresen

C Michael J. Brandemuehl, PhD, PE

C DATE:

C

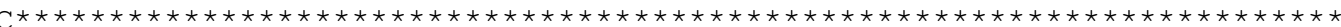

C INTERNAL VARIABLES:

C Patm Atmospheric pressure (Pa)

C CpAir Specific heat of dry air ( J/kg C)

C Cpliq Specific heat of liquid water (J/kg C)

C CpVap Specific heat of saturated water vapor (J/kg C)

C DViscAir Air dynamic viscosity (

C DViscliq Liquid dynamic viscosity ( $\mathrm{kg} / \mathrm{m} \mathrm{s})$

C KAir $\quad$ Air thermal conductivity $\quad(\mathrm{W} / \mathrm{m} \mathrm{C})$

$\begin{array}{lll}\text { C KLiq Liquid thermal conductivity } & (\mathrm{W} / \mathrm{m} \mathrm{C})\end{array}$

C Rholiq Liquid density ( $\mathrm{kg} / \mathrm{m} 3)$

C Hfg Latent heat of vaporization of water ( J/kg)

C RAir Gas constant for air (J/kg C)

C TKelMult Multiplying factor to convert user $\mathrm{T}$ to Kelvin

C TAbsAdd Additive factor to convert user $\mathrm{P}$ to Kelvin

tKel $=\operatorname{Prop}($ TKelMult $) * T+\operatorname{Prop}($ TKelAdd $)$

PaMult Multiplying factor to convert user $\mathrm{P}$ to Pascals

PAbsAdd Additive factor to convert user $\mathrm{P}$ to Pascals

$\mathrm{C}$
$\mathrm{Ca}=\operatorname{Prop}(\mathrm{PaMul} \mathrm{t}) * \mathrm{P}+\mathrm{Prop}$ (PaAdd)

C INTEger Patm, CpAir, CpWat,CpLiq, CpVap, DViscAir,

C \& DViscLiq, KAir, KLiq, RhoLiq,Hfg,RAir,

C \& TKelMult, TAbsAdd, PaMult, PAbsAdd

C REAL Prop (16)

C PARAMETER (Patm = 1)

PARAMETER (CPAir = 2)

PARAMETER (CPWat = 3)

C PARAMETER (CpVap $=4$ ) 


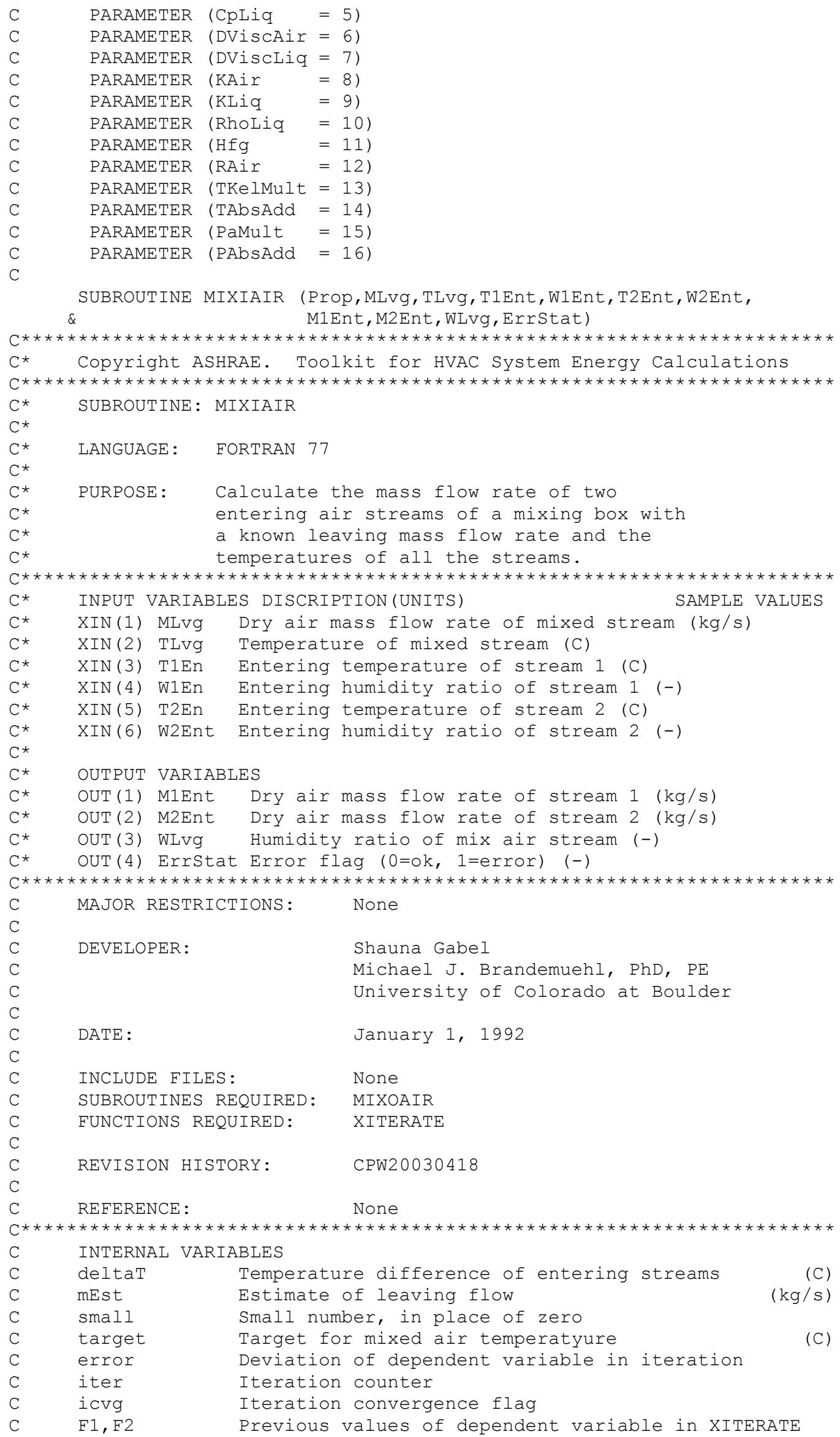




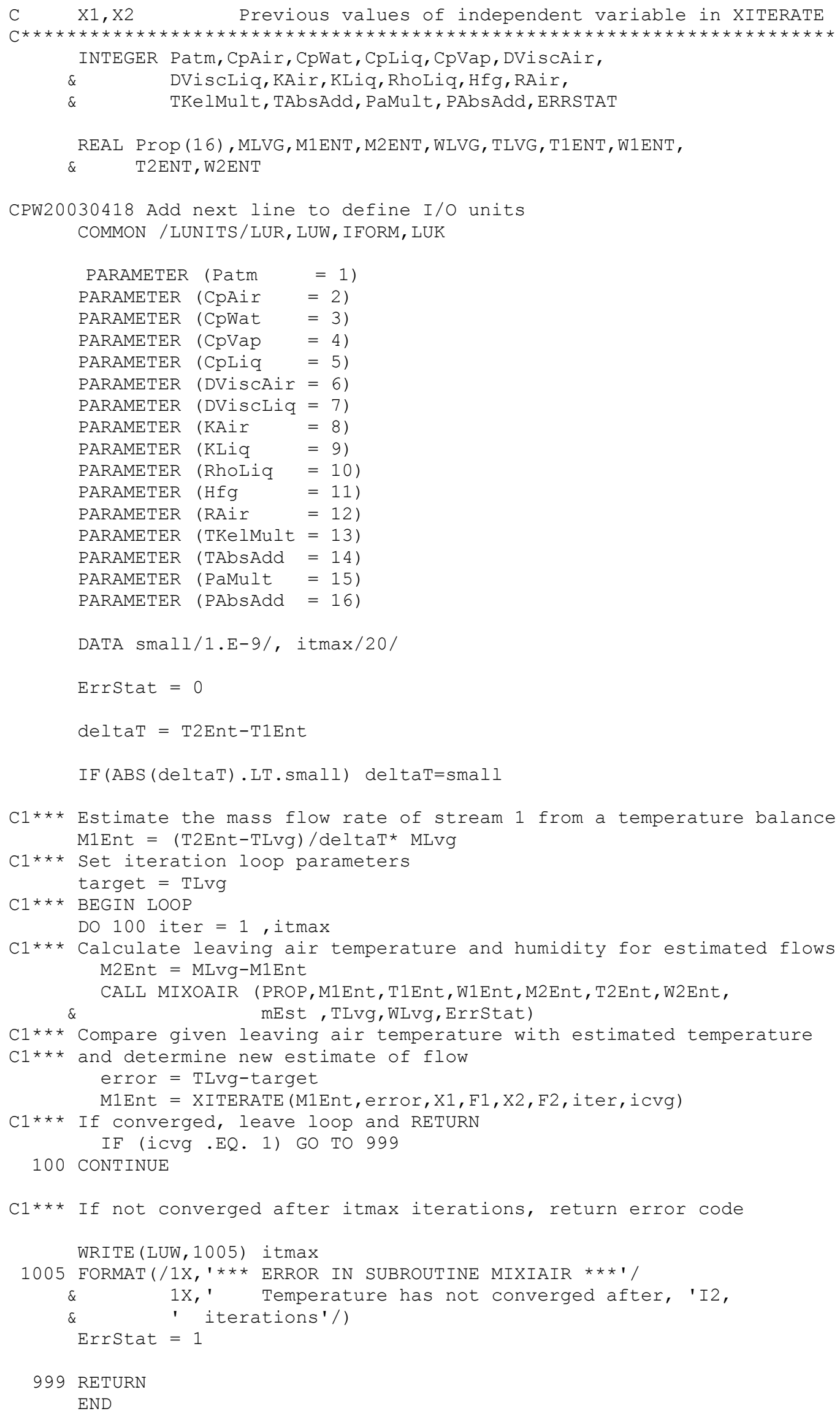




\section{Subroutine TYPE 81: Ceiling Return Plenum}

\section{SUBROUTINE AND FUNCTION CALL MAPPING}

OPEN PLENUM RETURN - Return air temperature is calculated from a steady

$\mathrm{C}^{\star}$

$C^{\star}$

$\mathrm{C}^{\star}$

$C^{\star}$ state energy balance on plenum. Heat gains/losses

from lights, duct conduction, duct leakage,

interior conduction, exterior conduction, and return air flow are included.

SUBROUTINE TYPE81 (TIME, XIN, OUT, T, DTDT, PAR, INFO, ICNTRL, *)

CALL TYPECK (IOPT, INFO,NI,NP,ND) -- subroutine in TRNWIN \Kernal \typeck.for

CALL RCHECK (INFO, YCHECK, OCHECK) -- subroutine in TRNWIN $\backslash$ Kernal \rcheck. for

\section{SOURCE CODE}

SUBROUTINE TYPE81 (TIME, XIN, OUT, T, DTDT, PAR, INFO, ICNTRL, *)

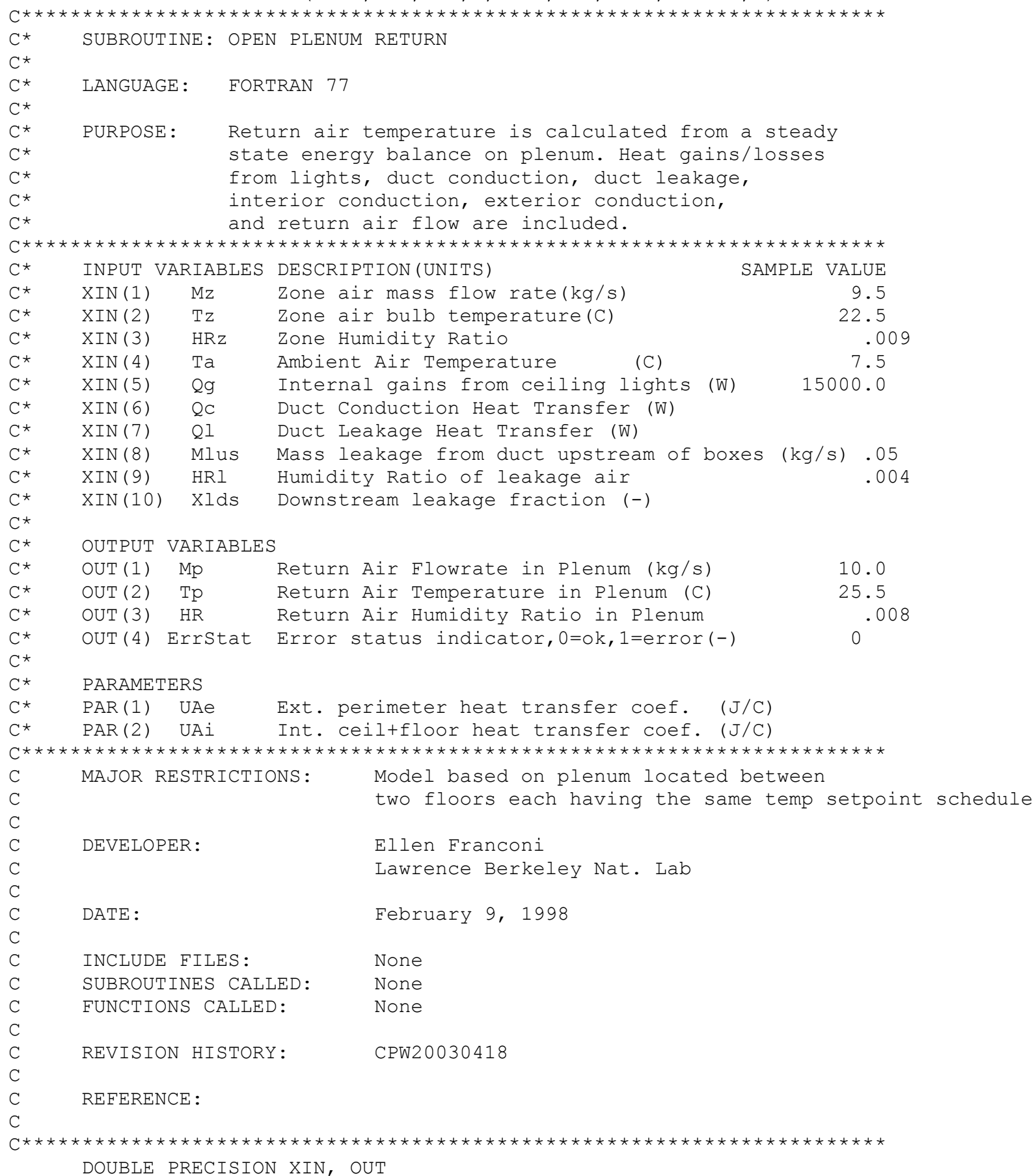




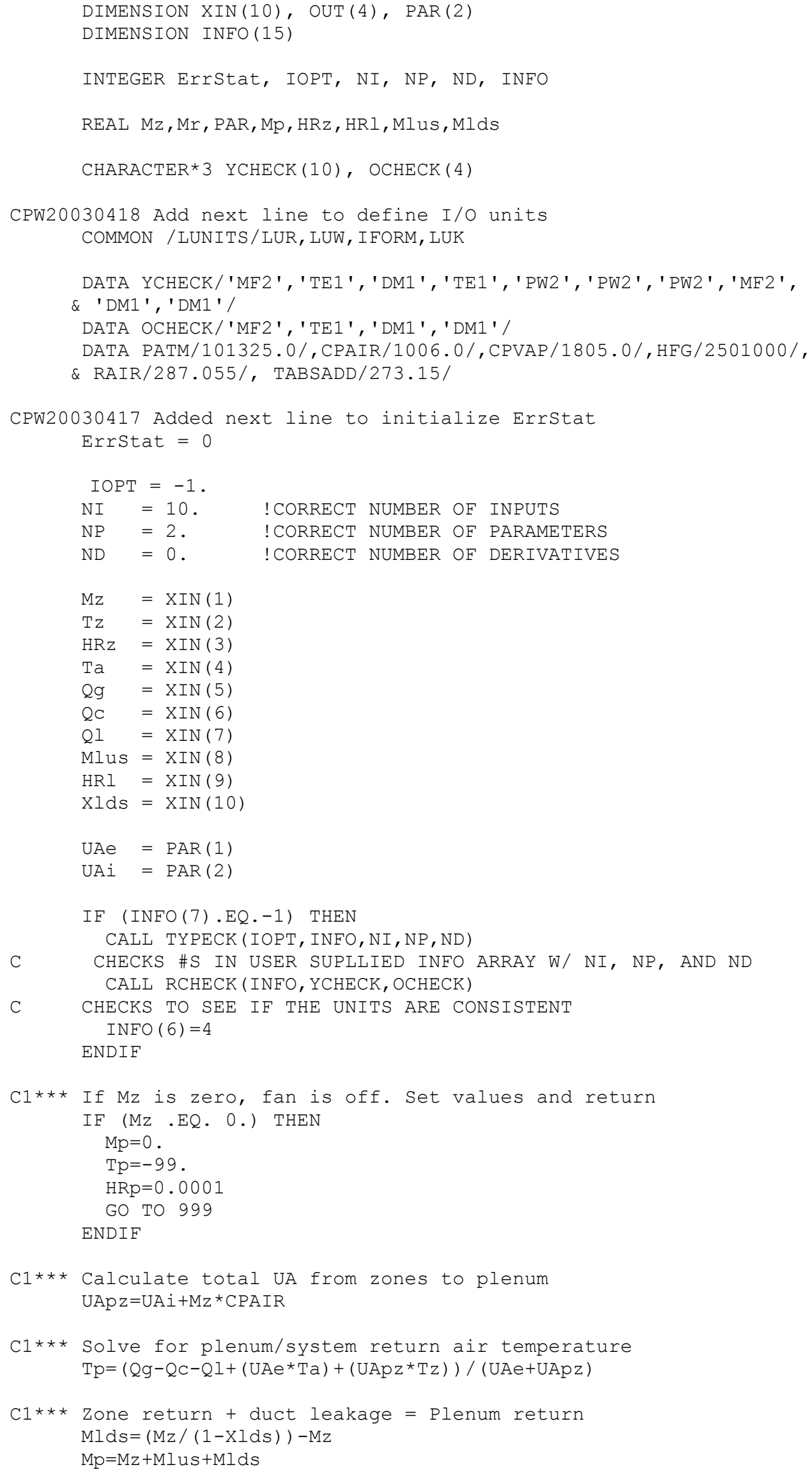


$\mathrm{HRp}=(\mathrm{HRz} * \mathrm{Mz}+\mathrm{HRl}$ * (Mlus $+\mathrm{Ml} \mathrm{ds})) / \mathrm{Mp}$

999

Continue

OUT $(1)=\mathrm{MP}$

OUT $(2)=\mathrm{Tp}$

$\operatorname{OUT}(3)=\mathrm{HRP}$

OUT $(4)=$ ERRSTAT

RETURN 1

END 


\section{Subroutine TYPE 82: Upstream Ducts}

\section{SUBROUTINE AND FUNCTION CALL MAPPING}

DUCT LOSS AND LEAKAGE- Calculates heat transfer from conduction and leakage

$C^{*} \quad$ in a ducted air stream. Losses based on a log mean

$C^{*} \quad$ temperature difference between air stream and

$C^{*} \quad$ surroundings (i.e. plenum). Conduction loss determined

$C^{*} \quad$ analytically using the effectiveness/NTU method.

$\mathrm{C}$

C

Leakage rate is set at fixed CFM upstream of boxes and fixed

\% of flow downstream of boxes

SUBROUTINE TYPE82 (TIME, XIN, OUT, T, DTDT, PAR, INFO, ICNTRL, *)

CALL TYPECK (IOPT, INFO, NI, NP, ND) -- subroutine in TRNWIN \Kernal ttypeck.for

CALL RCHECK (INFO, YCHECK, OCHECK) -- subroutine in TRNWIN $\backslash$ Kernal \rcheck.for

$$
\begin{aligned}
& \text { Talm = XITERATE (Talm, error,X1,F1,X2,F2, iter, icvg) -- function F14 } \\
& \text { in type } 75
\end{aligned}
$$

\section{SOURCE CODE}

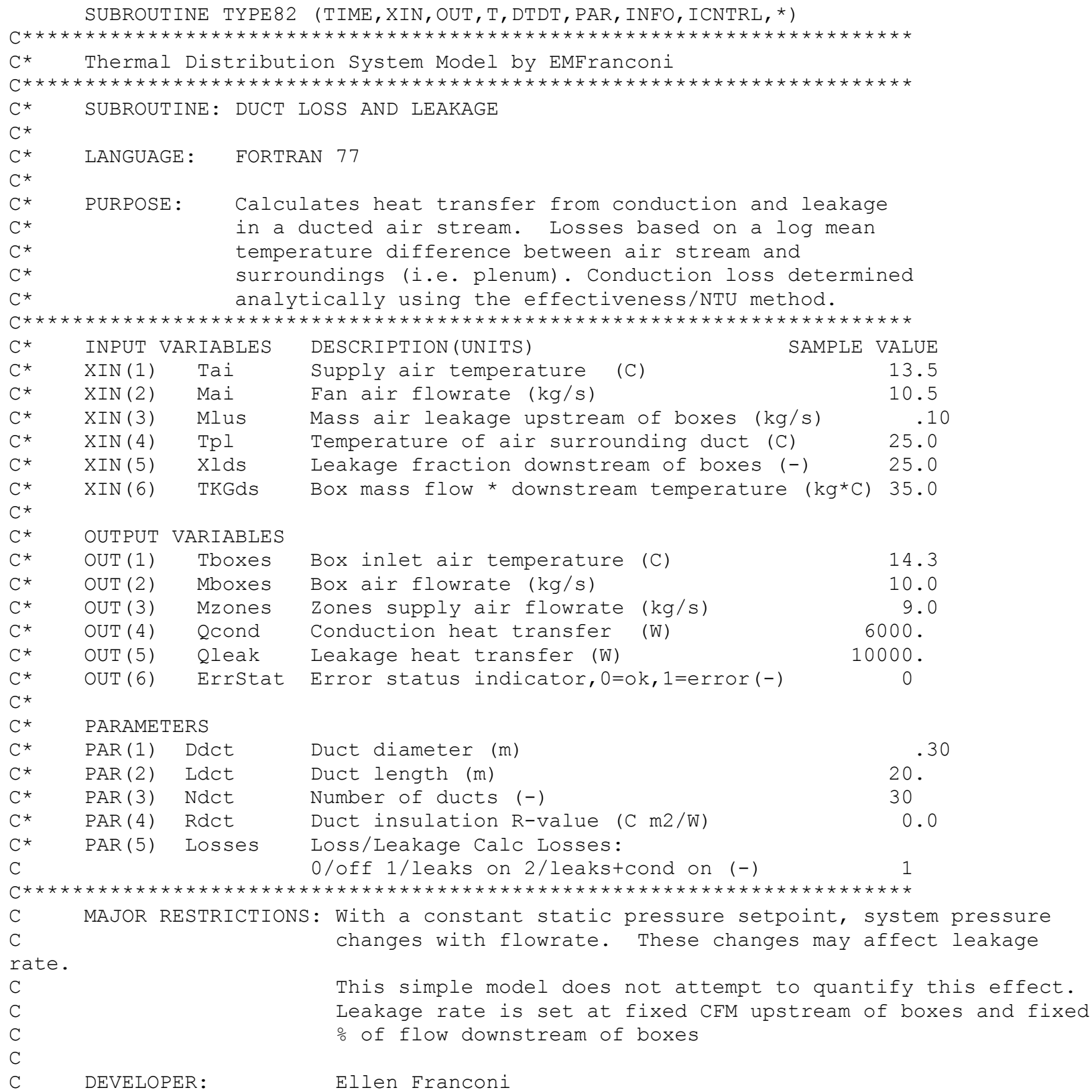




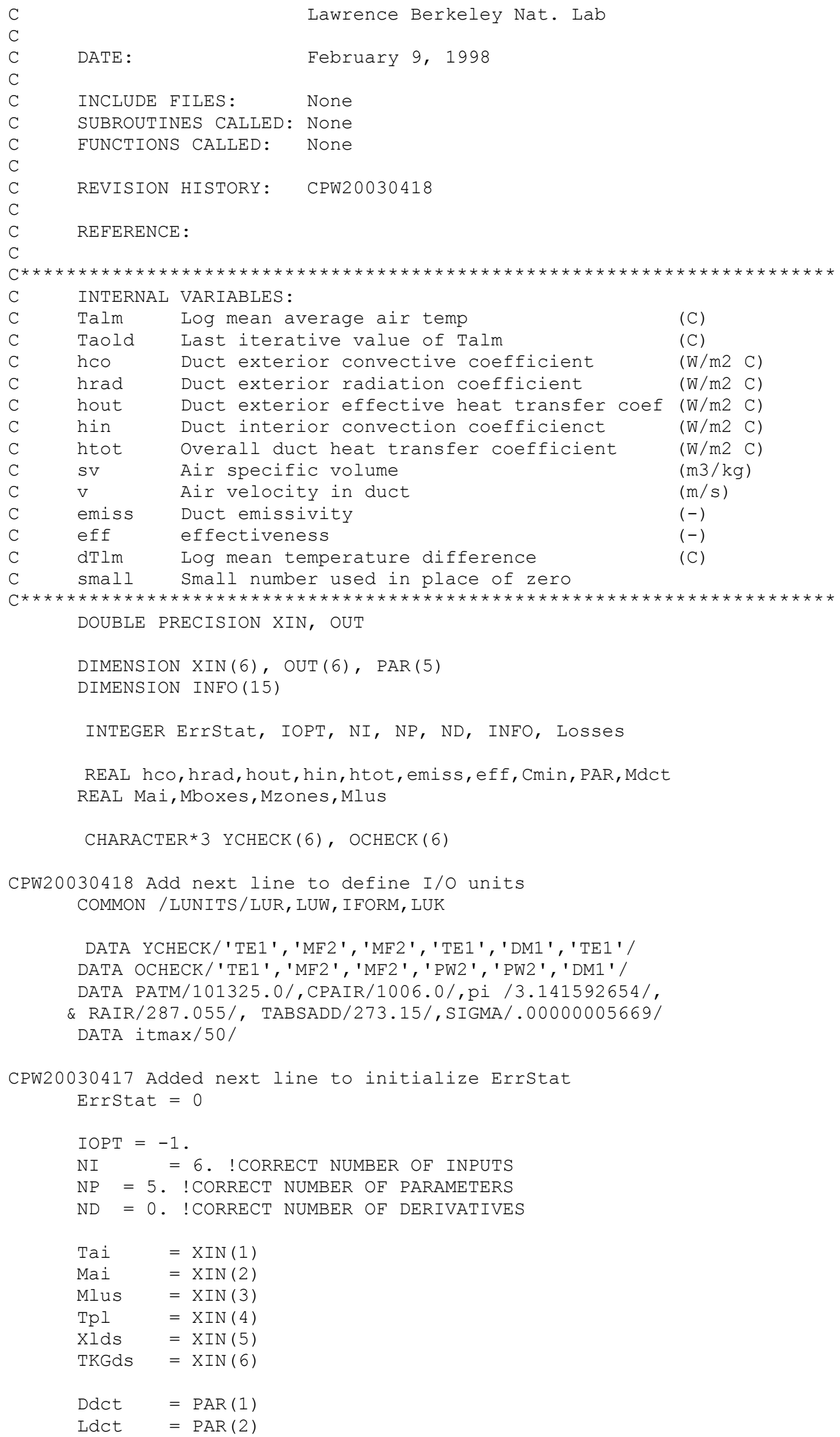




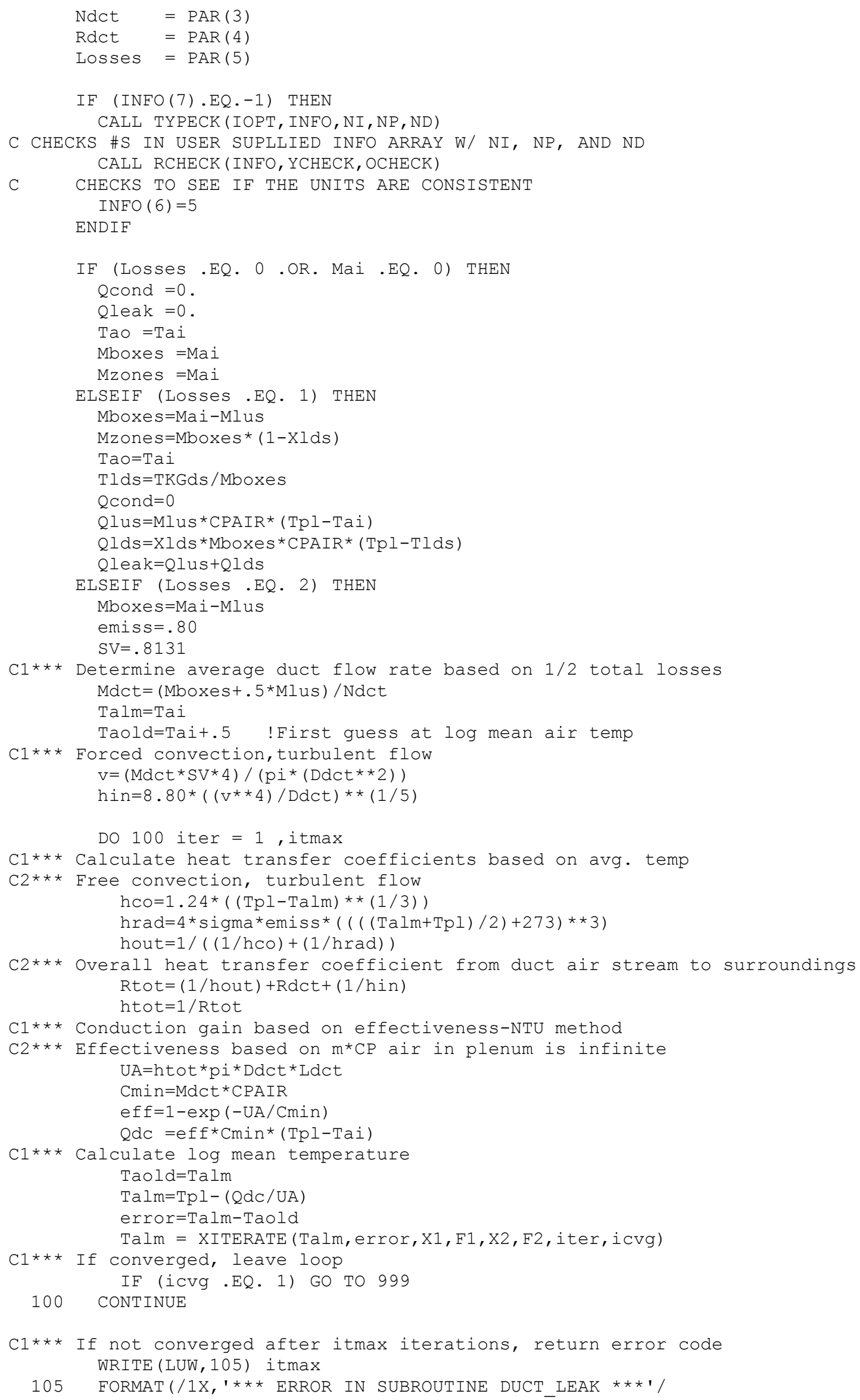




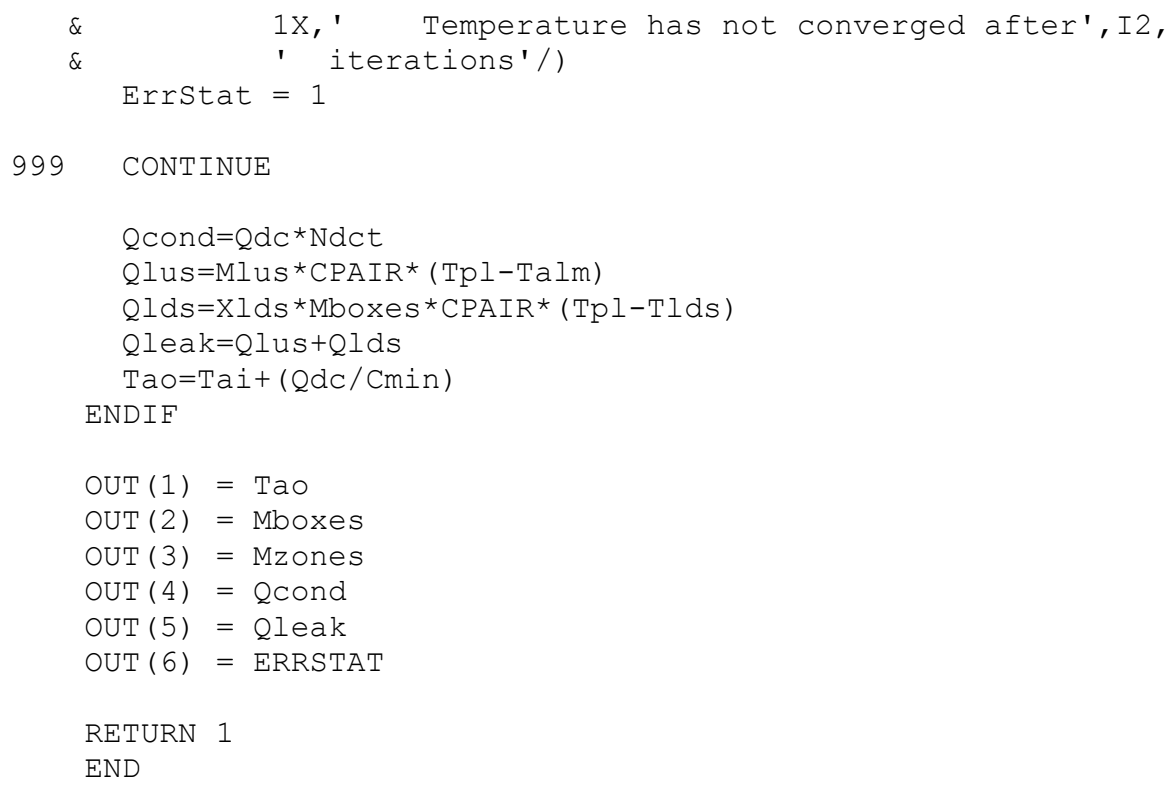




\section{Subroutine TYPE 86: VAV Box and Downstream Ducts}

\section{SUBROUTINE AND FUNCTION CALL MAPPING}

Zone Box w/ Downstream Leakage - Calculate the performance of a heating

$\mathrm{C}^{\star}$

$C^{\star}$

$\mathrm{C}^{\star}$

$C^{*}$

$C^{\star}$

coil by modeling as a crossflow, both

streams unmixed, heat exchanger. Results

include outlet air temperature and

humidity, outlet water temperature, sensible and total cooling capacities.

SUBROUTINE TYPE86 (TIME, XIN, OUT, T, DTDT, PAR, INFO, ICNTRL, *)

CALL TYPECK (IOPT, INFO,NI, NP,ND) -- subroutine in TRNWIN $\backslash$ Kernal \typeck. for

CALL RCHECK (INFO, YCHECK, OCHECK) -- subroutine in TRNWIN \Kernal \rcheck. for

UATot = UAHX (capAir, TAirRat, capLiq, TLiqRat, QTotRat, -- function F1

in type 75

configHX, ErrStat)

CALL DRYCOIL (Prop, MLiq, TLiqEnt, MAir, TAirEnt, WAirEnt, -- subroutine S1 in type 75

\& UATot, confighX,

TLiqLvg, TAirLvg, WAirLvg, QTot, ErrStat)

mLiq = XITERATE (mLiq, error,X1,F1,X2,F2, iter,icvg) -- function F14

in type 75

$\begin{array}{rlc}1 \text { PROP (PATM) } & = & 101325.0 \\ 2 \text { PROP (CPAIR) } & = & 1006.0 \\ 3 \text { PROP (CPWAT) } & = & 4186.0 \\ 4 \text { PROP (CPVAP) } & = & 1805.0 \\ 5 \text { PROP (CPLIQ) } & = & 4186.0 \\ 6 \text { PROP (DVISCAIR) } & = & .000018 \\ 7 \text { PROP (DVISCLIQ) } & = & .00144 \\ 8 \text { PROP (KAIR) } & = & .026 \\ 9 \text { PROP (KLIQ) } & = & .604 \\ 10 \text { PROP (RHOLIQ) } & = & 998.0 \\ 11 \text { PROP (HFG) } & = & 2501000.0 \\ 12 \text { PROP (RAIR) } & = & 287.055 \\ 13 \text { PROP (TKELMULT) } & = & 1.0 \\ 14 \text { PROP (TABSADD) } & = & 273.15 \\ 15 \text { PROP (PAMULT) } & = & 1.0 \\ 16 \text { PROP (PABSADD) } & = & 0.0\end{array}$

Atmospheric pressure (Pa)

Specific heat of dry air (J/kg C)

Specific heat of liquid water ( J/kg C)

Specific heat of saturated water

vapor $(\mathrm{J} / \mathrm{kg} \mathrm{C})$

SOURCE CODE

SUBROUTINE TYPE86 (TIME, XIN, OUT, T, DTDT, PAR, INFO, ICNTRL, *)

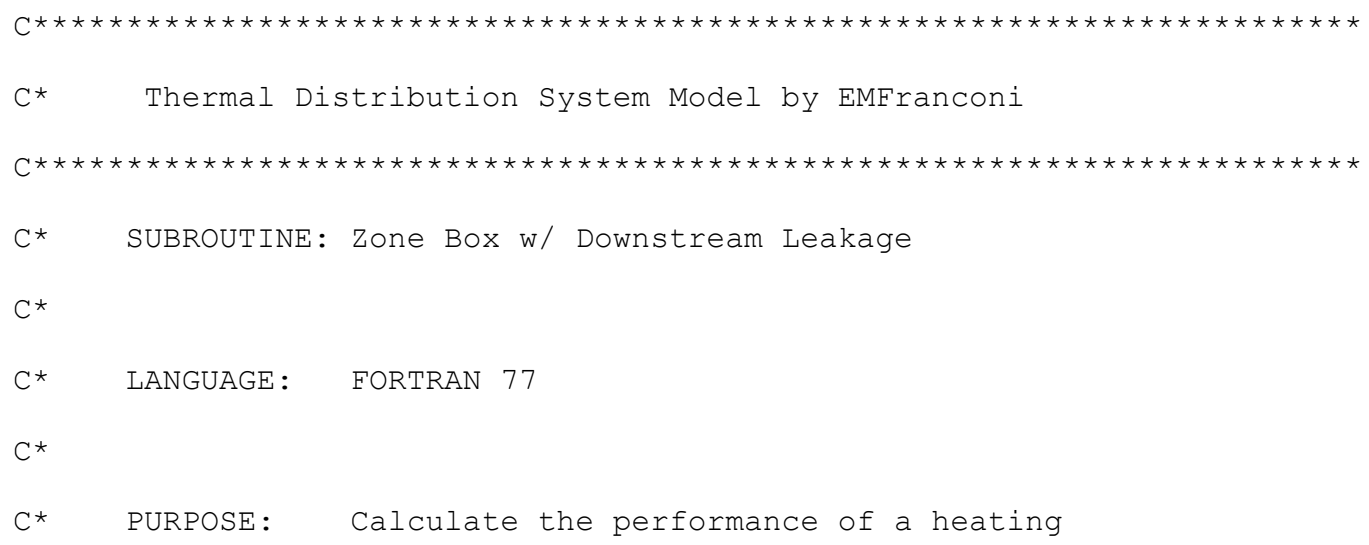




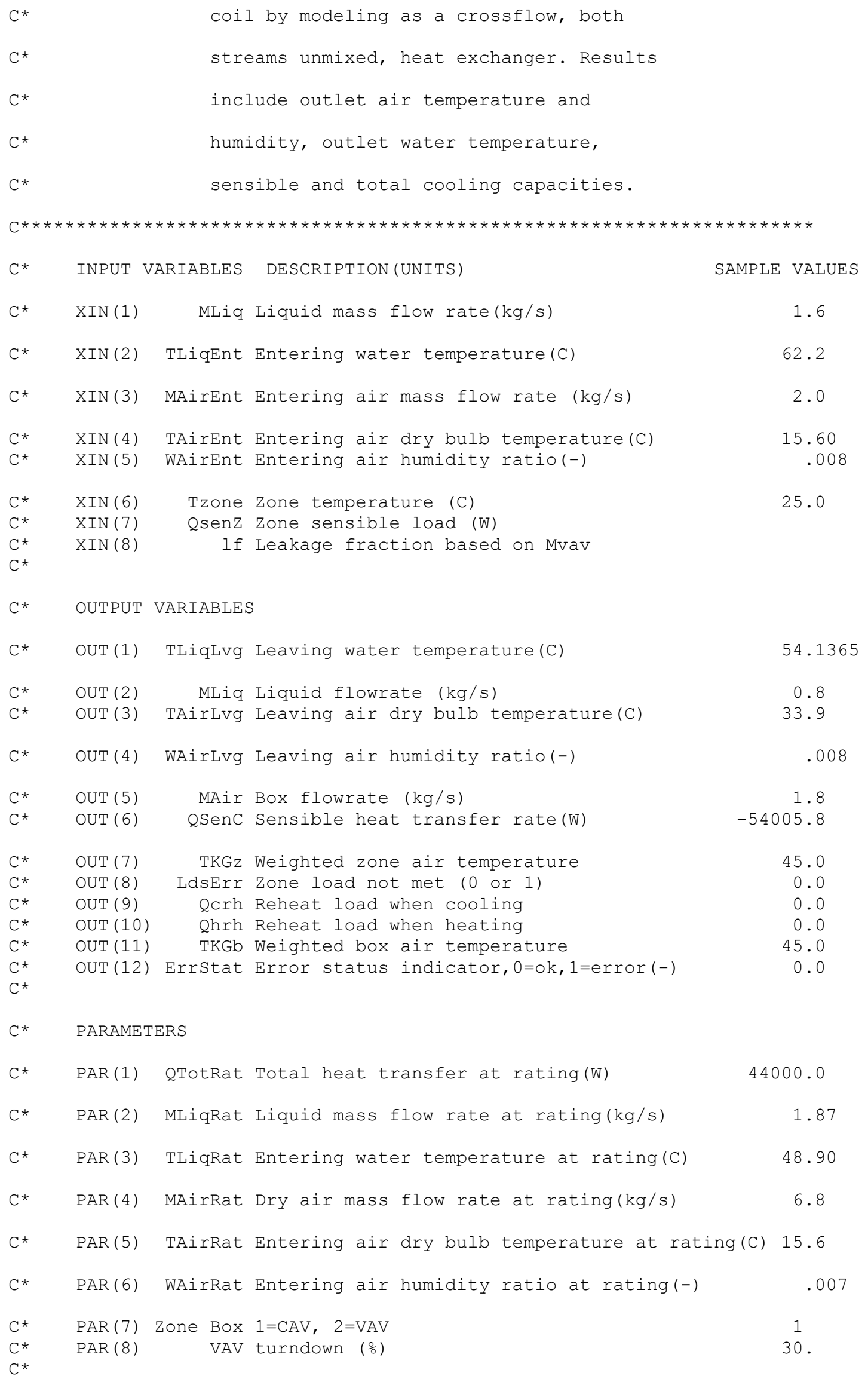




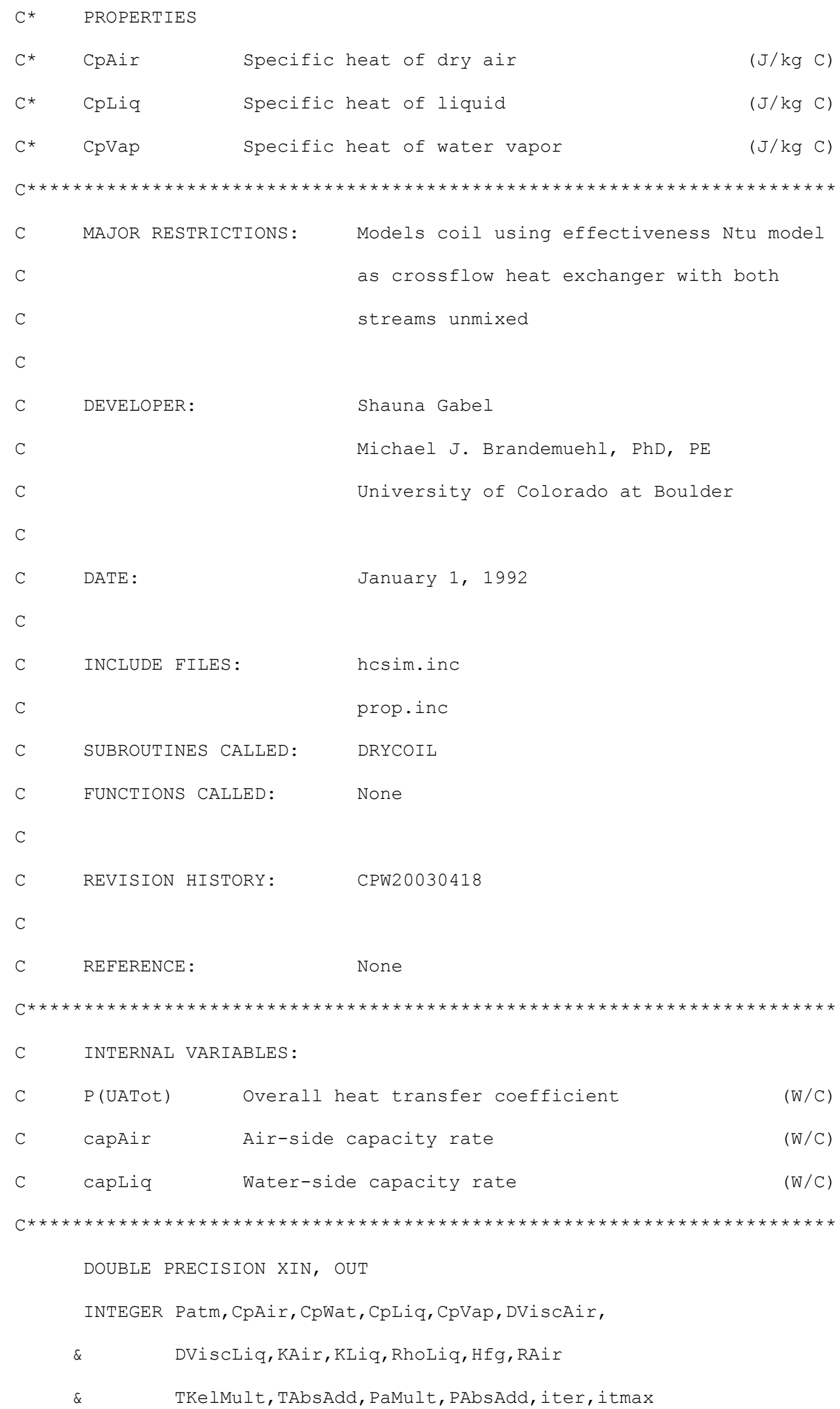




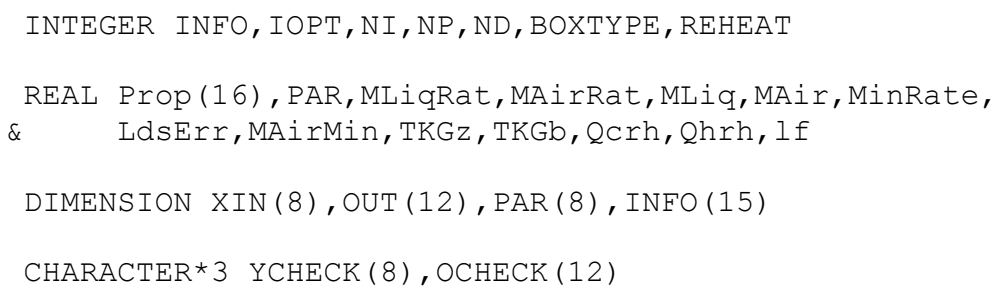




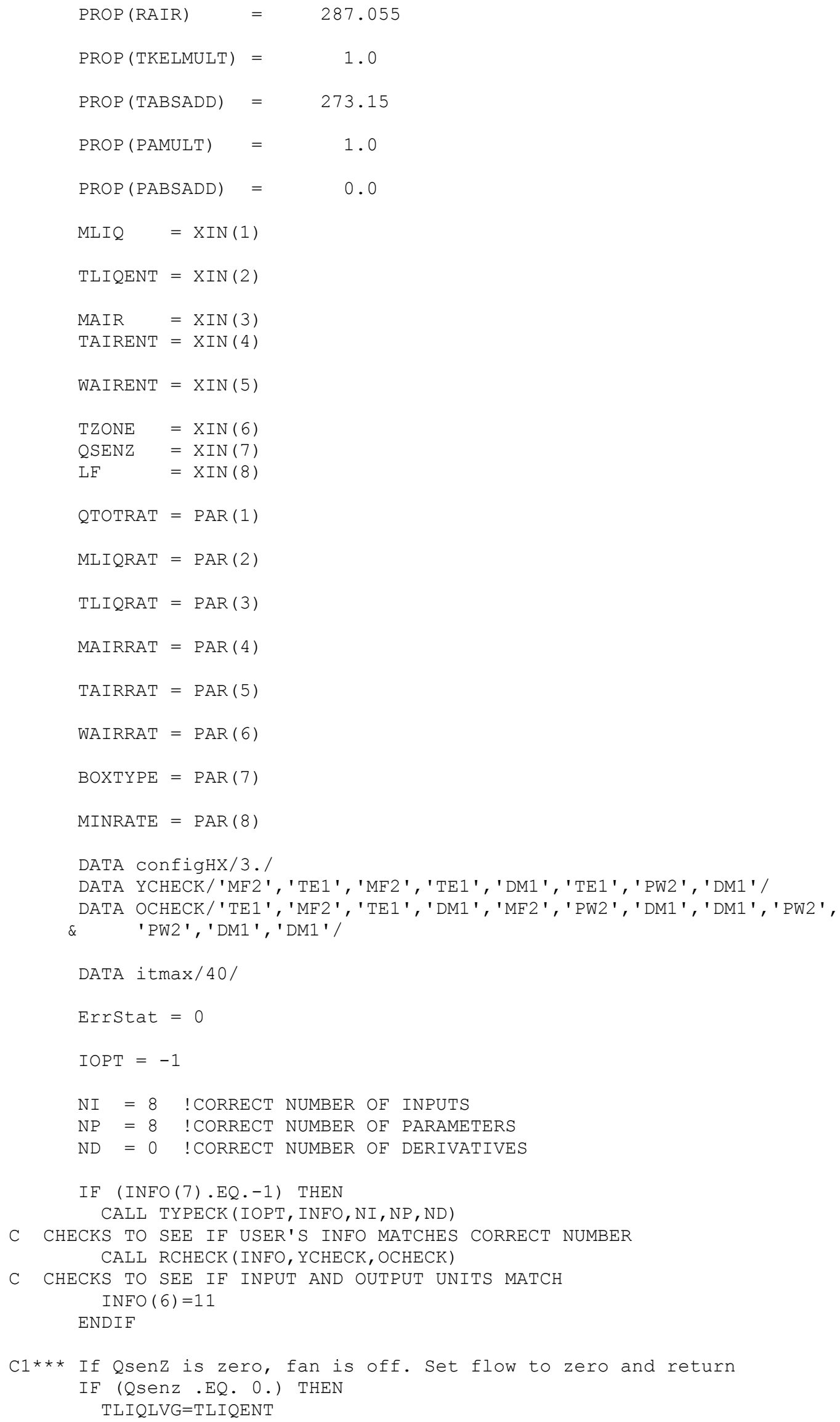




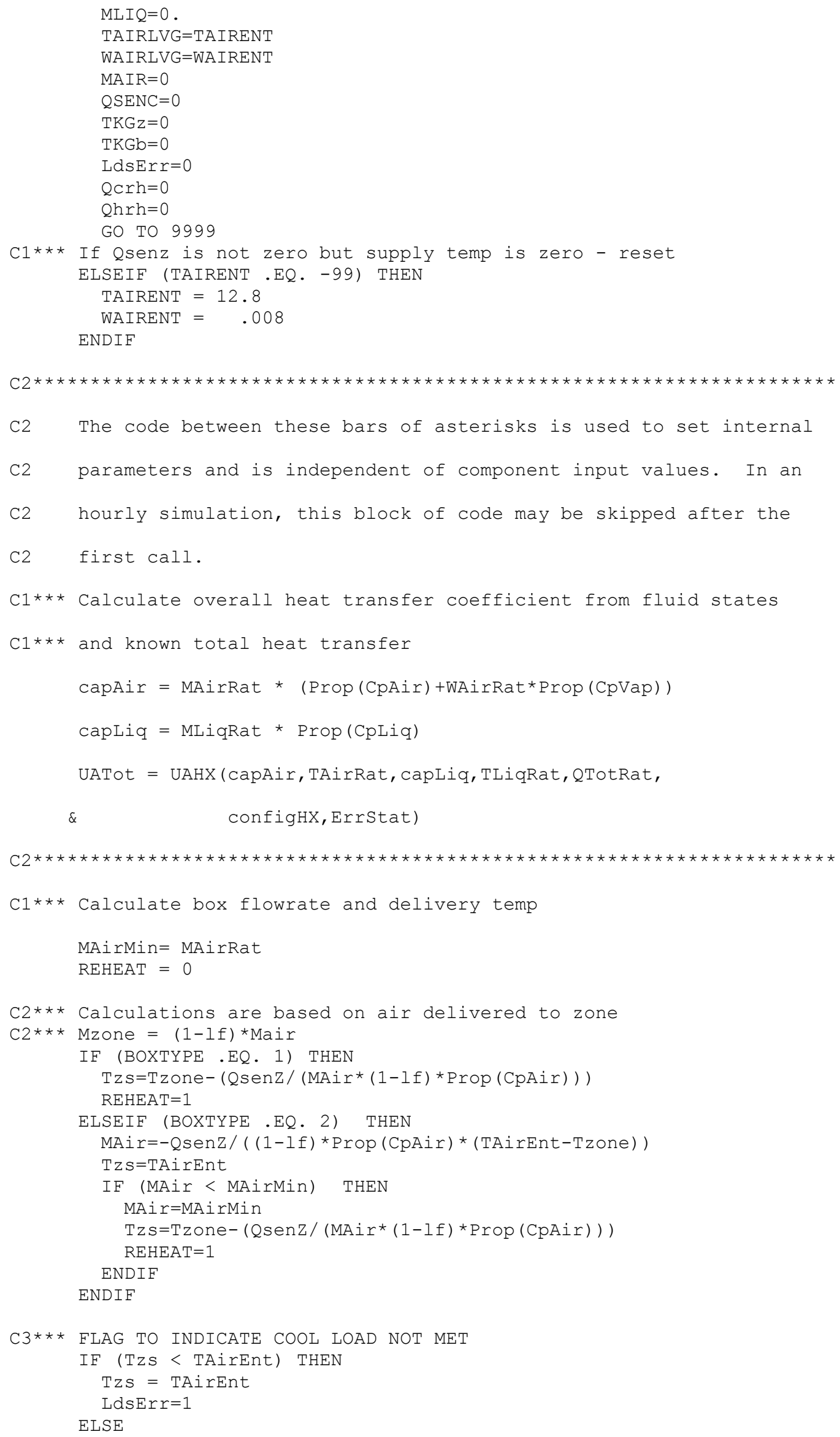




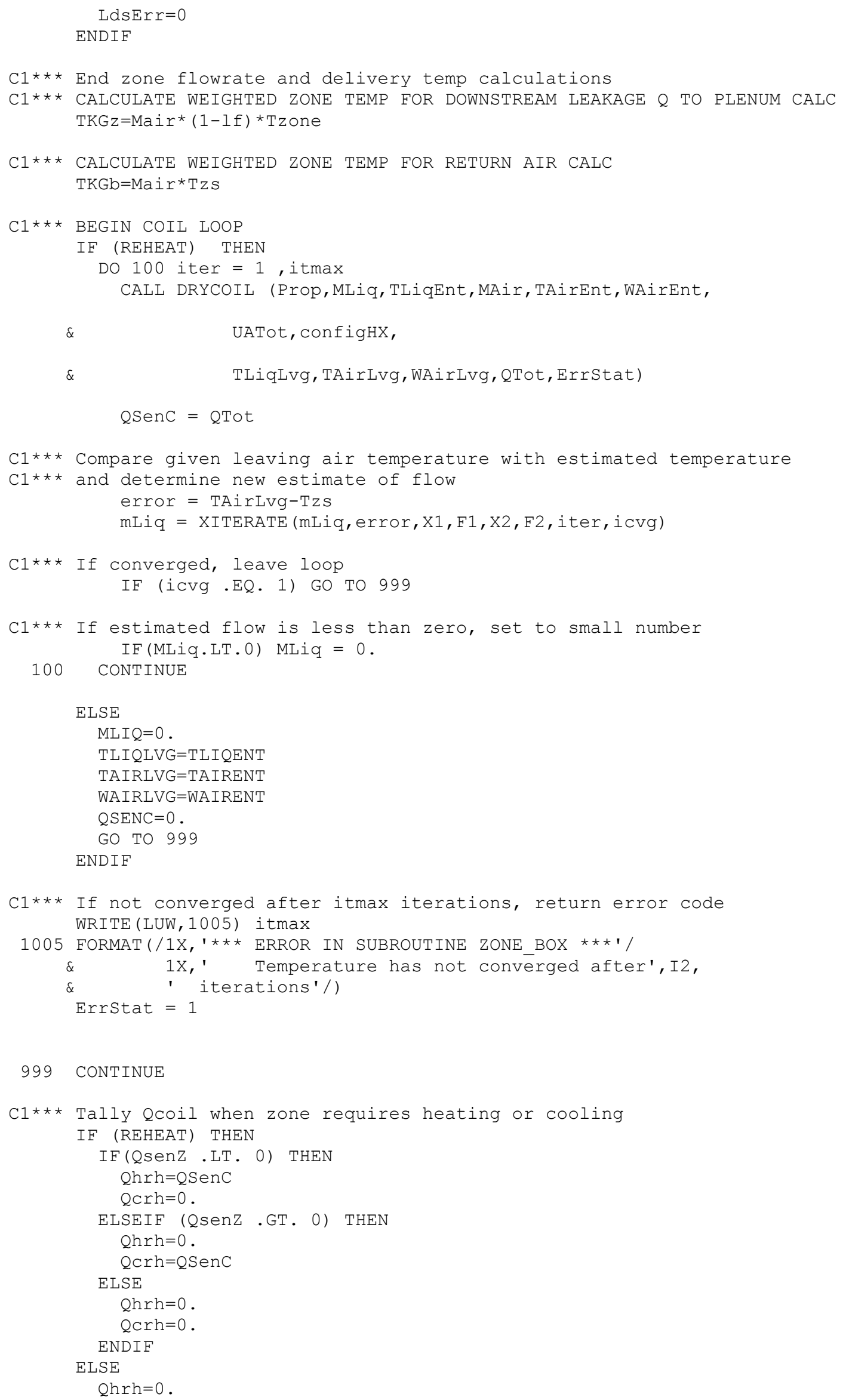


Qcrh $=0$.

ENDIF

9999 CONTINUE

OUT $(1)=$ TLIQLVG

OUT $(2)=$ MLIQ

OUT (3) = TAIRLVG

OUT $(4)=$ WAIRLVG

OUT $(5)=$ MAIR

OUT $(6)=$ QSENC

OUT (7) $=$ TKGz

OUT $(8)=$ LdsErr

$\operatorname{OUT}(9)=$ Qcrh

OUT $(10)=$ Qhrh

OUT $(11)=$ TKGb

OUT $(12)=$ ERRSTAT

RETURN 1

END 